SW

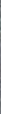
H. (5) $30,3,2: 3=$ (2)

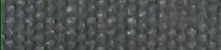

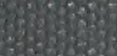

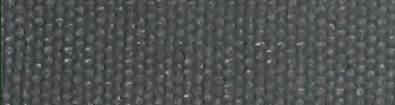
(3) (2)

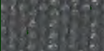

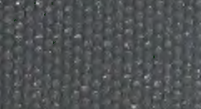

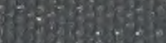
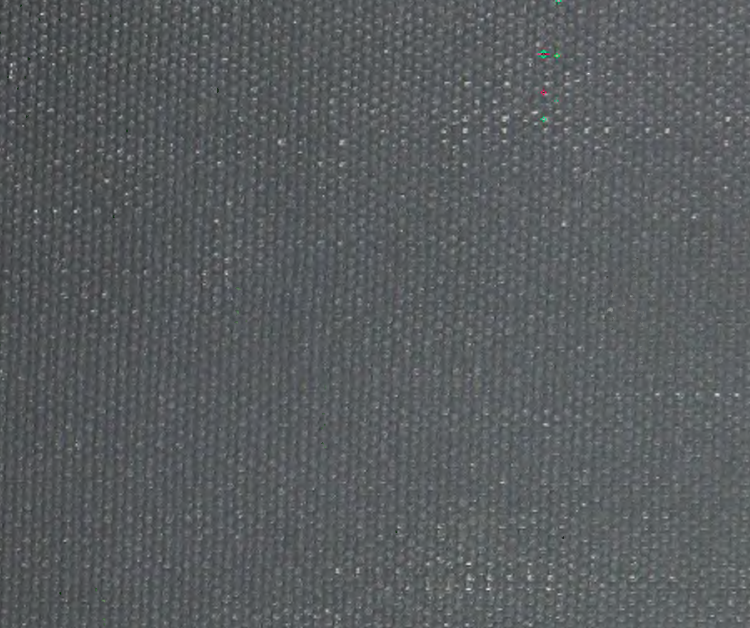

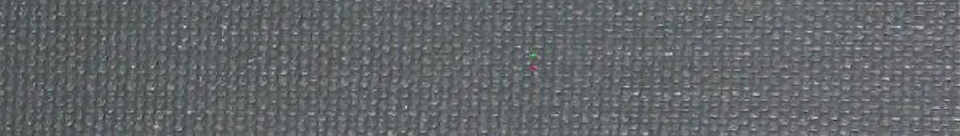

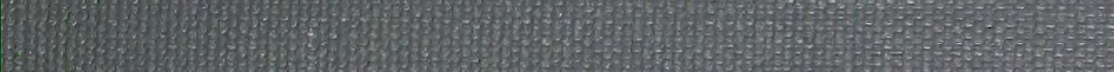

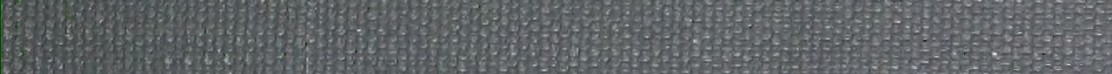

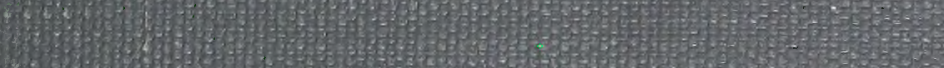

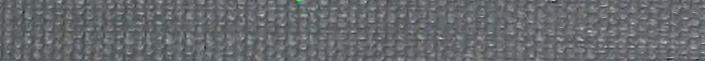




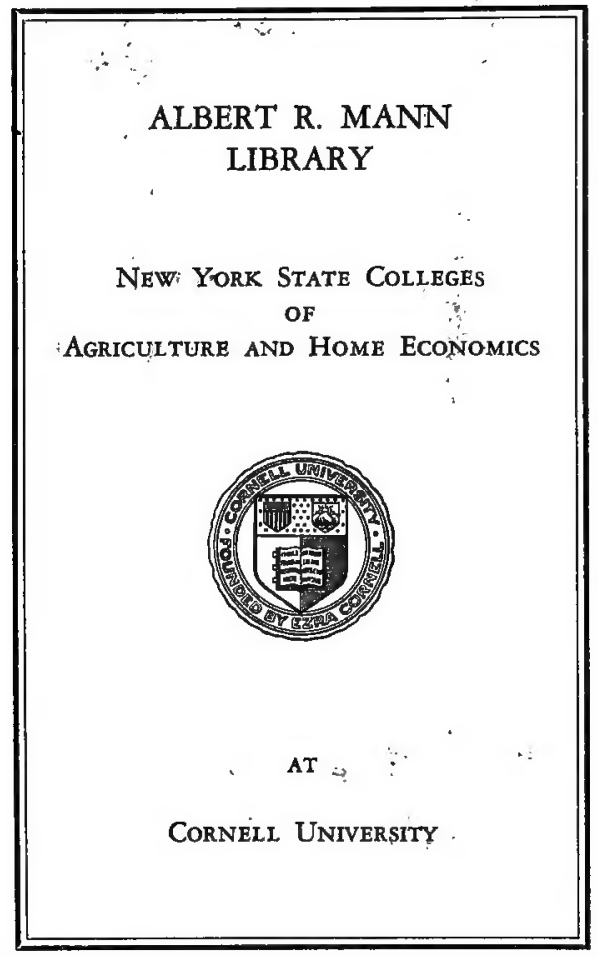




\section{QK $653 . \mathrm{K}^{\text {Cornell University Library }}$}

Flowers and their unbidden guests.

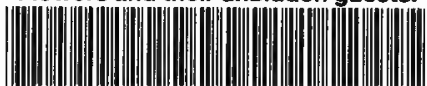

$\begin{array}{llll}3 & 1924000 & 426 & 431\end{array}$ 


\section{Cornell University Library}

The original of this book is in the Cornell University Library.

There are no known copyright restrictions in the United States on the use of the text.

http://www.archive.org/details/cu31924000426431 




\section{F L OWERS}

AND

THEIR UNBIDDEN GUESTS. 



\title{
FLOWERS AND THEIR UNBIDDEN GUESTS
}

\author{
BY DR. A. KERNER
}

PROFESSOR OF BOTANY IN THE UNIVERSITY OF INNSBRUCK

WITH A PREFATORY LETTER BY CHARLES DARWIN, M.A., F.R.S.

The Tramslation कुebised and Gdited

By W. OGLE, M.A., M.D.

SOMETIME FELLOW OF CORPUS CHRISTI COLLEGE, OXFORD

WITH ILLUSTRATIONS.

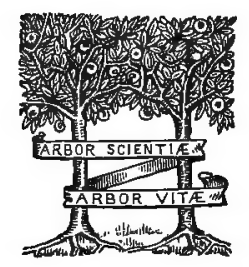

\section{LONDON}

C. KEGAN PAUL \& CO,, I PATERNOSTER SQUARE I 878 
The rights of Trausiation and of Reproduction are reserved. 


\section{PREFATORY LETTER.}

MY DEAR DR. OGLE,-I am extremely glad to hear that you have undertaken to edit Kerner's work on Flowers and their Unbidden Guests; for it opens out a highly original and curious field of research. It is possible that some of Kerner's generalisations may hereafter require to be slightly modified; but I feel sure that every remark which he has made well deserves careful consideration. The beauty and poetry of flowers will not be at all lessened to the general observer, by his being led through Kerner's investigation to notice various small, and apparently quite unimportant, details of structure,-such as the presence of differently directed hairs, viscid glands, etc., which prevent the access of certain insects, and not of others. He will, I believe, come to the conclusion that flowers are not only delightful from their beauty and fragrance, 
but display most wonderful adaptations for various purposes. I cordially wish that your translation may find many readers, not so much for your sake as for theirs.

Believe me very faithfully yours,

Chardes Darwin.

Down, Beckenham, Kent, August 17, 1878. 


\section{EDITOR'S PREFACE.}

THE year 1862 will ever be a memorable date in the annals of botany, as that in which Mr. Darwin published his classical work on the fertilisation of Orchids, and in so doing disclosed a wide and unexplored region to the research of physiological botanists. Since then a huge mass of observations has been gradually accumulating, the general result of which is to confirm with great certainty the truth of the Darwinian generalisation, that, so far at any rate as plants are concerned, "Nature abhors perpetual self-fertilisation." It has been shown that in the vast majority of flowering plants-exceptions may here be disregardedappliances exist which will at any rate secure a more or less frequent intercross, and that in many of them, moreover, these appliances completely exclude the possibility of self-fecundation.

The agency by which this result is obtained, and the pollen transported from one flower to another, may be either inanimate or animate.

In the former case it is the wind, or exceptionally (Valisneria spiralis) water. Plants thus fertilised present certain peculiarities. Their pollen, for instance, is dusty, so as to be easily diffused by a slight current. 
Their flowers have inconspicuous petals, or none; exhale no sweet odour; secrete no sweet nectar. They have no object in attracting insects, and consequently appeal to none of their senses.

It is quite otherwise when the agency of pollination is animate. The animate agent is in some comparatively few instances a bird, but as a general rule is an insect. These must be allured to the flower; and this accordingly appeals to their sight or smell by brilliant colours and by attractive scents. These colours and these scents draw the insect to the flower from a distance; but by themselves they would be but empty gratifications, unprofitable to insect and to flower alike. Something more substantial must be offered; something that will prevent the insect from merely loitering about the flower in idle satisfaction, and that will induce it to probe the recesses of the blossoms, and in so doing to transfer the pollen of one flower to the stigma of another. This further allurement is addressed to the palate; and though in some cases it is nothing more than the pollen itself, in most it is supplied by the secretion of a sweet fluid, the so-called nectar.

Now Nature, who at first sight often appears a prodigal, is always found on closer examination to be the most rigid of economists. If no insects are to be allured, she gives, as we have seen, no nectar; she cuts off the bright petals, and suppresses the attractive 
odours. Nor even when a bait is wanted will she give it one minute sooner than necessary. The brilliancy, the scent, and the nectar are only furnished when the flower is ready for its guests, and requires their presence; just as a thrifty housewife lights her candles when the first guest is at the door. The immature bud is furnished with no such attractions. Still more, even when the flower is mature, when its pollen is ready for transference or its stigma for fecundation, when all the allurements are consequently displayed and insects invited to the feast, she still shows her economy. Guests might come who were not of sufficient importance, and the banquet be wasted on them; for it is only when insects have a certain shape, size, or weight that she requires their visits, and can use them profitably for her purposes. She requires, moreover, that they shall make their entrance by the main portal, which she has specially adapted to suit their and her requirements. All insignificant and unremunerative visitors, all such, moreover, as would creep in by a back entrance, must be kept out; and the purpose of this treatise is to show by what various contrivances this exclusion is effected.

The subject is new, though a branch of the tree planted by Mr. Darwin. For if some feeble inklings of the existence in flowers of such excluding contrivances may have occurred to other persons,nay, may even have been distinctly enunciated by 
them,- - the fruitful recognition of the fact and its establishment by convincing evidence is to be found for the first time in this treatise of Kerner. To him exclusively will be due the merit of having interpreted the meaning of a vast number of floral structures, which before he wrote were passed over as purposeless.

It is curious, however, to note that so long ago as in the last century, Erasmus Darwin, in his Loves of the Plants, should have remarked on the protective function of one of the appliances described by Kerner, namely, of the water-cups formed by the connate leaves of the teasel; and should even have alluded to the nectar as one of the treasures to be thus guarded. ${ }^{1}$ As this writer was of course quite ignorant of the true relations between insects and flowers, which have been made known to us by his grandson, it is not easy to see why he should have supposed that the nectar required protection, or indeed what use at all he can have ascribed to this secretion. It is in a later and quite recent author that we find the first clear anticipation of Kerner. Mr. Belt, in his charming work on Nicaragua (p. 131-3), distinctly recognises the fundamental point in this essay of Kerner. "Many flowers," he says, "have contrivances for preventing useless insects from obtaining access to the nectaries;" and after illustrating this staternent by a detailed account of the

1 See Mr. Francis Darwin: Quart. Journ. of Nicros. Science, xvii. 269. 
contrivances for this purpose in Digitalis purpurea, he adds, "Great attention has of late years been paid by naturalists to the wonderful contrivances amongst flowers to secure cross-fertilisation. But the structure of many cannot, I believe, be understood unless we take into consideration not only the beautiful adaptations for securing the services of the proper insect or bird, but also the contrivances for preventing insects that would not be useful from obtaining access to the nectar;" and he instances the lengthy spur of Angroecum sesquipedale.

These are the only anticipations of Kerner that I have found in books, though doubtless there may be, nay probably are, others unknown to me. I may, however, perhaps be forgiven the little egotism that prompts me to give the following account of observations made by myself.

In the early spring of $1876 \mathrm{I}$ was spending a holiday at the Italian lakes. Close to my inn was a bank profusely covered with rough grass and flowers, amongst which Lychnis viscaria was pre-eminent. Having it constantly before me, I was led to speculate as to the possible uses of the viscous secretion, which in this plant forms a ring round the stem, just above each of the higher nodes. I was not then acquainted with the passage cited above from Mr. Belt's book, and my first surmise was that the viscous matter might act as a trap for small insects, which were to be seen 
adhering to it in numbers, and that these insects might then be digested and absorbed. But this I soon saw could not be the case. The viscons matter was without taste or smell, and clearly had no attractiveness to insects, for none were ever to be seen buzzing about it. Moreover, a few days' observation showed that the adhering insects were in fact not digested, nor even dissolved. Might not its use then be to keep insects that were too small to effect cross-fertilisation, and especially to keep ants, from crawling up the stem to the flowers?

That it did as a matter of fact keep them off was plain. The bank swarmed with ants, which were to be seen running up and down many of the other flowers in numbers. But not a single ant did I ever find climbing up a lychnis-stem. If one was put on a sticky ring it adhered there, and never succeeded in getting free. The ants seemed to have found out by previous experience how useless it was to try to mount this plant, and rarely was one to be seen even on the part of the stem which was below the undermost viscid ring. That the stem should only be viscid in part and not throughout was intelligible enough, on the principle of economy. But why were not the viscid rings reduced on the same principle to a single one? Seeing how efficacious and utterly impassable the viscid matter was, it seemed as though a single ring would do as well as a series.

The following appeared to me to be a possible ex- 
planation. Were there but one ring, the blades of grass and other plants that grew intermixed with the lychnis, and which came into contact with it at all kinds of points and all kinds of angles, would serve as so many ladders by which the ant might reach a point on the stem above the solitary ring, and so get at the nectar. The repetition of the rings would make this impossible, unless, indeed, the ladder chanced to be set against the flower itself, or against the uppermost extremity of the stem. Doubtless, if the viscid ring were at the very top of the stem, or if the calyx itself were viscid, the same result would be obtained. And as a matter of fact this was the arrangement in sundry plants, as in the Nottingham Catch-fly (Silene nutans), where only the calyx and uppermost stem were viscid, whereas in the English Catchfly (S. Anglica) the whole plant was sticky. The condition of the Lychnis viscaria seemed intermediate to these. The stem might perhaps have once been sticky all over; and then the viscidity have become limited on economical grounds to the nodes, and might in further ages perhaps become limited still further to the top of the stem. Nor were indications of such a possible event wanting, for already the lowest nodes of the stem were, as $I$ found, destitute of viscid secretion.

On my return home, I propounded my hypothesis as to the functional significance of viscidity to $\mathrm{Mr}$. Darwin, of whose inexhaustible kindness in listening patiently to the crude guesses of amateur naturalists I 
had previous experience. He very wisely said, that whether the hypothesis turned out to be a correct one or not, one thing was plain, that the amount of evidence I had to give in its support was not enough for the purpose. I left the matter therefore for the time alone, and promised myself to hunt for further evidence, when my next year's holiday should come. But before that time came, this essay of Kerner made its appearance, rendering all further evidence unnecessary. He shows, by a mass of evidence which cannot but enforce conviction, that a viscid stem or viscid calyx is only one amongst many contrivances, by which useless insects are excluded from the nectaries. The general result of his essay is to show, that, as the presence of nectar in a flower implies most surely cross-fertilisation by the agency of suitable animals, so also does it, with almost equal certainty, imply the presence of some or other contrivance by which that nectar shall be preserved from unsuitable ones.

The simplicity of some of the contrivances, and the ingenuity of others, and the variety of methods by which the same end is attained, are most striking. And if the reader derive but half the pleasure that $I$ have done from their study, he will feel grateful for having Kerner's essay made readily accessible to him.

\section{THE EDITOR.}

October, 1878. 


\section{CONTENTS.}

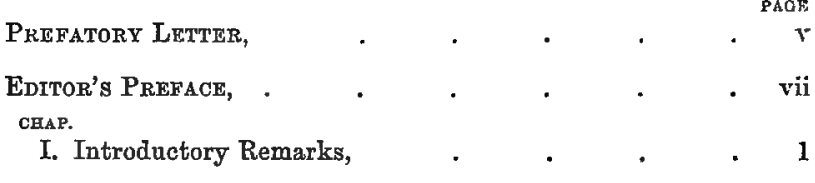

II. Advantages which accrue to the Plant from bearing Flowers, and especially from certain Conformations of Parts of the Flower, . $\quad$. $\quad$. $\quad$. 5

III. Disadvantageous Influences and Attacks to which Flowers are exposed during Blossoming, . . 14

IV. Means of Protection against those Injurious Influences and Attacks by which the Adrantages which accrue to the Plant from bearing Flowers might be lost, .

A. Protective Appliances of the Leaves, in which are formed the Materials for the Flowers, 28

B. Protective Appliances of the Flowers against Unbidden Guests, $\quad$. $\quad$. $\quad$. $\quad 32$

1. Protection from certain Animals by the Secretion in the Flowers of Distasteful Substances, . 35

2. Access to the Flowers Impeded by their Isolation in Water, . . . . . 39

3. Access to Flowers impeded by Viscid Secretions, . 49

4. Access to Flowers impeded by Prickles, . . 69

5. Access to Flowers impeded by Hairy Formations, 79 
CGAP.

PSOE

6. Access to Flowers impeded by Parts of the Plant, and especially Parts of the Flower, being bent, or dilated, or crowded together, . $\quad$ - $\quad$ - 98

7. Temporary Suspension of the Functions of those Parts of the Flower which attract Insects, . 130

8. Diversion of Visitors from the Flower, : . 135

V. Concluding Remarks, . . . . . 140

Explanation of the Plates, . . . . . 152

Index of the Names of Plants, $\quad$. $\quad 159$ 


\section{CHAPTER I.}

\section{INTRODUCTORY REMARKS.}

AmoNG. the current phrases which the flood of literature on the theory of natural selection has brought to the surface, there is scarcely one more frequently used, and perhaps also misused, than "the preservation of advantageous varieties." These words do in truth sum up the whole theory, and there is nothing in the theory itself which can be made a reasonable ground of objection to them. The questions, however, which lie at the base of this theory remain, and will long remain, open to discussion-the question, that is, as to "the primary cause of individual varieties," and further, the question as to "the advantages derivable from any given peculiarity in an organism."

It appears to me to be urgently necessary that instead of indulging in oft-repeated, wide-branching, theoretical discussions on the preservation of advantageous varieties, we should make the establishment of the 
facts our main object, should institute new experiments which may place the theory on a firmer basis, and should so solve the questions at issue by the experimental method. It cannot be denied that the foundations on which the theory at present rests were for the most part built up and obtained without known aim or purpose; that they consist of observations which were the result of accident rather than of definite intention, and which consequently present all the deficiencies which cling to chance or almost chance observations. The foundations, in short, are not such as can be relied on with perfect confidence, since most of the older observations leave room for doubt whether the observer even saw correctly, or whether, misled by some favourite hypothesis, he did not put down as an actual fact what was in reality no more than a conjecture. The records, at any rate, of botanical literature are vitiated by a larger intermixture of falsity and fiction than any one would have thought possible in an experimental science. Observers have been eager to make their conclusions harmonise with the systematic descriptions and artificial separations of species to be found until quite recently, nay, even in the present day, in the leading phytographical works; and one finds in consequence the most absurd statements set forth as "experimental results." Authors, who had neither the opportunity, nor moreover the requisite patience and determination, to test by experiment the 
pretended constancy or variability of species, declare with imposing certitude that, in laying down the boundaries between species, represented by them as systematic units, they were supported by results derived from the cultivation of plants under observation. Nay, even those who were in a position to proceed experimentally, did not hesitate, in their eagerness to support a preconceived idea, to issue as true coin fictitious observations. If to writers such as these we add those others who had no intention to deceive, but who rather deceived themselves in consequence of improper methods of research or carelessness of observation, then indeed must all confidence in the statements of past writers fail us; and this the more, as we have no possible means of correctly separating the chaff from the wheat.

Doubtless it is a very convenient plan to select, by your own standard, out of the chaos of existing statements, such as can serve to support a given hypothesis, and to adopt these as "recognised facts;" whilst you represent those which cannot be brought into harmony with it as the results of erroneous experimentation and of ignorant or inexact observation. But in the building up of a science no good can come from such an arbitrary choice of materials. Considering, therefore, the utter uncertainty we are in as to the use of the older statements, there remains no other course open to us than to begin the whole work afresh, and so 
4 Flowers and their Unbidden Guests.

patiently provide ourselves with fresh building-stones which shall be beyond suspicion. For the solution of the questions at issue, experiments and observations must be carried out with definite aim, so that all subjectivity may be as far as possible excluded, and so thàt each person may have it in his power to test their accuracy by repetition.

As regards one of the questions mentioned above as underlying the theory of natural selection, namely, "the primary cause of individual varieties or sub-species," I shall have an opportunity this year in another place of publishing a series of observations bearing on the question. To the solution of the second question, namely, "how far certain characters in the bearer are of advantage to the same," the following pages may furnish a small contribution. 


\section{CHAPTER II.}

\section{ADVANTAGES WHICH ACCRUE TO THE PLANT}

FROM BEARING FLOWERS, AND ESPECIALLY FROM CERTAIN CONFORMATIONS OF PARTS OF THE FLOWER.

ATTEMPTs have been made to arrange the characters of plants under two heads; those which give their bearers some definite advantage, and those which give none. The former are spoken of as physiological characters, the latter as morphological. It was thought inconceivable that any advantage could arise to a plant through having, for example, its leaves decussated instead of their being arranged quincuncially. This notion does not appear to me to be justified. That unadvantageous characters can appear in an individual, and in fact do appear not rarely, nay that deviations of formation arise which are of direct disadvantage, is not indeed to be disputed; and this fact is of wide significance in other questions. But just as certain is it, that the bearers of such unadvantageous characters never form the starting-point of a new species, but vanish, being driven from the scene by the bearers of advantageous characters. As regards the special case 


\section{Flowers and their Unbidden Guests.}

of a certain position of the leaf, the advantages it confers have been hitherto merely overlooked, or unrecognised. But the mere fact that a person does not at once perceive an advantage does not justify him in assuming that none exists; and any one who builds up a structure of hypotheses, the uncertainty of which is, moreover, increased by his own short-sightedness, must not be surprised to see his building forthwith tumble to the ground.

I hold the opinion that the position, direction, and shape, of the leaf is of just as great significance for the preservation of a species, as the form, colour, and smell of the flower ; and that no hair is meaningless, whether found on the cotyledon or the leaf, on the stem or the blossom.

It is true that we know as yet very little as to the functional significance of the position and form of the several parts of plants. The very elements of their biology are as yet scarcely well made out. There is in science as elsewhere a changing fashion, and this gives to its teaching a preferential turn, now in one now in another direction. Most workers give their attention preferentially to that object which seems at the time most important; and among the branches of Botany which during the last few decades have been shoved aside, is unfortunately to be counted Biology; that is to say, the determination of the functional significance of morphological characters. 
The part which hitherto has, in proportion to the rest, been most thoroughly studied is the significance of the endless varieties of form presented by the flower; and the relations which exist between the parts of the flower and the animals which visit it have been especial objects of attention. In this inquiry there has been indisputably no lack of one-sided views and erroneous interpretations. With the common tendency of explorers to confine themselves to the path indicated by some first successful experiments, men have tried to explain everything they possibly can by the relation between the shape of the flower and that of the animals that visit it; and, as was unavoidable, in so doing they have often overshot the mark, and by their one-sided mode of viewing the matter, have overlooked, entirely or in part, other definite advantages not thus to be explained.

In my treatise on the means by which pollen is protected from premature dispersal, and from wet, I have pointed out a number of such errors, and have shown that many peculiarities of shape presented by flowers, which it was supposed were to be explained only by reference to the visits of insects, are in reality, either not at all or not exclusively concerned therewith. It is manifest that those forms will be most likely to be preserved, and those structures to be most frequently developed, which combine a plurality of advantages; because thus the greatest possible results will be ob- 
tained with the least possible expenditure. And in fact it is rare that any part of a plant is so shaped as to be suitable for the attainment of but one end. Usually "two birds are hit with one stone," nay, often three or more.

It is precisely this varying accumulation of functions in parts morphologically identical, that determines the endless multiplicity of their forms. It is not of course meant that herein lies the explanation of how that multiplicity originated, and what was its primary start. This question, however, as also the further one, why plants in general produce flowers and fruit, and do not remain limited to the vegetative mode of reproduction, is outside our present inquiry. I purpose, in the following pages, to do no more than set forth the functional significance of a number of parts that present a very great multifariousness in their development. But while I thus limit myself, I must start with the assumption that the sexual mode of reproduction by periodic flowers and fruit is advantageous to every plant; and I may further intimate that, in my opinion, the advantage thus derived lies in its affording a possibility for the origination of new individuals differing in their external characters from their parents.

As, moreover, the advantages which accrue from bearing flowers and fruit manifestly cannot be obtained unless each several part fully performs its proper function, it will not be inappropriate to bestow here some 
words on the functions of the individual parts, and on the advantages presented by certain conformations of the perianth, the andrœcium, and the gynæcium.

The main functions of the andrœcium and gynæcium are sufficiently well known. And how essential it is, that the generative cells in particular shall be permitted to develop themselves without external disturbance, scarcely needs mention. So also we may assume it to be admitted, that one of the offices of the perianth, at the time when the generative cells are being developed, is to protect the parts in which this development occurs, that is to say, the andrœcium and gynæcium, from external interference. At a later period it is also certainly one of the most important offices of the perianth to protect the coherent pollen, when discharged from the anthers, against premature wetting by rain or dew, against displacement by wind and by unbidden guests, as also against the destructive attacks of sundry animals. A still further and very frequent function of the perianth is to bring about autogamy, in those cases, that is, where the pollen from other flowers is not brought into contact with the stigma. And a fourth

1 I understand by autogamy the fecundation of a flower by the pollen from the andrœcium of the same flower; by geitonogamy, the fecundation of a flower by pollen from other flowers on the same plant; by xenogamy, the fecundation of a flower by pollen from other plants. Geitonogamy and xenogamy may be classed together under the name allogamy. Such terms as "self-fertilisation" are to be avoided on account of their excessive indefiniteness. 


\section{IO \\ Flowers and their Unbidden Guests.}

not less important function is to attract by the secretion of nectar, by odours perceptible afar, and by colour's contrasting vividly with the green of the leaves, such insects as may carry the pollen from one flower to another, and so bring about allogamy. Finally, the perianth has still another function, namely, to protect the nectar, which is not always secreted only at the base of the perianth, but often also in hollows of different parts of the androcium or gynæcium, or by peculiar epiblastemes, sometimes of one sometimes of another of the floral whorls, or of the bottom of the flower, and which must be secured not only against injurious weather influences, but specially against the plundering of such insects as would visit the flower without conferring any advantage. Again the divisions of the perianth, in a more or less changed form, often act as a protection to the young fruits, which develop under their shelter. Often too they conduce to the dispersal of the seed, as when they form dry and membranous coverings which offer a relatively large surface to the wind (Trifolium badium), or when they adhere to roving animals either by viscidity (Plumbago, Linnoea), ${ }_{1}^{1}$ or by hooklets (Marrubium), or when they are converted into fleshy pericarps which serve as food for animals.

${ }^{1}$ [The fruit of Linnaea borealis, as also the calyx of several species of Plumbago ( $P$. micrantha, and rusea) are covered with glandular hairs. On the whole subject of special appliances for dispersal of seeds, consult the monograph of F. Hildebrand, Die Verbreitungsmittel der Pflanzen. Leipzig, 1873.-EDrTor.] 
These functions of the perianth are performed by it either quite alone, or, more frequently, in conjunction with special developments of the andrœcium and gynæcium. Many flowers thus become very complicated machines, in which it is of the greatest importance that each part shall work with perfect accuracy, that not a piece of the apparatus shall be too long or too short, shall get damaged or out of place, or become unfitted for its office by the injurious effects of weather, or by the attacks of animals.

If a leaf be gnawed by an insect, and in consequence suffer some loss of substance, or if a leaf undergo change in its shape and size through gall-producing insects, the performance of its function is thereby hampered, but, as a rule, not completely stopped. Quite otherwise is it with those floral organs which form a link in the chain of fertilisation. Here the smallest and most inconspicuous change in the size and shape of a part may render the function of the whole apparatus impossible. In Sternbergia and Colchicum, for example, when the erect flower closes, as it does in the evening, the pollen is pressed against the inner surface of the perianth, to which it adheres, and by its intermediation is conveyed to the stigma, which stands up above the anthers. This is brought about in the following manner:-The perianth increases in length during the blossoming period by intercalary growth; and this lengthening is just such as to cause those spots on its inner surface, which, on 
the first day of flowering, had been smeared with pollen from the outwardly dehiscing anthers, to stand on the last day, at the final closing of the flower, on a level with the stigma. Again, take those species of Pedicularis, in which the upper petals form a beak-shaped tube. At the end of the blossoming period ${ }^{1}$ the dusty pollen gets into this little tube, and then, in consequence of an angular movement of the corolla which happens at this time, rolls upwards through the tube to the stigma, which stands close over the mouth. This as before results in autogamy. But the whole mechanism can only be successful if the above-men-. tioned angular movement be of a definite strength, which again is only possible if the corolla be uninjured and undisturbed during the flowering period.

In the blossoms of many Caryophyllaceæ (which will be treated of more fully on a future page), the filaments of the stamens lengthen quite suddenly with the coming on of evening. The anthers are thus brought forward, above the tube of the corolla; they open, and, owing to the position they have now assumed, expose their pollen in such a situation that insects, attracted to the flowers by the nectar, must necessarily wipe it off, and, flying elsewhere, carry it to another flower on the same plant. If, at the time when the pollen is exposed in these

${ }^{1}$ [In the earlier period of flowering, Pedicularis has flowers most ingeniously adapted for cross-fertilisation; ef. Pop. Science Rev., 1870, p. 45, where I have described it.-EDIroR.] 
plants, that is, in the evening, the nectar should fail, then no insect would visit them, and the advantage of geitonogamy or xenogamy, brought about by their means, would be lost. The nectar, therefore, must be reserved for the evening, and special arrangements must be made by which other nectar-loving insects, which visit flowers at any time in the day, and which would steal the nectar without any advantage to the plant, may be kept off.

These two examples will suffice to show that a definite function belongs even to the most inconspicuous modifications of the individual parts of flowers, and that the parts of flowers must be protected, far more even than the leaves, from injury and disturbance in the performance of their functions, if the advantages attached to flowering are to be attained. 


\section{CHAPTER III.}

\section{DISADVANTAGEOUS INFLUENCES AND ATTACKS TO WHICH FLOWERS ARE EXPOSED DURING BLOSSOMING.}

$\mathrm{ON}_{\mathrm{N}}$ the presumption, that to produce flowers is an advantage to plants, there is an antecedent probability that each plant will do so, and will go through the successive stages of the process. But owing to the unceasing interaction which exists between plants and the outer world-inorganic nature on the one hand, and the animal kingdom on the other-this flowering process must necessarily be exposed to many possible interferences; in the one case to frost, drought, rain, or similar injurious action of the elements; in the other to the attacks of herbivorous, and therefore flowerdestroying, animals.

As regards the latter, though the dangers from the larger grazing animals, Ruminants, Solipedes, etc., etc., are the more conspicuous, yet those incurred from the attacks of smaller kinds, if less apparent, are by no means less real; from snails, that is, and wood-lice and insects, and from these latter, both in their larval and in their final stages of development. 
Of the Gasteropods, the voracious Helicidæ are especially dangerous and unwelcome visitors. They are, however, to be found, comparatively speaking, but rarely upon the flowers. This is not because the perianthleaves are distasteful to them, but because they can be kept off more easily than other uninvited guests. A simple group of bristles or prickles on any part of the plant that has to be traversed by the snail in order to get at the flower is enough to prevent its further advance. It avoids most carefully. all contact between its soft, easily injured body and the points of a bristle or a prickle; and, if it comes to a place so protected, it turns back at once, without any further attempt to overcome the difficulty. The same holds good for such insects as have soft bodies, and especially for numerous caterpillars, many of which would readily devour the perianth-leaves, or those which go to form the gynæcium, if they were not debarred from access to the flower.

I once also noticed that caterpillars sought out the just-opened tubular flowers of the garden Pentastemon gentianoides, as a corner protected from wind and weather, therein made their webs, and underwent their transformation, whereby the reproductive processes were rendered impossible in the flowers in question. Probably in those places where the Pentastemon grows wild, it is not exposed to such visitors. Nevertheless this observation is worth mentioning here, as it makes one suspect that the reason, why 
so many plants with bell-shaped or drooping flowers are provided with certain defensive contrivances, is that they may be able to keep off caterpillars from seeking in them a snug corner for their webs and transformations, and thus interfering with the functions of the floral organs.

Among the insects which have a soft outer skin, the wingless aphides require special notice. We usually find them in large numbers, and closely thronged, on the under side of the leaves, and on the stalks of the flowers and inflorescences. In flowers themselves they are only rarely to be met with, because there are special contrivances to prevent their access. If one transfers them to the perianth, or to other parts of the flower, they immediately thrust their rostrum into the juicy tissue, which shows that the petals would be perfectly acceptable to them. If placed on villous or tomentose, or upon bristly and prickly, leaves, they behave most awkwardly. They remain with their long legs hanging between the hairs, or injure themselves by their helpless movements on the sharp points of the trichomes and teeth of the leaves. Leaves, and groups of leaves, clothed with such defences, are therefore most carefully avoided by them, and this explains why the colonies of wingless aphides never advance farther up the stems and flower-stalks than the involucres and calyces, when these are clothed with woolly or matted hairs, or with bristles and prickles. 
In contrast with these soft-bodied animals are those insects that have a hard investment of chitin. These move with perfect ease even over very thorny and prickly stems and leaves. Only the terminal joints of their antennæ are sensitive to the touch of hard points, their bodies and legs not being easily wounded. But it is precisely among these chitinous insects that many species are to be found whose visits would interfere very prejudicially with the functions of some or other parts of the flower. For in most cases the bodily dimensions of such creatures are not adapted to the general conformation of the flower ; that is, their dimensions are so small that, in diving into the recesses of the flower for the nectar there secreted, they would touch neither the anthers nor the stigma. The result therefore of their visits would be that not only would the allurement, that is, the nectar, be taken away from those insects which possess bodies of a suitable size, and thus the advantage be lost which attaches to the visits of such invited guests, but that a further evil would ensue, inasmuch as these little unbidden guests would fill up the bottom of the flower, and so cause a mechanical hindrance, which would prevent the larger and welcome insects from pushing their trunks to the bottom of the nectaries.

On the Muttenjoch, in the Gschnitz Valley, I once saw the small moth, Agrotis cuprea S. V., which works not only by night but also most actively by day, 


\section{I8 Flowers and their Unbidden Guests.}

sucking nectar from the blossoms of the Gentiana bavarica. It flitted from one blossom to another, but I was surprised to see that it passed over some of the numerous flowers, though growing close together, without attacking them. My first suspicion was that the nectar might have been lately carried off from these flowers by other insects, and that the reason why the moth did not insert its proboscis was, that it smelt ${ }^{1}$ no nectar. But when I proceeded to open the flowers which had been thus passed over, I found that they were not void of nectar, but that the several canals in the lower part of the corolla-tube which serve as carriers for the secretion were crammed full with small beetles (Anthobium excavatum). I noticed a similar fact in the Gentiana germanica at Trins in the Gschnitz Valley. Those flowers of this plant which were left unvisited by the humble-bees (Bombus mastrucatus and Psithyrus vestalis) always contained numerous specimens of Meligethes exilis in their nectaries; and at a later period. I had the opportunity of making similar observations on the flowers of Digitalis ambigua Murr. Cuphea platycentra, Eremurus tauricus, Iris tuberosa, and Primula glutinosa Wulf. ${ }^{2}$

1 In Gentiana bavarica L, the nectar is stored at the bottom of the flower, where it cannot possibly be seen by flying insects, as the corolla-tube is closed by the large circular stigma (Plate I. fig. 37). The nectar must therefore in this, as in so many other cases, be smelt by the insects.

2 It is very probable that the species of Forficula also, which we frequently find working for days together in tubular flowers, so far 
The insects that are armed with a hard covering of chitin are usually winged, and then-supposing of course that they are vegetable feeders-generally reach the flowers by flying. Some of them, however, are wingless, and these, like the snails, etc., can only reach the flower by crawling and clambering over the axis and leaves. These wingless insects are unwelcome to the flowers under all circumstances; and their visits are disadvantageous even if they possess such bodily dimensions, that in pushing to the bottom of the flower they would rub against the pollen and the stigma in due succession. For such wingless insects, even when they leave a flower laden with pollen, cannot reach the flower of a second stem of the same species till after a long journey and a proportionally long space of time. A winged insect flies through the air from flower to flower with great rapidity, and often within a few minutes transports the pollen rubbed off from one flower to the stigma of a second, third, and fourth pretty distant one; whereas a wingless insect must first return from the flower to the ground, and then creep or climb over the axis and leaves of a second stem. Now, putting on one side the loss of time which this entails, consider to what dangers the pollen carried by the insect is exposed in this transit! How easily it may be rubbed off on interfere with the floral functions, as that by their presence other insects, whose visits would be of use, are prevented from sucking the nectar. I possess, however, no definite observations on this point. 
the way by leaves, stems, or hairs; or wasted by wind and weather; and how improbable it also is, that a second flower to which the wingless insect, in spite of all the dangers by the way, still brings some of the pollen from the first flower, will be one exactly suitable for its reception. Flying insects in their search for nectar frequently confine themselves during their rapid visitation of successive flowers to the blossoms of one and the same species, ${ }^{1}$ whereas the wingless ones, after visiting and leaving a given flower, take no heed to reach another of the same species, but when back again on the ground are diverted by the least thing, and make the best of anything that turns up of use in their further progress. Herein we have a very probable explanation of the fact that flowers of very small size, flowers, that

1 For example, in a meadow at Trins, in the Gschnitz valley, I saw Bombus montanus Gerst. visiting only the inconspicuous flowers of Anthyllis alpestris Kit., whilst the numerous and far more striking nectar-bearing flowers of Pedicularis Jacquini Koch. and Pedicularis incarnata Jacq. were passed over. Contrariwise, in another place, namely in a meadow in the Padail valley, I saw this same Bombus montanus buzzing from one Pedicularis flower to another, whilst passing over the intermixed Anthyllis alpestris. Neither in the one case nor in the other were the flowers in question filled with beetles; and the nectar of the despised blossoms would have been perfectly easily accessible to the humble-bee. It appears that the humble-bees always devote themselves at one time to the plunder of one species of plant.

[It is curious that a similar observation as to the habits of bees should have been made by Aristotle. "A bee," he says (H. An. ix. 40), "on any one expedition, does not pass from one kind of plant to another, but confines itself to a single species, for instance to violets, and does not change until it has first returned to the hive."-EDITOR.] 
is, in which very tiny insects, in pressing forward to the nectariferous recesses, would necessarily come into due contact with the anthers and the stigma (e.g. many Compositæ, Cruciferæ, Caryophyllaceæ, Saxifrageæ, Asperifoliæ, etc.), are yet provided with defensive appliances which keep off such insects as are wingless, and only allow access to such as fly.

Of all the wingless insects it is the widely dispersed ants that are the most unwelcome guests to flowers. And yet are they the very ones which have the greatest longing for the nectar, as numberless observations sufficiently show. Wherever there are aphides there one is sure to find ants seeking for the sweet fluid which these secrete. It is, moreover, well known that whereever honey, sugar, saccharine fluids, dried fruits, etc., are placed without protection, there ants are to be found. As regards the nectar of flowers they are especially formidable, inasmuch as they can smell ${ }^{1}$ saccharine fluids

I One of my colleagues at Innsbrïck kept some dried pears on the ground-floor of a house directly contiguous to the garden, and to these the garden ants immediately found their way. As these uninvited guests could not be kept from the ground-floor, the pears were transferred to a room on the second story. But, notwithstanding this, the pears were beset by these same ants the very next day, and when investigation was made as to how the ants could possibly have got to the up-stairs room, it was found that they had made their way by a bell-wire which went from the garden into the second story and ran by the window of the room. The following communication from Gredler at Botzen is also not without interest. One of his colleagues had for months been in the habit of sprinkling pounded sugar on the sill of his window for a train of ants which passed in constant procession from the garden to the window. 
even at a considerable distance, and moreover because they do not suspend their activity during the night, as I repeatedly noticed whilst making observations on the visitation of night-blowing flowers. But the reason why, notwithstanding this, wingless ants on the whole are found but rarely in flowers, is that there exists a large number of protective appliances by which the nectar is admirably protected against them. Should for once no such protective appliance be developed, or should it in any way be made useless or cease to act, should it in short in any way become possible for the ants to get at the nectar without harming themselves, then they forthwith appear in the flowers as guests. Of

One day he took it into his head to put the pounded sugar into a vessel, which he fastened with a string to the transom of the window; and, in order that his long-petted insects might have information of the supply suspended above, a number of the same set of ants were placed with the sugar in the vessel. These busy creatures forthwith seized on the particles of sugar, and soon discovering the only way open to them, viz, up the string, over the transom and down the window-frame, rejoined their fellows on the sill, whence they could resume the old route down the steep wall into the garden. Before long the route over the new track from the sill to the sugar, by the window-frame, transom, and string was completely established; and so passed a day or two without anything new. Then one morning it was noticed that the ants were stopping at their old place, that is, the window-sill, and again getting sugar there. Not a single individual any longer traversed the path that led thence to the sugar above. This was not because the store above had been exhausted; but because some dozen little fellows were working away vigorously and incessantly up aloft in the vessel, dragging the sugar crumbs to its edge, and throwing them down to their comrades below on the sill, a sill which with their limited range of vision they could not possibly see! (Gredler, Der Zoologische Garten, xv. 434.) 
this it is easy to convince oneself. Pluck, for instance, some of the flowers of Melianthus, or of any other plant in which, as in this, the nectariferous flowers, while growing in their natural position in the inflorescence, are admirably protected against the visits of ants, and having plucked them lay them on the ground. They are now unprotected, and in the shortest possible time they will be found swarming with ants. Another example is furnished by Phygelius capensis. Here the flowers are rich in nectar, all access to which is rendered impossible to ants during the period of flowering, by a method which I shall have to describe later on in detail. So soon, however, as the corolla detaches itself from the torus, the nectar, of which there is still an abundant store, becomes readily accessible, and ants (in the Botanical Gardens at Innsbrïck abundance of Lasius niger) immediately crowd in and greedily lick it up. They can be allowed to do so at this period without ill result. For, now that the flowers are falling off, their nectar is useless, and no longer wanted to attract such flying insects as cause intercrossing.

In this respect the case of Antirrhinum majus L. is also very instructive. Here the corolla remains closed so long as the stigma is unfecundated. Strong humble-bees can indeed force an opening and so bring about intercrossing; but ants are quite unable to squeeze in between the two closely compressed lips. But, when once the stigma has been covered with 


\section{Flowers and their Unbidden Guests.}

pollen, the tension of the corolla diminishes. The upper and lower lips separate from each other by a fissure, six $\mathrm{mm}$. long on the sides and one mm. wide at the extremity; and through this ants can now make their way and carry off the nectar, which has ceased to have any functional significance. I have convinced myself that, as a matter of fact, they do so.

In bringing this chapter to an end, I may, in addition to the ants, make special mention of the physopodous thrips, which are found almost universally ${ }^{I}$ in flowers. These have been regarded by some writers as injurious, by others as welcome, visitors. In my opinion they may be either. Their visits are injurious if, after ransacking a flower and quitting it, their further progress does not bring them to a second flower of the same species, or only brings them to it after a long circuit; in short, if they behave like other wingless insects. On the other hand, their visits are profitable, if, after rifling one flower, they pass over with its pollen to another similar one; behave, that is, exactly like flying insects, and, like them, bring about intercrossing. As

1 I found them in the majority of flowers on the sea-coast and in the Pusaten district in Hungary, no less than in the High Alps on the limits of eternal snow. They slip through the narrowest fissures, and are not kept back by hairs, even when growing very closely together, so long as these hairs are not sticky. Even close above the nectariferous base of the spur of Centranthus ruber $\mathrm{L}$, which could only be reached through a channel scarcely $0.8 \mathrm{~mm}$. in width and $12 \mathrm{~mm}$. in length, the inner side of which is covered all over with little hairs (see Plate III. figs. 97, 98), I still found thrips. 
they usually act in the latter manner, the advantages they confer on plants far outbalance the disadvantages. Observations, moreover, that have been made render it very probable that in many cases, owing to certain arrangements presented by the plants, these insects can only pass from one flower, or one flower-head, to another, by a series of continuous jumps. It is with the greatest difficulty, for instance, that they can get across places beset with glandular hairs, and they avoid these most carefully. If placed experimentally on such places, they try to get clear by jumping, but usually are unable to set themselves free, and remain sticking to the hairs, where they soon perish. Thus the glandular hairs which are found so frequently upon peduncles, involucres, and calyces, as also upon certain parts of the corolla, and which we shall have to deal with hereafter as protecting flowers from many crawling animals, probably have reference also to the visits of thrips.

Completely analogous to this action of the thrips is that of other larger insects. For here again it is the path and the mode of progression by which the flower is reached that determines whether the visit shall confer a benefit or an injury. There are, that is to say, numerous insects, among such as visit flowers and live upon them, which, if they come by flight, are beneficial visitors; but which, if they were not to use their wings, but to gain access by climbing up the stalk 
26 Flowers and their Unbidden Guests.

from below, would act injuriously. Nay, even insects whose sole method of access to a flower is by flight, may act sometimes advantageously and sometimes prejudicially, and, therefore, be sometimes welcome and sometimes unwelcome guests, according to the further course which they adopt within the flower itself. Of this, however, abundant evidence will be adduced later on. 


\section{CHAPTER IV.}

MEANS OF PROTECTION AGAINST THOSE INJURIOUS INFLUENCES AND ATTACKS BY WHICH THE ADVANTAGES WHICH ACCRUE TO THE PLANT FROM BEARING FLOWERS MIGHT BE LOST,

THe disadvantageous influences and attacks to which flowers are exposed, and which have been set forth in the preceding pages, are compensated by the development of a large number of protective appliances which obviate, as far as possible, the mischiefs threatened. Some of these guard the flowers from injuries which they otherwise might suffer from wind, rain, and dew; while others ward off the attacks to which the blossoms are exposed from the animal world.

As regards the latter, namely, the attacks of animals, it is, for the most part, in the flowers themselves that the protective appliances are to be found. In many cases, however, the axis and leaves are also protected, inasmuch as the destruction of these parts would endanger the formation of flowers. For the materials out of which the flowers are built up are formed, in all plants that have an axis, by the agency of that axis 
and of the leaves; and thus it is self-evident that any very extensive injury of these parts would also interfere with the perfect development of the blossom. Stem, therefore, and leaf-formations must, for a certain period and to a certain degree, be secured from the destructive attacks of animals, if for no other reason, yet in order that the material required for the formation of flowers and fruit may be forthcoming.

It will, therefore, I think, not be out of place to devote a few pages to the methods by which leaves and stems are protected.

\section{A.-Protective Appliances of the Leaves, in which are formed the Materials for the Flowers.}

In very many species of plants the foliage is preserved from any extensive ${ }^{1}$ destruction by means of certain alkaloids and other chemical compounds contained in the cellular juice. The leaves of Datura and Solanum, of Aconitum, Helleborus, and Paeonia, of

1 Minor injuries which interfere but slightly with the function of the leaves cannot here be considered. The leaves of Atropa belladonna L., for instance, may be eaten through and through by Haltica atropce All., and yet neither the development of the flowers nor the ripening of the fruit be in the least impeded. I do not mean to say that smaller animals than those referred to in the text may not do material damage to the foliage, or even destroy it completely. Their attacks, however, are not unprovided against, there being defensive appliances by which small creeping insects, snails, etc., are kept off from the leaves. Thus, to give a single example, the fimbriated cuffs constituting so many "weels," which are set round the petiole of Begonia manicata Vis., make it impos. sible for a snail to crawl up and get at the juicy blades. 
Veratrum and Colchicum, Conium, Cyclamen, Aristolochia, Asarum, Sambucus ebulus, Asperula odorata, of all Crassulaceæ, and of many other plants, are never touched by any ruminant. Some goats had one day unluckily got into the kitchen-garden of my summer residence. I noticed that they set to work vigorously at the cabbage, but passed over the leaves of the lettuce. This led me to make the experiment of presenting leaves of Lactuca, Chelidonium, Papaver, and Euphorbia to different ruminants; when I soon found that they would rather go without food at all than submit to such a diet. ${ }^{1}$ So again the green leaves of the Aposeris foetida, which are full of milky juice-a plant which in the open spaces of the North-Alpine woods often covers the ground in masses-are never touched by the cattle which are driven to the forest. pastures. The fact that many plants (Ballota, Lamium, Geranium Robertianum, Linaria vulgaris, Lepidium

1 This is the more remarkable, because lettuce leaves, as is well known, are readily eaten by numerous caterpillars. That which is sought for by one animal is frequently noxious to another; nay it often happens that some chemical compound in a plant is a deadly poison to one animal, while to a second it is not only harmless but an object of eager search. The Haltica atropa All, for example mentioned in the preceding note, is not injured by the alkaloid contained in the leaf of the Deadly Nightshade, which to many animals is a violent poison. Thrushes also eat the berries of the Atropa without harm, whilst they are made ill by the Phytolacca "berries, which many other birds feed on without injury. [Rabbits also eat the Deadly Nightshade with apparent impunity. I have myself fed a rabbit for a week on this plant exclusively.--See Medical Times and Gazetle, 1867.-EDITOR.] 


\section{Flowers and their Unbidden Guests.}

Draba, Plantago major, Juncus bufonius, etc.), which grow along the paths traversed by grazing animals, are able to maintain themselves and to develop their flowers and fruit without hindrance, in spite of their being exposed to the onslaught of these ruminants, has again no other explanation than the presence of certain chemical compounds in the cellular juice of their leaves which render them disagreeable to these animals.

In many plants, again, the foliage is of thick and leathery consistence, and this also acts as a security against injury from ruminants. The wide tracts in the Alps which are seen covered with evergreen carpets and shrubby thickets of Azalea procumbens, Arctostaphylos uva ursi, Dryas octopetala, Globularia cordifolia, Globularia nudicaulis, Daphne striata, Empetrum, Vaccinium vitis idaea, Rhododendron, and other characteristic plants, are avoided by sheep, as also by chamois. It is exceptional to find the leaves of these plants even mangled by grazing animals, and we never find them completely destroyed.

Even grasses and sedges, when their leaves are unpleasantly rigid, are carefully avoided by ruminants. Carex firma Host., which grows in thick masses on the wide flanks of the Alps, is never browsed. Nardus stricta L. again, and Juncus trifidus, which here and there in the Alpine regions form the fundamental part of the limited flora, are touched but exceptionally.

That the leaves of many plants are also protected 
from attack by prickly appendages need scarcely be mentioned. In the district of Monte Baldo, as also in the mountainous regions lying to the east and stretching out beyond the Etsch, a species of Festuca (Festuca alpestris Röm. et Schult.), is to be found very frequently growing in thick patches. This grass has stiff leaves which end in needle-shaped points, and when it grows in any abundance is burnt by the shepherds, because the grazing animals, in searching for other plants that grow with it, often get their nostrils pricked, and come home bleeding from their pasture-grounds. When it is the fully-developed leaves that require this kind of protection from grazing animals, one finds the thorns and prickles developed on the outer surface of the bushes and shrubs. When, on the other hand, it is the buds, the young unfolding leaves, or the bark, which must be insured against attack, or when the purpose is to keep off animals that creep up from the ground, it is on the stems that prickles are found, or it is the leaves or the stipules which are transformed into such organs. Many trees that are provided with thorns while young cease to develop such appendages when once they have attained a certain height. For their upper boughs, being above the reach of browsing animals, require no further protection for their leaves.

In many cases, it is true, it is only a portion of the foliage that is protected in the above-mentioned ways 
from destruction by grazing animals; just such a portion in fact as is necessary in order that the further developmentary processes, which in the total absence of leaves would be completely arrested, may be carried on. Thus much being safe, the remainder is left to the tender mercies of animals. The very existence' of herbivorous animals would plainly be impossible, were all the leaves of all plants rendered inaccessible to them or uneatable.

It does not, however, come within the scope of this treatise to deal with these relations between plants and animals in detail. In making the above remarks I merely wish to indicate that those structural arrangements by which foliage is preserved, or rather in part preserved, from animals, are not without significance as regards the flowers; inasmuch as these can only develop themselves out of material which has first been fabricated by the leaves.

\section{B.-Protective Appliances of the Flowers against Unbidden Guests.}

If it be of importance to a plant to have some of its leaves protected from animals, of still greater importance is it that this shall be the case with its flowers. It was therefore to be expected that the flowers, which are constructed out of leaves, should be even better protected than the leaves themselves. Plants, whose flowers 
were not protected against the prejudicial attacks of animals, and yet attracted them by dainty and inviting food, must sooner or later have been exterminated, as they would have been overgrown and supplanted by others, the blossoms of which possessed means of self-protection, and therefore stood at a decided advantage.

Animals and plants however do not always stand in the relation of enemies and prey. On the contrary, it is well known that many plants derive great advantage from the visits of animals, nay, even sometimes from their very attacks, since often it is only by such agencies that the stigma can be properly fecundated. ${ }^{1}$

Consequently many flowers have special arrangements to allure insects to visit them. These allurements, it is true, are meant only for certain insects ; for many kinds, owing to the conformation of their bodies, would be of no use, but would rather be prejudicial, in the ways already mentioned.

In relation to the vegetable world, or more correctly, in relation to each individual form of plant, animals may be divided into welcome invited guests, whose visits are of advantage, and into unwelcome uninvited guests, whose visits are prejudicial, or at least of no advantage.

These invited and uninvited guests are of endless variety; and corresponding to them, and of an almost

1 The benefits conferred by animals on plants in regard to the dispersal of seeds must be passed over here with this cursory allusion. 


\section{Flowers and their Unbidden Guests.}

inexhaustible multiplicity, are the allurements to visits and the means of protection against them. The diversity of the latter is so much the greater, inasmuch as the flowers of one kind of plant are not subject to the disadvantageous attacks of only one kind of animal, but to the attacks of animals of the most various forms; great and small; winged or wingless ; flying or creeping; biting or sucking; with a soft slimy skin, or armed with a layer of chitin and regardless of points and prickles; some greedy after one part of the flower, some after another.

On this account it happens very often that one single method of protection is insufficient, and that a plant, in order to preserve its flowers, allow them to blossom without disturbance, and let each part perform its right function, must be provided with two, three, or even more means of protection against animals of such various form and size.

But in spite of this great complication, and in spite of the extraordinary variety of the arrangements which we are justified in considering as means of protection against unbidden guests, we may perceive that certain types of defence, certain definite mechanisms and arrangements, are always repeating themselves, and that it is quite possible in a descriptive account to bring order into this chaos, and to arrange the different means of protection into general groups. From this point of view it is curious to remark that one and the 
same defensive appliance occurs sometimes on one part of a plant, sometimes on another; is sometimes developed on the stem, sometimes on the leaves, sometimes on the perianth; and that often plants, which having regard to other characters we should reckon as belonging to the most different families, are yet provided with identical means of protection.

The defences against unwelcome guests may, according to my views, be divided into those which directly protect the flowers or some part of the same, and those which, though they do not directly prevent entrance into the flower, yet present an indirect hindrance. These indirect methods of defence are again of two kinds. In the one, at the time when the visit of the insect would be prejudicial, the organ which attracts it discontinues its function; in the other, formations are developed on the path by which the insect must approach the flower, which themselves furnish a suffciency of dainty food, and so detain the visitor and prevent its further advance.

In the succeeding pages I shall follow the order thus indicated.

1. Protection from certain Animals by the Secretion in the Flowers of Distasteful Substances.

Any one who has bred butterflies, and for this purpose has fed caterpillars, knows that many of these latter eat the leaves of that plant which is their special 


\section{Flowers and their Unbidden Guests.}

food, whilst they would rather die of hunger than touch its blossons. Herbivorous mammals also appear to have a distaste for flowers. Our cattle and sheep pass over the most beautiful blossoms, not only not attracted but apparently repelled by their sweet smell. I have many a time noticed cattle, whilst grazing in open glades, snuffle at the richly-scented blossom of Pyrola uniflora, Platanthera bifolia, Gymnadenia odoratissima, Convallaria majalis, and Viola odorata, but never have $I$ seen them eat these flowers. So again in the autumn, when cattle are driven to their pastures through meadows bright with countless blossoms of Colchicum, Parnassia, and Euphrasia, we can easily observe how, as they go, they snatch the sprouting leaves of grasses and of other plants from among the flowers, but never touch the flowers themselves." Again I have offered cattle fresh petals of honeysuckle, mallows, lilies, dahlias, and pinks, and they have let them lie untouched. In the valley of Non Ziegen I once noticed that the foliage of Cytisus alpinus was eaten with the greatest eagerness, while the thick clusters of blossoms were left unmolested. Another time, in a place where chamois had lately been feeding, I found the leaves of Nigritella angustifolia, Phyteuma

1 [Mr. Darwin (Forms of Flowers, p. 6) quotes the following passage from his grandfather's Loves of the Planis, written in 1790 :- "The flowers or petals of plants are perhaps in general more acrid than their leaves; hence they are much seldomer eaten by insects."-EDrToR.] 
hemisphaericum, Gaya simplex, Hedysarum obscurum, Trifolium alpinum, Ranunculus glacialis and Senecio doronicum, partly bitten off, but the flowers all left uninjured. Round the herdsmen's buts one often sees great bush-like plants of Senecio cordatus, the foliage of which has been largely attacked by cows, sheep, and goats, whilst the flower-stems have been left intact. So along the roads where the cattle have gone to pasture, one may notice how the leaves of yarrow, the large flowered campanula, scabious, mullein, and similar plants, have been eaten off, while the greater part of their blossoms have been left unhurt. Parasitical plants and saprophytes, which have no green leaves, such as Orobanche, Neottia, Monotropa, Cuscuta, and Lathræa, are never touched by grazing animals. Many similar instances might be added.

A curious fact may here be noticed. In cases where the flowers are so intermixed with the leaves, or so close to them, that destruction of the one involves destruction of the other, the leaves even are avoided by the animals. For example, the Alchemilla vulgaris of our Alps, the little blossoms of which are imbedded among the large green leaves, is never touched, though growing in spots frequented by grazing animals. $^{1}$

1 In many sporiferous plants also the organs of reproduction are surrounded by leaves, and are thus protected from grazing animals. Ferns and mosses, for instance, are never eaten by such animals. 
$3^{8} \quad$ Flowers and their Unbidden Guests.

The singular composition of the flora which prevails on pasturages near to summer farms, mountain herdsmen's huts, and in all places which at recurring intervals are visited for long periods by ruminants, is explained in a measure by this aversion of animals to certain chemical, combinations in the blossoms. ${ }^{1}$ Naturally those plants which are avoided develop in greater plenty and spread more than those which are disturbed in their growth, and whose flowers and leaves " are more or less injured by grazing animals. The former, therefore, are the ones which strike the eye and give a special character to the vegetation. Just as in the neighbourhood of farms in the Puszten district in Hungary, we find Xanthium spinosum, Eryngium campestre, and thistles coming up again and again, together with Datura Stramonium, Hyoscyamus, Marrubium peregrimum, etc., so in the neighbourhood of the herdsmen's huts in the Alps we find species of Aconitum, Rumex Alpinus, Chenopodium Bonus-Henricus, Alchemilla vulgaris, growing together with Cirsinm spinosissimum in a confused mass; and many of the much grazed mountain pastures in the central Alps are covered almost exclusively with the luxuriantly green fan-like tufts of the parsley-fern, together with Nardus stricta, species of Euphrasia, Rhododendron

1 The result, however, is also partly determined by the intimidating action of other protective appliances, which will be described in future sections, and also by the form of the fruits and their mode of dispersal. 
ferrugineum, and species of Polytrichum-plants, one and all, of which the leaves and blossoms alike are unpalatable to grazing animals.

The substances which make the flowers nauseous to many animals, and by which ruminants in particular are kept from them, are sometimes alkaloids, sometimes resins, but chiefly ethereal oils. But just as those green leaves which contain any of these substances afford welcome food to one animal and unwelcome food to another, so also are the floral organs, when their juices are of this character, repulsive only to certain animals. To others they are not so; nay, it is unquestionable that ethereal oils exhaled by a blossom, and perceptible from afar, though offensive to ruminants, serve as an attraction to other animals, especially to insects, and allure them to the blossoms from a distance.

It is worthy of remark that the chemical compounds which prevent many animals from touching fresh flowers are either volatilised, or undergo change, when the petals are dried. Many flowers, when dried, lose their special scent, or change it, and mixed in the hay are eaten by ruminants without hesitation.

2. Access to the Flowers impeded by Isolation in Water.

Gardeners are well acquainted with a simple method of keeping off ants and woodlice from such 


\section{Flowers and their Unbidden Guests.}

plants as are exposed to their attacks when grown in a garden, though protected against them in the natural wild condition. They place the pots, in which the plants to be protected are grown, on other pots turned upside down, and these latter are put in a basin filled with water, so as to stand about a finger's breadth above the water-level. The plants are thus placed as it were upon an island, and by this isolation in the midst of water are well insured against molestation by creeping insects.

Whether the gardeners in thus acting are only imitating arrangements which they have noticed as existing in nature may be doubtful. This much, however, is certain, that not a few flowers when growing wild are most perfectly protected against creeping insects by a similar method. We find very striking examples of this among the Bromeliacex. In some of these (Billbergia, Tillandsia, Echmea, Lamprococcus) the rigid leaves are set in rosettes, and are more or less concave on their upper surface. Now each leaf is in such close contact with the two above it by the margins of its concavity as to form a funnel-shaped receptacle; and in these receptacles rain and dew not only collect, but are retained for a considerable period. In other species there is but one rosette, formed by the collective radical leaves. This forms a single large central basin, which will retain any water that gets into it. The peduncle of the inflorescence springs 


\section{Bromeliacee-Dipsacus.}

from the centre of this basin, and is thus surrounded with water at its base. Thus the flowers of these plants, which are as a rule gaudy-coloured, nectariferous, and dependent on the visits of flying insects, are set as it were upon an isolating stool; and wingless creeping insects, if they would get at them, must either cross over the water of one of the numerous small funnels, or over the large central basin of the radical rosette; a task which they naturally will not undertake. How considerable is the quantity of water retained in these funnels may be inferred from the fact that $I$ found the volume of rain-water collected in the central basin of a small Bromeliaceous plant, namely the Vriesia psittacina Morren, at the period of blossoming, to be $110 \mathrm{c.cm}$., and that in the basin of Billbergia pyramidalis to be $200 \mathrm{c.cm} .^{1}$ Dipsacus laciniatus L. affords another similar and very striking example. In this plant each pair of opposite leaves are connate at the base, so as to form a funnel-shaped basin which surrounds the stem. Atmospheric deposits fill these basins, and it is astonishing how long a time water is retained in them. When no rain had fallen for three whole days I found the larger basins, in a specimen of this Dipsacus, still full of water, the average depth of which was $8 \mathrm{~cm}$, the amount held in one being $180 \mathrm{c}$. $\mathrm{cm}$. As this

1 The rain-water contained in the tubular receptacles of the leafrosette of ALchmea cerulea C. Koch amounted to $215 \mathrm{c.cm}$., that in a rosette of Lamprococcus Weilbachii Beer to $230 \mathrm{c}$. $\mathrm{cm}$. 


\section{Flowers and their Unbidden Guests.}

specimen possessed eight of the larger basins, one above the other, on the main stem, and besides these a still greater number of smaller and shallower basins on the secondary stems, the quantity of water retained in a single plant may be reckoned at a litre and a half. On the fourth and fifth day there was no perceptible diminution to be noticed in the basins, although still no rain had fallen. This maintenance of level can only be explained by supposing that the small quantity of water, which daily evaporated from the comparatively deep basins, was replaced by the dew of the following morning; this dew being deposited on the broad surfaces of the leaves, and, owing to the slanting position of these, much of it trickling down into the contiguous basins. To this plant again. with its abundant nectar no other insects are welcome than such as fly, and minister to allogamy. Those that creep and would carry off the nectar without profit to the plant, nay even to its disadvantage, are unwelcome, and are kept aloof by the internodes of the stem, over which they must crawl in order to reach the flowers, standing out from the water in the basins like posts out of a pond. ${ }^{1}$

1 [Mr. Francis Darwin (Quart. Journ. of Microsc. Sc. xvii. 269), has shown reasons for suspecting that the "cups" of the teasel serve another purpose beside the protective one ascribed to them by Kerner. He believes that they serve as traps, in which insects are caught, and in which they are dissolved by the contained fluid, so as to serve as food to the plants. He points out the curious fact that " in the last century Erasmus Darwin should have remarked on the protective function of the 'bason' formed by the connate 
I have also noticed collections of water above the connate bases of the opposite leaves in the large gentians of the Alps, especially in Gentiana lutea, pannonica, and punctata. The quantity of water in the sheaths formed by the leaves is in this case only small; still it is quite sufficient to debar wingless insects from access to the flowers. If ants are placed on the stem of such a gentian, they run up and down it; and each time that they come to one of the little pools of water in the sheath-like basilar expansion of the pair of leaves which encircle the internode, they turn back; until at last, after vain journeyings up and down, they let themselves fall to the ground. Inasmuch as the receptacles formed by the leaf-bases of these gentians are very shallow, and the quantity of water which they contain but small, the effect of evaporation is much greater than in the earlier-mentioned cases. These gentians, however, grow in places where at the period of blossoming there is a very abundant dew on, rainless days, and the leaves project horizontally, with their concavities turned upwards, just like so many buckets set out on purpose to catch it. Thus the water required to fill the basal leafreceptacles is never wanting; and on no single occasion when I examined such a gentian did I fail to find

leaves of the teasel. He even alludes to nectar, as one of the treasures to be guarded in this kind of way, although he was not of course aware of the true relations existing between flowers and insects.—-(See Loves of the Plants, note 6.)"-EDTTOR.] 
44 Flowers and their Unbidden Guests.

water encircling the stem at the base of each internode.

We must here notice that wingless insects scarcely begin to be really active till most of the dew has evaporated. In vain should we seek for ants on a grass-plot while still dripping with dew. Such flowers as are only open in the morning ${ }^{1}$ are thus at once insured against the visits of creeping insects, and need no further means of protection.

We have seen that when the stem of a plant is encircled by water collected at the basis of the leaves, its flowers are protected from unwelcome guests. How much more perfect then must the protection be when the plants actually grow in water! Alisma, Butomus, Sagittaria, Hottonia, Utricularia, Villarsia, Nuphar, Nymphæa, Hydrocharis, Stratiotes could not be better protected against creeping insects in search of nectar or pollen, than they are by having their pedicles and peduncles floating in the water or rising out of it, so that their flowers stand either above or upon the surface of the water. It is worthy of remark that these water-plants are one and all without any other protective appliances, and that such are only developed should the isolating piece of water chance from any cause to disappear. From this point of view, the case of Polygonum amphibium L. is very instructive. The beau-

1 For instance Lapsana communis and Crepis pulchra have their flowers open only from 5.30 A.M. to 9 or 9.30 A.M. 
tiful rosy flowers of this plant are collected in small cymes, and these form a thick cylindrical rich spikeshaped inflorescence, 2.5 to $3.5 \mathrm{~cm}$. in length, and 1 to $1.2 \mathrm{~cm}$. in width. The segments of the perianth are free almost to the base. The ovary is surrounded by a red, fleshy, five-lobed, nectar-bearing cup; and the bottom of the flower also is richly filled with nectar. The stamens, which are adherent to the base of the perianth, are very short, and the anthers remain bidden in the interior of the flower. The two styles on the contrary are very long, and project beyond the divisions of the perianth. When the flower is in full blossom, the length of the perianth is $4 \mathrm{~mm}$, and its width, at the upper end, scarcely $3 \mathrm{~mm}$. As the nectar at the bottom of the flower is not protected by any special formation in the perianth, it appears to be very accessible to small insects, and is in fact much sought by them; but owing to the above-mentioned dimensions of the flower, even very small insects, so long as they come by flight, cannot help touching, on their way to the nectar, first the stignias, which project beyond the perianth and are somewhat divergent, and then the anthers, which are in close proximity to the nectar. And as the blossoms are proterandrous, even very small flying insects, since they visit many flowers and spikes of flowers in succession, will occasion intercrossing, which will sometimes be geitonogamous, sometimes xenogamous. Small wingless insects, on the 


\section{Flowers and their Unbidden Guests.}

contrary, that would reach the flower by creeping up from below, would not give themselves the trouble of climbing over the upper margin of the perianth, and so making their entrance by the projecting stigmas, but would get at the nectar by the much shorter and, seeing that their approach was from below, much more convenient way, namely, through the intervals between the deeply-divided segments of the perianth. They would, therefore, never touch the stigma at all, and thus the nectar would be sacrificed without the advantage of allogamy being attained. And as autogamy is an impossibility in this plant, owing to its being dichogamous, and owing to the above-described relative positions of its anthers and stigmas, the visits of these small creeping insects would put a complete stop to the formation of fruit. But such creeping insects are prevented from all possible access to the flowers, inasmuch as the Polygonum amphibium grows in water, which encircles the stalks of its inflorescence. But what if the water were to run off, and the plant be left on dry ground? Now it is very remarkable that when this happens special means of protection are developed, which did not exist while the plant was growing in the water. An innumerable quantity of horizontally projecting trichomes ${ }^{1}$ or glandular

1 [As the term "trichome" is as yet hardly in common use in English text-books it may be as well to explain that it is a general name given in the higher plants to all such outgrowths as originate 


\section{Polygonum Amphibium.}

hairs, about $0.7 \mathrm{~mm}$. in length, make their appearance on the epidermis of the leaves and stem. These are set as closely together as possible, especially on that part of the stem which bears the inflorescence, and their globular terminal cells secrete a viseid substance which causes the axis of the inflorescence to be quite sticky to the touch. Such small wingless creeping insects as might steal the nectar without bringing the advantage of a cross to the flowers, cannot get over this sticky axis. If they attempt to do so, they are held fast as on bird-lime. Entrance to the flower is therefore in these cases made impossible by the secretion of a viscid' substance on the path which leads to it. These sticky trichomes, as before remarked, are absent when the plant is growing completely in the water. If the ground on which a Polygonum has grown for years in dryness, so as to have become covered with these trichomes; again be flooded, and the stems and peduncles again therefore be encircled with water, the trichomes with their viscidity disappear, and the epidermis again becomes smooth and even. The water which surrounds the inflorescence is now a sufficient protection, and the viscous matter is therefore superfluous.

I need hardly demonstrate in detail that it is

from the epidermal cells, whatever their form or function; roothairs, woolly hairs, glandular hairs, prickles, paleæ and sporangia of ferns, etc., etc., are all included.-EDITor.] 


\section{Flowers and their Unbidden Guests.}

not only plants which actually grow in water, and have their stems therefore completely surrounded by it, that are sufficiently protected against numerous creeping insects, and especially against ants, but that the same is true of plants whose stems are encircled merely at the very base with fluid or even with semi-fluid mud. But if such proof be wanting, it can be afforded by observations which I made some years ago in the botanical gardens at Innsbrück. I there cultivate many water and bog plants, not in a common large aquarium, but each one by itself, in a special small tub, filled with its right medium, and then sunk in the earth in its proper place in the systematic division of the garden, amongst the plants of the same order. Many bog plants flourish luxuriantly in these tubs, and grow over the rim, so that some of their stems and leaves come to lie on the dry earth in which the tubs are sunk. Among others this happened to Comarum palustre, and it was curious to see how the flowers of those shoots which had grown beyond the edge of the tub on to the dry ground were quite covered with ants, sucking the honey from the deep nectary; whilst the blossoms borne by the shoots in the middle of the tub, and surrounded by liquid mud, were not visited by a single ant. The little insects in their search for nectar could pass unhindered over the dry ground to the leaves and stems which lay upon it, and from these 
could reach the flowers of the shoots standing just over the edge, whilst they carefully avoided pressing forward over the fluid mud in the tub in order to reach those shoots which stood up in the middle.

\section{Access to Flowers impeded by Viscid Secretions.}

I have already mentioned that trichomes, of a special kind, which secrete a viscid substance, are developed on the epidermis of Polygonum amphibium L., when this plant is not surrounded by water but grows on land from which the water has been dried up; and that these glandular trichomes act as a protection to the flower from the visits of creeping insects. This form of protection is one that occurs in plants with special frequency, and is an excellent defence to their nectar, not only from creeping insects, but also from unwelcome flying ones. ${ }^{\text {I }}$

It is always epidermal structures that furnish the viscid substance by which the path to the flower, or to certain parts of it, is made impassable for disadvan-

1 The viscid substances with which parts of plants are coated are not always intended to act as a protection to the flowers from unprofitable visits. The viscid coating of many young leaves, especially in plants whose flowers are nectarless, and whose pollen is dusty (Populus, Alnus, Betula, Juglans), protects these leaves while still young from evaporation and desiceation, acting as a layer of varnish. In many cases also the sticky secretion protects the foliage from herbivora. That the viscid coverings also frequently facilitate the dispersal of the seed by means of animals has been already mentioned on an earlier page (p. 10). 


\section{0 \\ Flowers and their Unbidden Guests.}

tageous, and therefore unbidden, visitors. These structures are generally special epiblastemes of the epidermis, namely glandular trichomes, which have the function of colleters, inasmuch as their cells secrete a viscid substance which is discharged on the outer surface. This discharge either occurs spontaneously by diffusion, or, in many cases, is determined, in increased amount, by stimulation from contact with animals, frequently indeed by the rupture of the cellwalls occasioned by such contact. But it often happens that there are no special epiblastemes, and that the viscid secretion is discharged by the ordinary epidermal cells. The cuticle in such cases separates itself from the secreting cells, and the secretion is discharged into the spaces thus formed under the cuticle, which it forces up into a kind of vesicle. The viscid matter then flows out, either spontaneously or through the bursting of the vesicles in consequence of some exterior pressure.

The viscid matter is a colloidal substance, sometimes resinous, sometimes mucilaginous, or frequently resembling the compound known as blastocol. It is always tenacious, and adheres very readily to other bodies. That milky juice also may become viscid, when discharged from the tissue and exposed to the air, I shall have an opportunity of showing in greater detail at the close of this chapter.

The viscid substance is found most frequently on 
the peduncles, or on those parts of the axis which are immediately beneath the flowers and over which creeping animals must necessarily pass in order to reach them. In Robinia viscosa Vent. the twigs that bear the inflorescences are furnished with five glabrous leaves, free from viscidity; but the twigs themselves, as also the lower part of the peduncles up to the first flower of the inflorescence, are closely beset with darkbrown wart-shaped colleters, and are coated over with an extremely viscid layer secreted by these colleters. ${ }^{1}$

In Epimedium alpinum L. (Plate I. fig. 24) the lower parts of the stem, as also the leaves, are without glandular trichomes, and the perianth also is smooth and free from viscidity. The peduncles alone are furnished with glandular hairs, which stand out horizontally, and prevent small animals from creeping up to the flowers, which are rich in nectar and adapted to flying: insects. Drosophyllum lusitanicum

1 In this plant, as soon as the blossoming is over, and a disturbance of the flower by creeping insects is no longer a matter that needs to be guarded against, the colloidal layer dries up and ceases to be sticky. In other cases, on the contrary, the viscidity of the secretion continues even after the blossoming period; thus in Linnoea borealis L. (Plate I. figs. 12, 13), which will be mentioned again on a later page, as also in Plumbago europaca L. (Plate I. fig. 32), and in other species of Plumbago and several species of Salvia, the same colleters, which at the period of flowering keep'off creeping animals, contribute at a later period to the dispersal of the seed by means of animals. On many fruits, also, as for example on those of Adenocarpus, colleters are to be found which are not developed till the flowering is over, and which only discharge the viscid substance, by means of which they stick to animals, when the fruit is mature. 


\section{Flowers and their Unbidden Guests.}

L. on the contrary, has not only its peduncles, but also its leaves, provided with glandular trichomes that secrete an abundance of viscid matter. Similar to one or other of the types of which the above are examples are-Aquilegia, Dictamnus, Allionia, Ledum, Cistus populifolius and Cistus ladaniferus L., Listera ovata, Aconitum paniculatum and vulparia, Geranium silvaticum, Linum viscosum L., Euphrasia viscosa L., Pulicaria viscosa (L.), and numerous Saxifrages, Labiates, and Scrophulariaceæ. But more remarkable than all are those Caryophyllaceous plants, in which the peduncles are transformed into actual lime-twigs. The species which might here be enumerated are to be counted by hundreds, and I will therefore simply remind the reader that not a few of the Caryophyllaceæ bear names which at once indicate the viscidity of their peduncles and stems, and point to the fact that small insects stick to them. Such are Silene muscipula L., Silene viscosa Pers. Silene viscosissima Ten., Lychnis viscaria L., Dianthus viscidus B. Ch., Alsine viscosa Schreb.; Holosteum glutinosum F. et M., etc. etc.

If, experimentally, small insects are placed upon the viscid axis, it will be seen that, however slight the contact may be, the tenacious substance immediately adheres to them, and is drawn out into threads by their movements, especially by the raising up of their legs. The insects try to rid themselves of the sticky stuff by aid of the mouth. In so doing however they get their 


\section{Caution of Ants.}

heads and the hinder parts of their bodies involved, and in a short time they are done for. Some ants (Formica cinerea Mayr) which I found on the viscid peduncles of Silene muscipula L. and Silene inaperta $\mathrm{L}$, in a very short time were smeared all over with the sticky substance, and after ten to twenty minutes ceased to move. Wingless ants, however, that always feel their way most carefully with their antennæ, will not readily venture of their own inclination on these limetwigs, and, when they come to a sticky place, as a rule turn round and try if possible to go back. Still not unfrequently they undertake the risk, and step on to the sticky places, when they infallibly are lost.

The number of insects which meet their deaths from these traps is usually very considerable. Thus I counted sixty-four small insects sticking to a single inflorescence of Lychnis viscaria, and even the number of different species which I have noticed on some plants of this kind is much larger than one could have believed. For instance, in the immediate neighbourhood of Trins, in the Gschnitz valley (Tirol) I collected over sixty species from the viscid flower-stems of Silene nutans alone. ${ }^{1}$

1 They were as follows:-Ants : Frormica fusca, F. rufa, Lasius umbratus, L. alienus Först., Myrmica lavinodis Nyl., M. ruginodis Nyl., M. lobicornis Nyl., M. scabrinodis Nyl., Leptothorax acervorum (very many specimens !), L. muscorum; small Hymenopteræ of the genera: Bassus, Campoplex, Bracon, Chelonus, Microgaster, Eurytoma, Pteromalus, Ceraphron, Oroctotrupes, Scelio, Leptaris, Platigaster, Gonatocerus, Diapria, Leptorhaptus; Beetles: Oxitelus depressus Gr., Trichopterix fascicularis Hbt., Atomaria pusilla 


\section{Flowers and their Unbidden Guests.}

Many of these insects had certainly not visited the flowers intentionally, and may have been brought by mere accident into adherence with the sticky peduncles, having been carried there by currents of air, just as happens with the fruits of Compositæ, or with grains of sand, which are so commonly to be seen adhering among the insects. A considerable number, however, of the animals had doubtless come in search of nectar, but were such as would have been very unprofitable and unwelcome visitors to $\boldsymbol{S}$. nutans, inasmuch as they would have stolen the nectar without bringing foreign pollen to the stigma, and therefore without producing intercrossing.

The viscid substances are found on the leaves no less frequently than on the stems, and especially on those parts of them over which creeping insects must

Pag., Corticaria elongata Gyll., Apion Aavipes Fab., Thyamis burida Sc.; bugs : Globiceps selectus ; severul Aphides ; one Cicada: Deltocephalus distinguendus, and of Diptera: Melanostoma mellina L., Melithreptus menthastri L., Gymnopternus germanus W., Pipienulus pratorum Fl., P. Silvaticus, Mg., Hilasa lurida Fll., Ccenosia mollicula Fll., C. sexnotata Mg., Morinia melanoptera Fell., M. nana Mg., Anthomyia floralis Fll. Chlorops rufina Zett., Ch. hypostigma Mg., Ch. nasuta Schrank., Empis hyalipennis, Cyrtoma spuria Fll., Phytomyza affinis Fll., other Diptera again from the genera Canosia, Platypalpus, Ceratopogon, Chironomus, several species of Sciara. I have to thank my kind friends von Dalla Torre, Heller, G. Mayr, Palm and Rogenhofer for the determination of the animals mentioned above, as also of the others mentioned in this treatise. Many of the insects which were found sticking to the peduncles of Silene nutans were so injured that it was impossible to do more than determine the genus.

1 With regard to silene nutans see p. $130, \$ 7$, "On the temporary suspension of the functions of individual parts of the flower." 


\section{Pinguicula.}

pass to gain access to the flower. Thus we find these substances on the radical leaves, on the stipules, on the bracts, on the perianth leaves, on the androecium, and, exceptionally, even on the gynæcium.

The genus Pinguicula is worthy of prominent notice here, for it is, with certain Primulaceæ (Primula glutinosa Wulf., Primula villosa Jacq., Primula hirsuta All, Primula viscosa, P. tiroliensis Schott), one of the most instructive examples of those cases in which creeping insects are prevented from gaining access to the flower by viscid radical leaves, spread out in a rosette on the ground. The structure of these flowers reminds one very much of the Bromeliaceæ, already described, (Vriesia psittacina, etc.), where the rosette of leaves forms a basin out of the middle of which rises a slender flower stem. But whereas in these latter plants the basin is filled with rain and dew, in Pinguicula alpina I., $P$. leptoceras Rchb., $P$ grandiflora Lam., P. vulgaris $\mathrm{L}$., etc., the upper surface of the leaves which form the radical rosette is coated over with a tenacious viscid slime. This sticky matter is secreted by small glandular trichomes that are so thickly crowded together on the upper surface of the leaves that (in $P$. alpina L.) I could count nearly a hundred of them on a square $\mathrm{mm}$. (Plate I. Fig. 3, section of a leaf). These glandular trichomes are of two lkinds. Either they are wart-shaped epiblastemes of the epidermis which are divided into from eight to twelve chambers or cells 
by repeated partitions in a radial and tangential direction, or they closely resemble in shape a small mushroom; a one-celled cylindrical stalk, somewhat contracted above, supporting a lenticular disc which is composed of from sixteen to eighteen wedgeshaped secreting cells, grouped together radially round the upper end of the stem. (Plate I. fig. 4.) The secretion which is discharged by these trichomes is colourless, slimy, and very tenacious. No small animal that comes in contact with it, and once adheres, can ever again get free. The largest insect which I found sticking to this viscid layer and dead was Myrmica loevinodis $\mathrm{Nyl}$, an ant $4 \mathrm{~mm}$. in length. Should larger and stronger insects get on to the leaf-rosette, they can manage to free themselves from the viscid substance. When they have accomplished this they always try to reach the outer edge of the rosette, so as again to get firm land under their feet, and they avoid climbing up the flower-stalk which rises nearly from the centre of the rosette. Darwin's statement that the glandular trichomes on the upper side of the leaves are stimulated to increased secretion by contact with these insects, firmly stuck, or, I might almost say, imbedded in the slime, and that the insects themselves are actually digested, ${ }^{1}$ I can simply confirm

1 I must not neglect to record the observation that Diatomaces are not digested by the leaves of Pinguicula alpina and vulgaris, indeed that generally they are not killed. I have repeatedly found 


\section{Pinguicula.}

by my own observations. Neither can there be a doubt that the dissolved nitrogenous constituents of these insects are absorbed by the plants and utilised as nutriment; but no less certain is it that the Pinguiculæ (at any rate the four species mentioned above, which I have investigated) flourish perfectly well without animal food, and therefore are not dependent upon it. The primary function of the glandular trichomes on the leaves of Pinguicula, and numerous other plants, is certainly, therefore, to keep off those creeping insects whose bodily dimensions are so small that their visits would not bring about allogamy; but this, of course, does not exclude the possibility of such insects as get caught and remain adherent being digested, and serving as welcome, if not very luxurious, food.

There are plants in which the glandular trichomes that secrete the viscid matter are set on the higher not on the radical leaves, and are there very abundant. If these leaves are so shaped and so placed

Diatoms in the mucus secreted by the glandular trichomes on the upper side of the leaf, and they appeared quite at home in this medium, lived there for weeks, and apparently, indeed, multiplied. For instance, at Innsbrück, I scarcely ever failed to find the elegant Epithemia Argus on Pinguicula alpina. This observation appears to me to throw a ray of light on the significance of the finty shells of the Diatomaceæ. It is at any rate a very probable supposition that the Diatomacer are protected by these flinty shells against exterior influences which would occasion a disadvantageous chemical change in their protoplasm, as, for example, against the operation of the secretion of the Pinguicula-leaves; and it appears to me very probable that this secretion may even serve as food for many Diatomaceæ. 
58 Flowers and their Unbidden Guests.

that their base must be crossed by any insects that creep up from below, as, for example is the case in Saponaria porrigens, Sap. glutinosa, Angelonia grandiflora, Silene noctiflora, Senecio viscosus, etc., then the glandular hairs contribute most certainly to the exclusion of these insects; and, as a very instructive instance, showing that it is of advantage, even to plants with very small flowers, to be insured against the visits of creeping insects by trichomes on their sessile leaves, I will here describe more particularly the last in the above list, namely, Senecio viscosus. In this plant the distance between the mouth of the small corollatube, which is full of nectar, and the point of the projecting style (which at the first stage of the flowering carries the pollen, and at a later period exposes the stigmatic surfaces), is not more than half a millimetre; and flying insects, that make their approach either from above or from the side, must unavoidably come in contact with the stigma and with the pollen in due succession, even though their organs of suction and the anterior part of their bodies be scarcely half a millimetre across.

Creeping insects, on the contrary, though of precisely similar dimensions in these parts, could, inasmuch as they make their approach from below, get at the nectar without touching the stigma at all, as this stands out above the corolla-tube, and so without bringing about allogamy. Their visits, therefore, are always unprofit- 
able; and they are consequently kept off by the viscid matter which the glandular trichomes on the sessile leaves and on the leaf-stalks secrete in abundance.

The stipules confer this kind of protection even more frequently than the leaves themselves, and for this office they are admirably suited by their situation at the base of the leaf-stalk and around the stem. A large number of plants are, as is well known, furnished with highly developed glandular trichomes upon their stipules; and these stipules with their viscid secretions are placed directly across the path of upward-crawling animals, in such a position as to render it quite impossible to get round them.

Yet more frequently it is the involucres and bracts of the inflorescence that are provided with colleters. ${ }^{1}$ For instance, the foliar organs that stand at the bottom of the flower-bearing shoot of "Acer platanoides L. have their under surface, that is, the side which is presented to any up-crawling animal, completely covered with a layer of viscid matter; and the same is true of the small leaves that invest the catkin-bearing shoots of Satix pentandra L. But the bracts which are most frequently converted, in virtue of their colleters, into a protective viscid screen are those which form the involucrum of Compositæ, over which

1 [Colleter is the name given by Hanstein to the glandular hairs which coat the leaf-buds of many plants with a gummy secretion or with blastocol, i.e. gum-mucilage and resin.-EDIToR.] 
any creeping animal must necessarily pass before it can reach the flowers. The variety presented by these is very great. Sometimes it is the epidermis of the bracts which itself directly secretes the viscid matter; the epidermis, therefore, acting just as it does on the flowering axis of Cistus ladaniferus, Ledum palustre, Lychnis viscaria; sometimes, on the other hand, the secretion is discharged from trichomes, the so-called glandular hairs, which grow in countless number and endless variety from the epiderm of the bracts, and give the involucre its villous aspect and its stickiness. From the vast number of forms which come under this heading, I select a single one as an example; and of this $I$ have given a drawing at Plate I. fig. 9. This represents on an enlarged scale a small portion of the capitulum of Crepis paludosa $\mathrm{L}_{\text {., }}$ with three of the marginal ligulate flowers, each with its anther-tube and with its style protruding beyond this tube. The style is divided into two branches, which have bent themselves back in an arch, so as to expose the stigmatic surfaces as freely as possible to any flying insects. Such insects, if they would suck the nectar which is to be found at the bottom of the corolla-tube, can scarcely help brushing against the stigmas, placed as these are; and as the insects also visit flowers that are in an earlier stage, in order to get pollen, their visits will, as a rule, promote intercrossing. Crawling insects, on the other hand, would be able to get up 
from below to the mouth of the corolla-tube, and to attain the nectar without ever coming into contact with the arms of the style, were it not for the protection afforded to the flowers by the black gland-tipped trichomes, with which the involucral scales are thickly covered.

Analogous in all essential points to these viscid bracts is the viscid calyx, such as is developed in Sedum dasyphyllum, Stellaria cerastoides, in species of Spergula and Cerastium, in many species of Erodium, Geranium, Hypericum, and Prunus, in numerous Labiatæ, Scrophulariaceæ, and Saxifrageæ, in Saxifraga controversa, Sternbg. (Plate I. fig. 11), Linnoea borealis, L. (Plate I. figs. 12, 13), Ribes grossularia, L. (Pl. I. fig. 25), Plumbago europoca, L. (Plate I. fig. 32), Circcea alpina, L. (Plate I. fig. 10), and in numerous other flowers. In Circoea alpina, L., we can again see, with very great clearness, that nectariferous flowers, even when of very minute dimensions, are not without protection of some kind or other from crawling insects. In the proterogynous flowers of this plant, the distance which separates the anthers and stigma from the edge of the cup which contains the nectar is so small that, in getting to this latter, even animals no more than $1.5 \mathrm{~mm}$. in circumference must necessarily come into contact with the pollen or the stigma, as the case may be. Now, amongst the numerous small wingless creatures that frequent the places where Circoea alpina grows, 
there are many of this small size. Though these in visiting the flowers would brush off the pollen, yet they are kept away by the glandular hairs that stick out horizontally from the lower and tubular part of the superior calyx, because the pollen thus brushed off would be completely wasted; whereas small flying dipterous insects, inasmuch as they flit from flower to flower in rapid succession, will carry the pollen with them, and transfer it to the stigmas of other flowers.

One of the most remarkable instances of a calyx so modified as to keep out unbidden guests, is presented by Cuphea micropetala, H. B. R. The petals are here reduced to minute lancet-shaped bodies, which are inserted on the calyx-tube at the upper extremity of certain niche-like hollows, which occupy the interspaces between the contiguous sepals. (Plate I. fig. 26 -a bit of the calyx-tube cut open, and showing two of the lanceolate petals.) The calyx is of tubular form, coloured like a corolla, 22 to $28 \mathrm{~mm}$. in length, and 6 to $7 \mathrm{~mm}$. in breadth, has a saccular recess at its base above the ovary (Plate I. fig. 28, longitudinal section of flower), and secretes abundant nectar from the inner surface of this recess. ${ }^{1}$ The ovary is tolerably large, is placed obliquely, and, at the point where it is

1 The knob-shaped body, which is to be seen in this nectarcavity immediately above the base of the ovary (Plate I. fig. 28), and which at first sight might be taken for a nectary, does not secrete nectar, and is to be explained as an abortive carpel, through the arrest of whose growth the nectar-cavity has gained in space. 
continuous with the style, presents a swelling, which is closely applied to the upper side of the calyx-tube: (Plate I. fig. 28, longitudinal section of flower; fig. 29, transverse section, at right angles to the axis of flower at the base of the triangular style). As the ovary is on either side in close apposition to the calyx-tube, the nectar is, as it were, corked up inside the saccular dilatation of the calyx. But on either side of the ovary, to the right and left, as may be seen in fig. 29, is a furrow, which widens out anteriorly like a funnel, so as to form a passage, half a millimetre in width, leading into the cavity behind the ovary; a cavity which is not only itself full of nectar, but also usually overflows into the passages. Flying insects that would get to the nectar, and whose visits, owing to the marked proterandry of the flowers, would promote intercrossing, must insert their trunks through these passages. But it would naturally be far from agreeable to them to find the mouth of the passages swarming with ants, licking up the nectar and blocking up the entrance; ${ }^{1}$ and therefore it would be a disadvantage to the plant to have its nectar accessible to these wingless creeping

1 If ants are attacked with a fine bristle, they do not as a rule take to flight, but stand on the defensive, seize hold of the bristle, and work at it with their jaws. They act in a similar way if imprisoned in a small bottle. It is therefore very probable that ants, when disturbed in their enjoyment of the nectar in a flower by the intrusion of an insect's proboscis, seize hold of the proboscis and bite it. 


\section{Flowers and their Unbidden Guests.}

insects; and yet the nectar of Cuphea micropetala must have some special attraction for ants; for in no other plant have I ever found so many of them fall victims to the viscid secretion, which they elsewhere avoid with the greatest care, as in this. ${ }^{1}$ The corollatube, moreover, is so wide, being 4-5 $\mathrm{mm}$. in diameter in its narrowest part, that most of the smaller kinds of ants could get along the sides of the ovary to the mouths of the nectar-passages with perfect ease. Such access, however, to the interior of the flowers is rendered impossible, not only to ants, but to all creeping insects, by the following very curious arrangement:Round the margin of the calyx, and above the stunted petals, certain knob-shaped epiblastemes stand out, each provided with six or seven somewhat diverging glandular trichomes, which secrete an abundance of viscid matter, and may be aptly compared with lime-twigs. (Plate I. fig. 26.) These lime-twigs crown the margin of the calyx-tube, and collectively form a "weel," on which no ant that creeps up from the base of the calyx can step without being irretrievably lost. Such flying insects, on the other hand, as remain hovering in front of the flower while sucking the nectar, as also such smaller flying species as use the anthers, which project beyond the margin of the calyx (Plate I. fig. 27), for a landing-place, are in no wise hampered by

1 I once found three specimens of Lasius niger firmly glued to a single flower. 
the lime-twigs, inasmuch as these stand out from the margin of the calyx in a somewhat oblique outward direction; but then these insects are in the highest degree welcome visitors to the flowers of Cuphea micropetala.

In all the cases as yet mentioned it has been creeping insects that are kept back from the flowers by the viscid secretions. There are, however, other species where flying insects are similarly shut out from the nectar, when their visits would confer no advantage on the plant. Such for instance is Monotropa glabra Bernh., of which I give drawings (Plate I. fig. 30, longitudinal section of whole flower; fig. 31, longitudinal section of magnified style). The petals which form the cylindrical corolla of the above-mentioned Monotropa are saccate at their base, and the thick firm tissue of which these saccate portions are made secretes internally an abundance of nectar. ${ }^{1}$ The remaining and pointed portion of the petals is, on the other hand, made of soft tissue; and these almost membranous ends of the petals are closely applied to the end of the

1 The crooked horn-like growths which project in pairs into these saccular dilatations, and have been held to be nectaries (Eichler, Bl. Diagr. 346), do not secrete nectar. They form two whorls, the parts of which alternate with each other, as also with the members of the two whorls of stamens, and with the divisions of the single whorl that constitutes the corolla. They represent abortive stamens ; and the advantage that accrues to the flower from their abortion consists probably in their preventing the nectar from running out from the saccular dilatations, when the flower is in a drooping position. 
style. This style is of considerable size, and shaped much like a clarionet. It is only the inner surface of its funnel-shaped extremity that is stigmatic; the outer surface, on the other hand, is somewhat swollen, and covered with a layer of viscid matter secreted by the epiderm. The stronger kinds of flying insects, that have a proboscis not less than $12 \mathrm{~mm}$. in length, are in no wise hampered by this viscid matter; for they can insert their proboscis without harm between the viscid ring and the closely applied petals, and so reach the nectar below. These large insects, however, in so doing and in flying from flower to flower, will carry pollen with them and transfer it to the mature stigmas. Creeping insects, on the contrary, as also the smaller flying ones, whose visits would not conduce to this desirable result, are caught by the viscid ring in their attempt to purloin the nectar, are held fast, and perish. 1

Before bringing this chapter to an end, I must record a very noteworthy observation, which I chanced to make for the first time in the summer of last year. With the view of watching the behaviour of woodlice, insects, snails, etc., when on plants; I placed such animals in some cases half-way up the stem, in other cases on the viscid rings, in others on the prickly or

1 I found a small winged beetle Epurea silacea, as well as a wingless ant, Leptothorax muscorum, sticking to the viscid ring of Monotropa glabra Bernh. 
hairy leaves, and the like. Amongst other experiments, I placed various kinds of ants upon sundry plants that were full of milky juice, and especially upon Lactuca augustana Chaix, and Lactuca sativa, L. Having done this I was not a little surprised to see the ants ${ }^{1}$ very soon glued down by the milky juice. Such, however, was the case. No sooner had the ants reached the uppermost leaves, or the peduncles and the involucral bracts, than at each movement the terminal hooks of their feet cut through the epiderm, and from the little clefts thus made milky juice immediately began to flow. Not only the feet of the ants but the hinder parts of their body were soon bedrabbled with the white fluid; and if the ants, as was frequently the case, bit into the tissue of the epiderm in self-defence, their organs of mastication also at once became coated over with the milky juice. By this the ants were much impeded in their movements, and in order to rid themselves of the annoyance to which they were subjected, drew their feet through their mouths and tried also to clear the hinder part of their body from the juice with which it was smeared. The movements, however, which accompanied these efforts simply resulted in the production of new fissures in the epiderm and fresh discharges of milky juice, so that the position of the ants became each moment worse and worse. Many of

1 The species used in these experiments were Camponotus ligniperdus, Myrmica loevinodis $\mathrm{Nyl}$, and Formica rufa. 
them now tried to escape by getting, as best they'might, to the edge of the leaf, and letting themselves fall from thence to the ground. Some succeeded, but others tried this method of escape too late; for the air soon hardened the milky juice into a tough brown substance; and after this all the strugglings of the ants to free themselves from the viscid matter were in vain. Their movements became gradually fewer and weaker, until finally they ceased altogether, and the dead animals were left adhering to the involucre or the uppermost leaves.

I do not hesitate to infer from this observation that the presence of milky juice in certain parts of plants is to be regarded as another of the appliances by which flowers are protected from the unwelcome visits of creeping animals; and I find a further support for this view in the fact that the leaves and the internodes in the various species of Lactuca and Asclepias contain a larger abundance of milky juice the nearer they are to the flowers. Creeping insects can ascend without any difficulty over the lower leaves and lower parts of the stem of these plants ; for the passage of the little creatures over these parts causes no discharge of milky juice. It is only when they come nearer to the nectariferous flowers, intended, as these are, for flying insects, that their sharp hooklets cut into the turgid epidermal cells, and that the milky juice is discharged in streams from the rents thus made. It is further 
worth noticing that plants such as these have smooth leaves, and are without any other of those appliances for the protection of flowers from crawling animals, which have either been described in former pages or have yet to be described in succeeding ones.

The epiderm of the stem is in some plants covered with a coating of wax; and there can be no possible doubt but that this also can serve to hinder the ascent of crawling insects, and so to protect the flowers from unbidden guests. The catkins of Salix daphnoides Vill, rich in nectar, and swarming with crowds of bees, are thus protected; and their flowers, which, being dicecious, can only be fecundated by xenogamy (so that the visits of wingless ants would be highly unwelcome), are placed beyond the reach of any creeping animals. No sooner does one of these tread on the epiderm of the catkin-bearing shoots, coated as this is with wax, than down it slides, as though on slippery ice, and often pays for its attempt to get at the enticing nectar by tumbling to the ground from a height of several metres.

\section{Access to Flowers impeded by Prickles.}

It is abundantly clear from the preceding remarks that the viscid substances secreted by the colleters, if deposited on those parts of the plant which must be traversed in order to reach the flower, serve specially 


\section{$70 \quad$ Flowers and their Unbidden Guests.}

to exclude such creeping insects as have a tolerably hard investment of chitin; and amongst these the wingless ants play the most important part. Creeping animals, whose skin is soft, are kept back by these viscid secretions with much less certainty. Snails and slugs especially show no great wish to avoid such substances; for they have learnt an easy method of passing over the sticky places when they come on them, without the least risk; namely, by covering the stickiness with their own slimy secretions. On the other hand, like all animals with soft outsides, they are peculiarly sensitive to thorns, prickles, and sharp points (see p. 15); so that while ants pass without harm not only over prickly leaves but over most thistleheads, these softer animals stop short when they come to such obstacles, and avoid all contact with them. It is impossible, therefore, for flowers to have a better protection against such animals than is given by prickles, sharp points, or hard bristles, set on the parts which must be traversed on the way to them. It matters not whether these structures be mere outgrowths of the epiderm, or modifications of the stipules or of the stem-leaves; provided only that they are so placed as to make the path, which crawling animals must follow in order to reach the flowers, a dangerous one, they have in the vast majority of instances the same significance, namely, that of defences to these flowers. The cases which come under this heading are 
so excessively numerous and so well known, that I may spare myself the trouble of giving a more detailed account of them. There are, however, two points which I must touch on, at least in a cursory manner.

While spines (modified branches), as a rule, either stand out horizontally or have their points directed upwards, and thus evidently protect the leaves behind them from wholesale destruction by the larger browsing animals, the prickles and sharp bristles on the axis usually point downwards, so as to present a threatening front to all animals that might wish to crawl up the stem. Even leaf-prickles will be found to have in part a similar arrangement; and an examination of thistleheads will show at once that the prickles on the involucrum, at least on its lower bracts (see, for instance, the capitulum of Carlina vulgaris L., Plate I. fig. 20), point downwards. I have also noticed that not unfrequently these down-pointing needles are massed at certain spots. The most frequent spot is the upper end of the internode, where the leaves are given off, and where such an arrangement is the more feasible, because it is at this place that the prickles and bristles which shoot out from the epiderm of the stem intermingle with those which proceed from the leaf-bases. This may be noticed, for instance, in many Asperifoliæ, Labiatæ, and Dipsaceæ, and may be especially well seen in Galeopsis grandiflora, pubescens, Tetrahit, and 


\section{Flowers and their Unbidden Guests.}

in Knautia dipsacifolia Host, which is figured as an example at Plate I. fig. 7.

It may again be laid down as a general rule, that the closer to the flower the greater the accumulation of the prickly formations; and every one must have noticed that in our common thistles the lower leaves are less prickly than the upper ones, and these again than the leaves of the involucrum. There are many plants moreover where the stem and leaves are perfectly smooth and free from prickles, while the involucrum is studded with rigid points. Of this latter condition good examples are furnished by many species of Centaurea, and in Plate I. fig. 8, I have given in illustration of this an enlarged drawing of the involucrum of $C$. cyanus, $\mathrm{L}$, a widely spread species of this group. In this plant neither stem nor leaves show any trace of prickles, while every one of the lower and middle involucral bracts is beset with stiff, sharp, scarious teeth round its whole margin, excepting where overlapped by a neighbouring bract. All these teeth curve downwards, so that their fine needle-like points are presented to any animal that would creep up to the flowers. The involucrum thus furnishes a protection which is deterrent even to ants, who are not easily stopped by opposing points; and the protection is so much the more complete, inasmuch "as the bracts of the involucrum overlap like tiles, so that an animal that has by luck got over a lower bract will find itself 
on a second similar one, equally beset round its margin with down-curved points.

The Centaurea cyanus L., which I have just taken as an example of one statement, is of interest also in a second way; for it serves to show that the question whether the visits of animals are advantageous or prejudicial to a flower, depends not merely on the shape of the animal that visits it, but also upon the path by which the animal makes its entrance. I have already, at page 25 , referred to this very noteworthy fact; but this will be a proper place to consider the structural arrangements in plants which are therewith associated. For this purpose it will not be necessary to start with a detailed description of the flower-structure of Centaurea cyanus. It will be enough to say that its flowers are proterandrous and adapted for allogamy. The upper part of the style, which in the earlier stage of the flowering process sweeps out the pollen from the anther-tube, and at a later stage lays bare the receptive stigmatic surfaces, projects $4 \mathrm{~mm}$. beyond the tube of the corolla, and is so placed that even small insects, if they come flying from above or from the side, must inevitably graze it on their way to the nectar; but should these small insects, on the contrary, reach the flower from below, they would be able to get at the nectar-which is so abundant as to fill the bell-shaped expansion of the tube half-way upwithout ever coming into contact with the stigma, 


\section{Flowers and their Unbidden Guests.}

which would be $4 \mathrm{~mm}$. above them; and thus the nectar would be expended without profit to the plant. Such access, however, to the flower from below is rendered impossible to all small insects, winged and wingless alike, by the above-described formation of the involucrum. Supposing a small winged insect to have crept up the stem as far as this involucrum, and still to aspire after the nectar, there is no other course open to it than to take to its wings, pass over the obstacle by flight, and thus approach the flower from above, that is, by the path which will inevitably bring it into contact with the stigma. Thus the prickly scales of the involucrum protect the flowers, or rather the nectar which the flowers secrete, only in the sense that they prevent the nectar being got at from below. It is only when visitors would make their approach in this direction, that they are unwelcome. Let them come from any other side, and their visits are in the highest degree acceptable. Protective appliances of this characterto which we may not unfitly give the name of " pathpointers"- are of extraordinary frequency, and amongst them are to be reckoned numerous prickly formations occurring in the neighbourhood of the flowers.

It has already been stated that the prickles and sharp bristles which beset the epiderm of the axis, as also the needle-like processes of the lower bracts, usually point downwards; the object manifestly being to keep off such soft-skinned animals as would creep up 
from below. But from what has been said concerning Centaurea cyanus, it is plain that such down-turned bristlesmay servealso as "path-pointers" to flyinginsects; for these might occasionally creep up from the ground, or, having first lighted on the leaves, might then try to pass upwards to the flower along the stem. But the parts which pre-eminently, and above all others, act as path-pointers are those upturned bracts which surround the flowers and inflorescences of many Umbelliferæ (Eryngium alpinum, etc.), as also the involucres of many Compositæ (Atractylis, Carduus, Kentrophyllum, and innumerable other Cynarocephalae), with a dense circlet of sharp points; and again the prickles which so often tip the sepals of the Labiatæ. It is by no means uncommon to find one and the same involucre with down-pointing prickles on its lower, and up-pointing prickles on its topmost, bracts ; an arrangement by which defences are provided against visitors of the most diverse kinds. This may be well seen in Centaurea cyanus, and also in Carlina vulgaris; the involucrum of which latter, already referred to, is represented in Plate I. fig. 20.

Amongst these protective appliances, of which I said above that they also act as "path-pointers," are again to be reckoned those minute tooth-like pricklets which are found on certain spots of the inner surface of the perianth, as also on the androecium of some Labiatæ and Scrophulariaceæ. A very pretty example 
is furnished by Leonurus heterophyllus Sweet. Here, as in most Labiates, the style and anthers are placed under the roof-like upper lip, so as to be sheltered from rain and dew. The mouth of the corolla is however so widely open, that small flying insects could pass their proboscis along the lower surface of the corolla-tube, and reach the nectar at the bottom of the flower, without towching the stigma or anthers, which lie concealed under the upper lip. This robbery however is rendered impracticable by the under side of the corolla-tube being studded on its inner surface with numerous sharp pricklets, into contact with which no insect will bring its proboseis and antennæ. The insect therefore is led to try some other mode of access. Avoiding the pricklets, it makes its way in higher up under the upper lip, and in so doing rubs either against the stigma or, if the flowering process has reached a more advanced stage, against the anthers.

Precisely the same occurs in Pedicularis recutita, CEderi, foliosa, rosea, and verticillata. It would occupy too much time, and moreover would be out of place here, to describe the no less complicated than wondrous mechanisms of these flowers; mechanisms which aim primarily at cross-fertilisation by the aid of insects, but yet, in default of insect visits, produce autogamy. It will be enough to give one example to illustrate this function of pricklets; and we may select the corolla of Pedicularis recutita, since this is represented in Plate II. 
fig. 50. In this flower a groove, bordered on either side by a swelling, runs along the median line of the lower lip. The humble-bees which visit the flower must pass their proboscis down this groove, if their visit is to be of any use ; for it is only by attacking the nectar in this manner that they can cause the upper lip to incline forward with a peculiar angular motion, rendered possible by a pair of lateral joints; in which case the powdery pollen will fall out of the anthers, and the concealed stigma be brought down on the back of the bee. Should the bee insert its proboscis higher up, above the groove, the angular motion would not occur, and the mechanism would not be brought into play. In order, however, that the humble-bees may not so act, but may be compelled to introduce their proboscis by the only way which can benefit the flower, the upper lip is in this region studded with small sharp teeth; all contact between which and their proboscis the humblebees have good reason to shun.

The several species of Melampyrum present a precisely analogous arrangement in their flowers. As, however, may be seen in Plate II. fig. 71, which represents a flower of Melampyrum pratense L., the pricklets are now set not on the corolla, but on the filaments of the anthers, which enclose the entrance to the nectariferous recess like a frame or a pair of toothed jaws. Their purport, however, is precisely the same as in Leonurus or in the above-mentioned species 


\section{Flowers and their Unbidden Guests.}

of Pedicularis. In the one case as in the others the visitors are warned to adopt the right mode of entrance, that is, the one most advantageous to the flower.

The function of the minute pricklets which are to be found inside the corolla of certain Asperifoliæ, notably of some species of Symphytum, is slightly different. The pricklets are here placed neither on the inner surface of the corolla nor on the filaments, but on certain epiblastemes of the corolla. These epiblastemes, which alternate with the stamens, are made of tough tissue, have an elongated triangular outline, and are beset round their edges with small sharp teeth, which may almost be compared with the processes on a swordfish's spear. (See Plate II. fig. 74). They project into the corolla-tube, and are so closely apposed to each other as to form a hollow cone, the apex of which. points towards the mouth of the flower, and has in its centre an opening through which the style is seen to protrude (Plate II. fig. 73, longitudinal section' of a flower of Symphytum officinale). It is only at their very tips that the epiblastemes or throat-scales are without teeth. But it is these tips that surround the small central hole in the apex of the cone, which gives issue to the style; and through this hole such insects as have a proboscis long enough to reach the bottom of the flower can therefore suck the nectar without hurting that sensitive organ. It is, moreover, only by this method of suction that they will 
come in contact first with the stigma and then with the anthers, and so will convey pollen from one flower to another, and promote intercrossing. They will never thrust their tender proboscis through the lateral chinks between the adjoining scales, defended as these are by pricklets. So far, therefore, the pricklets act as " pathpointers" to invited guests. But inasmuch as they also shut out all such smaller insects with shorter proboscis, as would, in their absence, get at the nectar without first striking the stigma and then getting powdered with pollen, they are to be considered not only as path-pointers, but also as protective appliances against unbidden guests.

\section{Access to Flowers impeded by Hairy Formations.}

The protective appliances hitherto considered are developed as a rule along the road which creeping insects must follow in order to pass from the ground to the flowers, and only in exceptional cases are to be found inside the flowers themselves. Viscid substances indeed, collections of water, or chevaux-de-frise of sharp prickles, could scarcely be placed with profit inside the flower; for this would prevent the visits of almost all flying insects to the nectar. But amongst these flying insects are, as is well known, not a few whose visits are not merely advantageous but actually indispensable for the production of germinable seeds; and these, of 
course, are insects that, instead of being repelled, are to be attracted, and to whom every possible facility is to be given of rifling the nectar. It might, therefore, be expected, even a priori, that no impassable barriers would be found inside the flowers on that short tract which these welcome visitors must traverse either with their proboscis or with the fore-part or whole of their body, but merely such formations as would keep out unbidden guests, and direct bidden ones on the right way.

Soft hair-like trichomes are pre-eminently suited for the construction of apparatus which will serve this double function. When collected in large number, so as to form trellises, "weels,"1 or similar aggregations, these trichomes can easily render all access impossible to one insect, while they offer no hindrance to a second, whose longer thin proboscis can be readily thrust between the soft hairs, or whose greater strength enables it to push open the latticed door.

Such hair-like trichomes are, in fact, used in a vast number of cases to form the internal defence of flowers against unwelcome flying visitors.

It must not, however, be inferred that every such trichome, when found inside a flower, has this and no other function; nor yet that stems and leaves are

- 1 ["Weel" is the technical name for those wicker baskets with a small terminal opening that are used by fishermen to catch eels, etc. The arrangement of the stamens in the flowers represented in Plate III. fig. 87, will give a tolerably correct idea of the shape of such a weel.-EDIToR.] 
never protected by similar formations. All that can be said is that such trichomes, when developed on stem or leaves, as a rule fulfil some other function than that of keeping off insects from the flowers; and on the other hand that when developed inside a flower, their office in the great majority of cases is the exclusion of unbidden guests. ${ }^{1}$

Just as thorns are sometimes to be considered as modified leaves or parts of leaves, at other times as epiblastemes of the epiderm, so also are the hair-like structures in question sometimes to be looked on as parts of a fibrillated petal (Gentiana ciliata, Plate II. fig. 64 ; Tellima grandiflora, Plate II. fig. 75), and sometimes as epiblastemes of the floral organs. In the latter case again they may present themselves as a

I Hair-like trichomes, when inside the flower, have various functions. Sometimes they keep the anthers for a time in some fixed position (several species of Euphrasia, Thesium); sometimes they cause the discharged pollen to fall in some definite direction (Trixago, Pedicularis, Orobanche); sometimes they sweep the pollen out of the tube formed by the anthers (Compositæ), or collect the pollen grains (penicillate and feathery stigmas); sometimes they serve as a bridge for insects, leading them to the right entrance into the flower (Campanula barbata), etc., etc. Hair-like formations in many cases are of no use until the process of flowering is over. Such, for instance, is the case with the "weels" in the calyx of Thymus serpyllum; and such, of course, with all the hair-like structures that minister to the dispersal of fruits and seeds. Hair-like trichomes, when on the stem and leaves, in part protect the leaves from too great evaporation; in part act as a cooling apparatus, inasmuch as by their powerful radiation of heat they bring about condensation of moisture and abundant deposition of dew. 
delicate fringe round a leaf-like epiblasteme (a so-called para-corolla), as for example in Gentiana nana Wulf. (Plate II. fig. 72), and Soldanella alpina L. (Plate II. fig. 76), or as simple hairs, i.e. trichomes in the limited sense of the term. As far as function is concerned these morphological distinctions and hair-splittings are utterly irrelevant. What, however, is really of importance, is the manner in which these hair-like structures are grouped inside the flower; and in this respect we find an extraordinary amount of variety.

One form of protective appliance which recurs with great frequency, and which manifestly serves to preserve the nectar, or much more rarely the pollen, from insects of such small bodily dimensions that in visiting the flowers they would not come necessarily into successive contact with the stigma and the pollen, is the introduction into the flower of lattice-work and "weels" of hairs. ${ }^{1}$ These are usually composed of straight

1 These "weels," which are especially frequent in the flowers of Labiatæ, as also the internal tangles of trichomes, which will be dealt with at length later on in this chapter, and of which we have examples in the flowers of various geraniums, have hitherto been usually explained as serving to protect the nectar from rain and dew. But this is certainly a mistaken interpretation. Were it a true one, we ought to find the trichomes dripping with moisture after every fall of rain or dew ; which is never the case. Such trichomes are, as a rule, completely covered in by the perianth, so as not to be exposed to rain or dew; and such flowers as turn their faces upwards when expanded in the sunshine (e.g. most species of geranium) hang them downwards in rainy weather, or when evening comes on; so that the perianth at such times is not like an up-turned funnel, but like a down-turned bell. When leaves form 
flexible elastic trichomes, set in a circle round the inner surface of the tubular portion of the corolla, and having, each and all, their free ends turned towards the centre of the tube. Such, for instance, is the arrangement in PhIomis, Lamium, Leonurus, Stachys, Ballota, and numerous other Labiatæ, as also in many Scrofularineæ, especially in most species of Veronica, and again in sundry Verbenaceæ and Asperifoliæ. The position of this diaphragm of hairs within the tube is variable; sometimes it is placed near the mouth of the tube, as in Verbena officinalis and Anchusa arvensis (Plate II. fig. 49), and as in Gentiana germanica and G. nana (Plate II. fig. 72); sometimes it lies deeper in towards the bottom of the tube, as for instance in the Prunellas, in Horminium pyrenaicum (Plate III. fig. 99, longitudinal section of flower; fig. 100, transverse section just in front of the diaphragm), and in Phlox paniculata (Plate III. fig. 101, longitudinal section of

basin-like hollows in which water collects, this water protects the flowers from crawling animals, and is retained in the basins for a considerable time; but when flowers have this basin shape there are numerous reasons why they should be prevented from getting filled with water, and in fact they are so protected by manifold contrivances (see A. Kerner: Schutzmittel des Pollens gegen die Nachtheile vorzeitigen Dislocation und Befeuchtung). When there is no special protective appliance, as for instance in those Saxifragea and Umbelliferæ whose flowers neither close nor bend downwards nor sidewards during rain, it will be found that such protection would be superfuous. The nectar in such flowers forms but a very thin layer, and is neither washed away, nor even diluted by raindrops, for these, as also dew, run off the slimy layer of nectar, as if from a varnished surface. 
84 Flowers and their Unbidden Guests.

whole flower; fig. 102, longitudinal section of lower part of tube). In Veronica officinalis the "weel " is placed at the mouth of the tube, but, as the tube is very short, is still only just above the nectar which it protects (Plate III. fig. 94, longitudinal section; fig. 93, front view of the flower). The trichomes which constitute the weel do not always form a complete circle round the corolla, but are frequently given off only from one side; in which case however they are so long as to extend over the whole central space of the tube. This, for instance, is the case in Veronica Chamoedrys (Plate III. fig. 91, lateral view of corolla; fig. 92, longitudinal section of same).

In Passion-flowers the whole corona constitutes a single, double, or treble "weel," as may be seen very beautifully in the section of the flower of Passiflora vespertilio (Plate III. fig. 81). Lastly, a very remarkable weel-formation is to be found in many lilies (e.g. Lilium chalcedonicum), and in several gentians, especially of the genera Ophelia and Swertia. The nectar is here secreted in certain pit-like depressions on special epiblastemes of the corolla; and the annular margin of each depression is broken up into a fringe of hair-like processes, whose points converge, and which twist and interlace so as to form a kind of cage over the nectariferous pits (Plate II. Swertia perennis, fig. 67, longitudinal section of flower; fig. 68 , lower part of the petal, with its pair of nectariferous epiblastemes; fig. 69, longi- 
tudinal section of a single nectariferous epiblasteme). Strong and flying insects that approach the flower from above, and, in sucking the nectar, strike the stigma and the anthers in due succession, can push their proboscis between the bars of the trellis that covers in the nectarpit; while smaller insects, that try to creep in from below and from the side, and so would not come into contact with stigma and anthers, are excluded from the nectar by means of the trellis. In Malvaceæ the nectar is secreted in small hollows placed at the basal commissures of the united petals; and each of these little hollows is guarded by a "weel" of radiallyset trichomes (Plate III. fig. 105, Malva rotundifolia. Transverse section of corolla, close to the bottom of the flower).

Such "weels" and trellises are also often to be found on parts of the androcium. For instance, in Haplophyllum patavinum (Plate III. fig. 109, longitudinal section of flower), the lower portion of the filaments is furnished with trichomes which point inwards, and form a trellis-work over the nectariferous disk that supports the ovaries. A similar formation is also to be seen in Physalis atriplicifolia. In this instance the trichomes are, it is true, very short; but this is compensated by a knobby thickening of the base of the filaments. Often again the stiff filaments stand in a circle round the nectary, like the staves of a cask, and have their lateral margins beset with trichomes that 
project in horizontal and parallel lines; so that small weels are formed, and fill up the interspaces between each stave and its neighbour. This is more especially the case when the anthers also contribute to the closure of the nectary; conniving and coming into lateral contact with each other, so as to form a conical hollow space within the flower, the apex of which points outwards, while the base is upon the filaments ; as may be seen for example in Vaccinium oxycoccos (Plate III. fig. 103, longitudinal section of flower ; fig. 104, transverse section of the circle of stiff filaments, laterally beset with trichomes). A like arrangement may be also noticed not unfrequently in the androecium of the Compositæ and Campanulaceæ. I have tried to illustrate this in Plate III. fig. 111, by a longitudinal section of a flower of Cirsium spinosissimum; and in Plate III. fig. 89 , by a drawing of a single anther with a much dilated and hollowed base from a flower of Campanula barbata.

Lastly, the gynæcium may be the seat of the weelformation. A beautiful example of this is furnished by Monotropa hypopitys $\mathrm{L}$. In this flower there is a coronet of trichomes on the style, just below the protuberance which surrounds the stigma. These trichomes radiate from the style, and touch the petals with their free ends, so as to form a circular diaphragm. (Plate I. fig. 19, longitudinal section of anterior part of flower; fig. 18, end of style seen from above.) 


\section{Tangles of Trichomes.}

In many cases the protecting trichomes do not, as in the above instances, form "weels"-that is, rows of straight close-lying processes in form of fringes, hairs, and staves - but are simply tangles, that is, irregular bundles of soft hairs, which block up the tubular or funnel-shaped entrance of the corolla-like plugs of wool; plugs, which entirely exclude all smaller weaker insects, and such as have but a short proboscis, while they in no wise prevent the larger stronger species, with long proboscis, from access to the spaces beyond them. This kind of formation, again, is found sometimes on the inner surface of the perianth, sometimes on the androcium, sometimes on the gynæcium, and, lastly, sometimes on more than one of these parts in one and the same flower. In Menyanthes trifoliata (Plate II. fig. 70, longitudinal section of flower), in Lycopus, Thymus, Calamintha alpina, Paederota Bonarota, and $P$. Ageria, Primula minima, Lonicera sempervirens, Arctostaphylos alpina, and $A$. uva ursi (Plate III. fig. 110, longitudinal section of flower), Geranium palustre, and many other flowers, it is the corolla which is the seat of the formation, the interior of this being covered with a fleecy tangle of trichomes, which extends either over the entire surface, or is limited to the lower and narrower part above the nectar-cavity. In Geranium silvaticum, Rhododendron hirsutum, and R. ferrugineum, Lonicera nigra, $L$. xylosteum, and $L$. alpigena (Plate III. fig. 96, longitudinal section of flower), 
the corolla is partly covered with trichomes, but these combine with others given off from the filaments to form a thick tangle that covers in the nectary.

In many cases the inner surface of the corolla is smooth; and the tangled trichomes that cover in the nectary are confined to the base of the filaments. Such is the case, e.g., in Lyeium barbarum, Atropa belladonna, Ipomoea violacea, and Polemonium cceruleum. In Cobcea scandens (Plate III. fig. 85, longitudinal section of flower), the base of each filament looks as though it were wrapped up in white fur; and the fine fur-like bundles of trichomes form, by their juxtaposition, a stopper, which divides the bell-shaped corolla into two chambers, the posterior of which secretes the nectar, while the anterior shelters the stigmas and anthers. In Tulipa silvestris (Plate III. fig. 95, base of ovary, a single stamen, and lower part of a perianth leaf, which has been cut across) the nectar is secreted by the bases of the filaments, just as in the Geraniums. Each filament is hollowed out at its base on the side turned towards the perianth, and these hollows are full of nectar. They are completely covered in by bundles of trichomes, which are given off from the part of the filament just above them; so that an insect cannot possibly get at the nectar without forcing its way in underneath the bundle of trichomes, and slightly lifting up the whole stamen.

In Marrubium peregrinum and Daphne Blagayana 
(Plate III. fig. 112, longitudinal section of lower part of corolla-tube) it is the gynæcium, in fact the ovary, that is furnished with a tangle of trichomes. These reach from the ovary to the inner side of the perianth, and exclude all unbidden guests from the nectar in the space below. In Vinca herbacea (Plate III. fig. 106, longitudinal section of lower part of flower; fig. 108, a single stamen; fig. 107, the style) there is a tuft of trichomes at the top of each stamen. These interlace with similar trichomes on the top of the disc-shaped head of the style, and with their aid stop up the corolla-tube, giving the impression of a plug of cotton-wool being stuck in the mouth of the tube. One of the most curious arrangements which have to be noticed in this section is that which exists in Centranthus angustifolius and C. ruber. The corolla-tube in these flowers is twelve $\mathrm{mm}$. in length, and hardly one $\mathrm{mm}$. in diameter. It is divided throughout its whole length into two compartments by a membranous septum. In the upper and smaller of these compartments lies the thread-like style, while the inferior and somewhat wider one is prolonged at its base into a saccular spur, in which nectar is secreted (Plate III. fig. 97, longitudinal section of flower of Centranthus ruber; fig. 98, transverse section). This lower compartment is thickly set with trichomes the whole way down from its mouth to the spur; and though these trichomes permit the insertion of a proboscis, they render it quite impossible for any of the 
smaller insects (Thrips alone excepted) to creep in and reach the nectar.

That the purpose of all these structures is the protection of the nectar from such insects as are too small to conduce by their visits to cross-fertilisation, is shown quite clearly by those Labiatæ in which the filaments and style are so elongated as to bring anthers and stigma to a point considerably in advance of the upper lip (Origanum, Thymus, Mentha, Lycopus). Here no other insects than such as approach the flower on the wing and from the side can possibly come into due contact with the far-projecting stigma and anthers; while such as come creeping up from below, and have a body not more than $1.5 \mathrm{~mm}$. in thickness, were no barrier put in their way, might steal in over the underlip, between and beneath the filaments and style, and rifle the nectar without so much as touching stigma or anthers, which would be in advance of them during their whole visit. In such case the nectar would be expended to no purpose. But it will be found that in all such Labiatæ, in all, that is to say, which are characterised by far-projecting anthers and stigma, the corolla is invested with a thick fleecy covering of trichomes, by which small and creeping insects are effectually excluded.

The "weels" and tangles of trichomes which we have as yet been considering effect the complete exclusion of unbidden guests from the recesses of the flower, 
making it impossible for them to get at the nectar. In other cases, however, similar trichomatous structures, in endless variety of form, merely keep off welcome and invited guests from some or other part of the flower, and compel them in their visits to follow some definite and predetermined path. These formations, to which in a preceding section I gave the name of "path- pointers," are, like the other formations, to be found sometimes on the gynæcium and andrcecium, sometimes on the perianth, and sometimes on the involucre or other of the floral appendages.

Among the best known of these are, perhaps, those curious structures which are interposed in Parnassia palustris between the anthers and petals, and are usually spoken of as nectaries. In fact they are rightly thus designated, for they each have two small longitudinal depressious on their inner aspect, and in these nectar is secreted. This nectar, however, is unapproachable except on the side turned towards the ovary; and any insect that gets at it must necessarily come into contact with the central part of the flower, where in the first stage of flowering the pollen, and in the later the mature stigma, is exposed. The insects therefore, inasmuch as they must fix themselves on the centre of the flower in order to suck the nectar, will inevitably rub in some cases against the anthers, in others against the stigma, and, flying from flower to flower and from plant to plant, will bring about allogamy. But how 


\section{Flowers and their Unbidden Guests.}

about the insects that alight on the edge of the petals ? If they approach the nectaries from the edge of the out-spread perianth, they find an obstacle in their path in the shape of a trellis, formed by a hair-like fringe given off radially from each nectary (Plate III. fig. 83, longitudinal section of flower; fig. 84, a single nectary seen from the side turned towards the ovary). This obstacle, however, is not insurmountable; for the hairs of the fringe neither secrete viscid matter nor end in sharp points, but terminate each in a small globular yellow head. The insects can therefore clamber over the trellis with perfect ease and without any damage whatsoever, and, so reaching the nectary (fig. 84) on the side turned towards the ovary, can get what they sought. But in thus clambering they must also inevitably come so close to the floral centre as to strike either anther or stigma, as the case may be. Whether, therefore, the flying insects alight directly on the centre of the flower, or alight first on the edge of the perianth and then approach the nectar by a roundabout way, their ultimate mode of entrance is the same.

Very much the same part is played by the long thin twisting trichomes of Campanula barbata. These are given off from the edges and inner surface of the segments of the corolla, and project into the interior of the bell-shaped flower. It is to them that the plant owes its name "barbata" At first sight it might be supposed that these trichomes, which cover in the 


\section{Campanula Barbata.}

mouth of the bell like a net or lattice-work, were intended to guard the nectar from such flying insects as were too small to come in contact with the centrally-placed stigma and pollen-smeared style, when making their approach from the edge of the perianth. But this is certainly not the case; for independently of the fact that the nestar in this flower is protected by another method, which will be described in the next section, it is easy to convince oneself, by actual observation of the behaviour of insects in visiting the flowers, that the long trichomes which trellise the mouth of the corolla are no protection whatsoever against such insects as may alight on the edges of the petals. On the contrary, such insects will be seen to climb over the trellis until they reach the free ends of its component hairs, which come close to the centre of the mouth of the bell, where the style ends in three spreading or recurved stigmas. (Plate III. fig. 88, longitudinal section of flower.) The insects pass over to these stigmas from the trellis hairs in order to make a further advance into the recesses of the bell; the trellis in fact serves them simply as a bridge; and conducts them eventually, though after a circuit, to the self-same entrance as that to which humble-bees direct their flight at the very first. Whichever method of approach then is adopted by the insect, the result is the same; and I have myself seen small beetles (Anthobium sorbi Gyll., Meligethes 


\section{Flowers and their Unbidden Guests.}

ceneus Fabr.), after alighting on the tips of the corolla, and passing thence by the above-mentioned circuit to the centre of the flower, smear the stigmas with pollen which they had brought from other flowers of the same species. ${ }^{1}$

In the genus Tropæolum again there is a "weel" formed by the fringes into which the laterally constricted margins of the three lower petals are slit, and over this "weel" all the smaller insects that light on the edge of the petals must climb, if they would get at the nectar. Now suppose a flower, say of Tropoeolum majus, to be without this "weel." In that case an insect, whose body was not more than $2.5 \mathrm{~mm}$. in thickness, would be able after alighting on the three lower petals to creep in between the style and the filaments, and get to the nectariferous spur of the calyx, without touching either stigma or anthers. But if the "weel" be there-consisting as it does of fringed processes 4 $\mathrm{mm}$. in length, and not more than $0.5 \mathrm{~mm}$. apart, nay even occasionally intertangling with each otheran insect in climbing over it cannot possibly help coming into due contact with stigma and anthers, seeing that these lie immediately behind it. Similar weels and trellises made out of fringes are to be

1 These little beetles tried, indeed, to get at the nectar in the bottom of the bell, but, owing to the arch which protects it (which will be described in the next section), without success. At last they returned over the style, and contented themselves with the pollen with which this was coated. 
seen in Gentiana ciliata, Tellima grandiflora and Cuphea platycentra; and their action is precisely the same; that is, they in nowise absolutely exclude from the nectar such insects as light upon the outer side of the corolla, but merely serve as "path-pointers," or as bridges which conduct the insect eventually to a door of entrance, of which it cannot avail itself without necessarily rubbing against the stigma and the pollen. ${ }^{1}$ To describe these three flowers in detail, and the manner in which insects visit them, would be little more than to repeat what has already been said. I may therefore content myself with referring the reader to the plates, in which all three are represented (Plate II. fig. 64, Gentiana ciliata; Plate II. fig. 75, Tellima grandiflora; and Plate III. fig. 82, Cuphea platycentra). There is, however, one point respecting Gentiana ciliata and Tellima grandiflora, which should perhaps not be left unnoticed. If the trellis formed by the laciniate petals were not present in these flowers, insects that alighted on the outside of the perianth would be able to get at the nectar through the open chinks between the contiguous petals, without, of course, duly touching stigma or anther; so that it is a matter of great importance as regards the protection of the nectar that these chinks shall be closed by the fringed trellis-work. If the insects

I It need hardly be mentioned that all these flowers are dichogamous. 
clamber over the trellis, and get inside the flower through the central entrance, then they must necessarily come in contact with the stigma, and in due succession with the anthers. ${ }^{\text {I }}$

In the cases with which we have been dealing it is the corolla that is split up into a fringe. But in many other flowers it is the margin of the calyx that is thus fringed, or that is beset with hair-like trichomes which prevent insects from getting at the nectar by back-doors, and direct them to the main entrance, where anthers and stigma are placed to meet them. I purposely select a very inconspicuous small flower, Alyssum calycinum (Plate I. fig. 40, flower seen from above), as an example of this frequently recurring arrangement. The segments of the calyx are here separated by deep fissures, which reach almost to its base, and inasmuch as the claws of the petals which stand in front of these fissures only close them imperfectly, it would have been possible for very small insects, that had settled. on the stem, or had crawled up from the ground, to creep in through these lateral clefts and so get at the nectar. But the hair-like trichomes which grow on the convex surface of the sepals interdigitate repeatedly with each other, and form a lattice-work in front of the clefts, their free points reaching as far as

1 I saw the small beetle Meligethes exilis fecundate a flower of Gentiana ciliata, after it had been compelled by the "weel" to get in at the central entrance, which brought it into direct contact with the mature stigma. 


\section{Path-pointing Bracts.}

the petals. Insects when they find themselves at these trellises never try to penetrate them so as to get to the bottom of the flower through the clefts behind, but use them as bridges by which to mount on to the lamina of the petals, and thence pass on to the nectar through the central aperture of the flower.

It has already been noticed in an earlier section, that bracts also, when split up into a lattice of intercrossing fringes, or when covered with hair-like trichomes, confer a similar advantage on the flowers and inflorescences which they surround; and that they compel such small insects as may light on the involucre to follow that path which alone will make them welcome visitors. Such "path-pointing" bracts are to be found in plants of the most widely separated species; and I will merely mention here a few examples taken from the most diverse families. Such then is, the very beautiful involucre of Lagcecia cuminoides (Umbelliferæ), and of Nigella damascena (Ranunculaceæ); such also the trellised bracts that surround the blossom of Cleonia lusitanica (Labiatæ), and of Rhinanthus angustifolius Gmelin (Serophulariaceæ); such again the involucre of Centaurea pseudophrygia C. A. Meyer (Compositæ), of which last a drawing is given in Plate I. fig. 17.

Finally, I may remark that hair-like trichomes, when found on stems and leaves, stand in most cases in no direct functional relation to the visits of animals; 
98 Flowers and their Unbidden Guests.

though there are at the same time indisputable cases where they prevent animals from crawling up to the flowers from below. Such, for example, is the case in Sempervivum arachnoideum L., and other nearly allied species, where the radical rosette, the stem, and the sessile leaves, are covered over with a web of such trichomes; such also in many Compositæ, where similar formations are found on leaves and stem, sometimes (e.g. Cirsium eriophorum) as high even as the involucrum. Many small wingless animals are utterly debarred from any possible progress by such trichomes; many are caught and held in the tangle of fibres as securely as in a spider's web, and once in can never again get free.

6. Access to Flowers impeded by Parts of the Plant, and especially Parts of the Flower, being bent, or dilated, or crowded together.

In all cases where the nectar is abundant, and yet is not protected by any of the hair-like structures described in the preceding section, one may reckon with almost certain confidence on finding such protection afforded by the peculiar position or formation of some or other parts of the flower. These, to mention the main features, are either curved, or dilated, or crowded together; and so form grooves, tubes, tubercles, saccular recesses, chambers, in such endless 
variety of form as to render it a difficult task to give a general view of them.

For our purpose it will perhaps be best to divide them into two groups, one containing those structures which completely cover in and enclose the nectar, the other containing those in which the closure is incomplete, a narrow orifice being left through which animals can insert their instruments of suction.

In the former group, then, we have completely closed cavities, to which insects have no means of access except by lifting up or pushing asunder the over-arching, or dilated and closely approximated, parts. Notwithstanding the elasticity and flexibility of the parts, such a separation of them always implies a vigorous push, and requires a certain amount of strength in the animal that effects it; so that the smaller and weaker kinds are as a rule effectually excluded from these perfectly enclosed cavities. Nor is it hard to recognise the close relation that exists between the strength or size of the visiting insect and the mechanical arrangements of the visited flower; and it may be laid down as a general rule that whenever animals are of such small dimensions as not necessarily to come into contact with the pollen and the stigma of a given flower when visiting it, they will also be without the strength required to push asunder the parts which form its nectar-cavity.

The walls which enclose the nectar-cavity may be 


\section{Ioo Flowers and their Unbidden Guests.}

parts of the variously-contorted perianth or parts of the andrœcium and gynæcium, and in no few instances parts of several different floral whorls contribute to their formation.

Amongst the best known of the flowers which present this kind of formation may be mentionedCorydalis, Fumaria, and Diclytra, as also many with what are known as "personate" corollas, such as Antirrhinum, and many species of Linaria (Plate II. fig. 41, Linaria alpina). In these plants the lower lip of the corolla is strongly curved, and has an arching protuberance, the convexity of which is in immediate contact with the upper lip, so that the entrance to the flower is completely closed. An insect that alights on the lower lip cannot possibly get at the nectar in the spur, unless, by forcible pushing and shoving, it causes a depression of this lip.

In many cases the over-arching is brought about by epiblastemes or outgrowths of the corolla, which assume the form of humps; and which, being closely approximated to each other, must be pushed asunder by force before an insect can insert its proboscis into the nectarcavity. The Cynoglossum pictum, represented in Plate II. fig. 60 in longitudinal section, is an instance of this. Sometimes instead of humps there are merely scales or valve-like processes, which are given off by the corolla, and project into the interior of the flower, so as to divide it, as with a diaphragm, into two chambers, in 
the lower of which the nectar is stored. Such, for instance, is the case with Achmea comulea and Soldanella alpina (Plate II. fig. 76, longitudinal section of flower).

Still more peculiar is the arrangement in the several species of Nigella, where the nectariferous cavities, formed in the petals, are closed by moveable lids. (Plate III. fig. 77, side view of such a petal of Nigella elata, L. ; fig. 78, longitudinal section of the same petal ; fig. 79, a petal of Nigella sativa, L., seen from above; fig. 80 , view of the same petal after the removal of the lid-shaped excrescence.) Each petal is here seen to be hollowed out into a kind of pit, into which nectar is secreted in abundance by the surrounding tissue. The part of the petal beyond the pit forms two curious divergent processes; while the other, or basal part, is reduced to a mere stalk, so that the whole petal comes to have somewhat the shape of a spoon. At the point where the handle is continuous with the bowl, the petal gives off an excrescence which covers in the whole nectar-cavity like a lid, closing it completely. No animal, therefore, can possibly rifle the nectar unless it be strong enough to lift up this lid. I have seen ants that had crept up from below striving in vain to make their way into the cavity. Our common honeybees, on the other hand, can raise the lid with perfect ease. But then these bees are also of such a size that, in visiting the flowers and making their way to the closed nectaries, they must inevitably rub against the 


\section{IO2 Flowers and their Unoidden Guests.}

stigmas that lie just above, and in due succession against the anthers.

Very frequently again it is the androcium, or some part of it, that roofs in the nectariferous base of the corolla, and thus contributes to the formation of a closed cavity, inaccessible excepting to animals of a certain strength. The parts concerned may be either the anthers, which are then longer and closely approximated, so as to form a hollow cone, the apex of which points outwards; or the filaments, which are then thick and often dilated into laminar expansions; or, thirdly and lastly, the entire stamens, which are then set in numerous successive rows, overlapping each other.

Familiar instances of the first of these three methods are furnished by Ramondia, Cyclamen, Dodecatheon, as also by many Solanaceæ, Asperifoliæ, and Ericaceæ.

Of the second, where it is the filaments that roof in the cavity, we have examples in Hemerocallis and Gladiolus, with their large meetaries. The usual plan is for the filaments to have their bases flattened out into laminæ; as, for instance; in the genera Campanula and Phyteuma, in Nicandra physaloides and Epilobium angustifolium, which last is represented at Plate III. fig. 86 (longitudinal section of flower). The filaments are somewhat expanded at the base, and are in close lateral contact with each other, while their upper and narrower parts bend over in a body until they join the style; thus they form a hollow cone which domes in 
the nectariferous annular disk at the base of the flower. Precisely similar is the structure of the nectar-cavity in Campanula persicifolia, C. pyramidalis, C. carpatica C. spicata, C. trachelium, C. rapunculoides, and C. barbata, of which last I have given drawings (Plate III. fig. 88, longitudinal section of flower; fig. 89, a single stamen, from the side turned towards the style). Here again the filaments are much dilated towards their base, and usually at the same time much bent, and converted into scaly lamellæ, which are concave on the inner side so as to form an arch over the nectariferous disk. As a rule, these dilated filaments are in close contact with each other, and tolerably firmly set; so that an insect must have some strength to push them apart. Moreover, their margins are often set with trichomes, whereby the cavity is closed with still greater security. $^{1}$

The third mode of completely closing in the nectarcavity by means of the androcium is the crowding together of the stamens. This occurs in very many Mesembryanthaceæ and Cactaceæ, especially in Opuntia and Mamillaria, and also in some Rosaceæ and Amyg-. daleæ (Dryas, Potentilla, Geum, Persica). In Mamil-

1 There are some Campanulaceæ, however, e.g. Campanula patula, where the vault formed over the nectariferous disk by the dilated parts of the filaments is not completely closed. The filaments are not in actual contact with each other laterally, but are separated by chinks. These, however, are invariably guarded by a thick investment of trichomes. 
I04 Flowers and their Unbidden Guests.

laria glochidiata, the flower of which is shown in longitudinal section in Plate III. fig. 87, numerous stamens emerge from the upper margin of the tubular and nectariferous portion of the flower. The filaments of these stamens lie closely packed together, whorl upon whorl, and half way up bend inwards in a body so as to form a regular dome, which allows the style to pass through its centre, but elsewhere can only be penetrated with difficulty. A similar formation may be seen in Potentilla micrantha Ram., the flower of which plant is represented in Plate III. fig. 90 in longitudinal section. The filaments, however, which are given off from the upper margin of the basin-shaped nectariferous space form in this case only a single row; they run moreover in a straight line, and are in close contact laterally. The stigmas also do not project above the dome formed by the filaments, and the closure of the opening above is effected by the closely packed anthers. This occlusion of the nectar-cavity by the crowding together of the stamens is brought about in a very peculiar manner in the white ranunculuses of the Alps. I select as an example Ranunculus glacialis (Plate I. fig. 21, longitudinal section of the whole flower; fig. 22 , a single petal seen from above; fig. 23 , a longitudinal section of such a petal seen from the side). The nectar is here secreted in a little pit on the upper surface of the petals, just above the point where the roundish lamina passes into the tolerably thick claw. 
In front of this nectar-pit is a scale-like excrescence, which is given off from the lamina at an angle of from 40 to 50 degrees. The stamens, which radiate in great number from the centre of the flower, and form several closely superposed whorls, lie immediately above these scales, the filaments being in direct contact with their margins. Thus a small closed nectar-cavity is formed at the base of each petal; and this is only accessible to such insects as are strong enough either to lift up the obstructing filaments or to push down the scale.

In this species, then, instead of a single nectarcavity, there are as many cavities as there are petals. In many other Ranunculaceæ, e.g., in some largeflowered species of Clematis and Atragene, the number of closed nectar-cavities is still greater; and there are actually almost as many of them as there are stamens. In Atragene alpina L., for example (Plate I. fig. 14, longitudinal section of flower, natural size; fig. 15, a single anther-twice natural size ; fig. 16, a group of anthers, placed one behind the other, and covering each othertwice size of nature), the filaments are somewhat dilated in their lower half; and each petaloid dilatation is hollowed out on the side turned towards the gynæcium into a groove in which nectar is secreted. Now there are numerous whorls of stamens; and as the hinder whorls successively cover in those in front of them, and are closely applied to their posterior surfaces, and as, moreover, the whole mass of stamens is 


\section{I06 Flowers and their Unbidden Guests.}

held together byan external whorl of upright rigid spoonshaped petals, the grooves at the base of the filaments are converted into so many small closed nectar-cavities, which are utterly inaccessible to the weaker insects, and can only be forced open by strong humble-bees, who thrust the closely packed stamens asunder.

Thus far it has been some part either of the perianth or of the androcium that has completely closed up the nectar-cavity. The occlusion may, however, also be effected by the gynæcium. In such cases the usual arrangement is that the ovary plugs up the tubular or funnel-shaped part of the perianth above the nectariferous space. In Phygetius capensis, ${ }^{1}$ for instance, the extraordinarily abundant nectar that fills the gibbous base of the tubular corolla is completely shut in by the contorted ovary, which comes into close contact with the inner surface of the corolla-tube above the nectarcavity. (Plate II. fig. 53, longitudinal section of flower.) In Tricyrtes pilosa (Plate II. fig. 45, longitudinal section of flower) the three outer perianth-leaves have similar gibbosities, full of nectar, at their base; but above this they are in close contact with the large triangular ovary. Thus the ovary looks like a plug, stuck into the lower

I It is worth mentioning here that very many plants of the Cape flora are characterised by a remarkably abundant secretion of nectar. The flora of any other region might be searched in vain to find such copious nectar as that of Phygelius Capensis, of many Mesembryanthaceæ and Amaryllidaceæ, and especially of Melianthus. It is highly probable that this abundant nectar in the Cape flowers is rifled chiefly by honey-birds. 


\section{Cavity closed by Gyncecium.}

part of the perianth, and completely closes up the three nectar-pits at the bottom of the flower. None but strong insects,-insects therefore of such a size that they must, in getting to the nectar-cavity, rub first against the stigmas and then against the pollen (which is exposed in the extrorse anthers that project above and in front of the gibbous perianth), -are able to separate the stiff perianth-leaves from the ovary, and to insert their proboscis into the nectar-pits. In Sedum maximum again it is the thick carpels that over-arch the small nectaries at the base of the petals, and that protect the nectar which these secrete. Lastly, a precisely similar arrangement occurs in the genus Hypecoum. In Hypecoum procumbens (Plate II. fig. 66 , the whole flower; fig. 65 , one of the inner petals seen from the side turned towards the ovary) the nectar is secreted in a little depression just above the claw of each of the two inner petals. Immediately above this depression the petal gives off a very peculiar appendage, just as in Ranunculus glacialis, on which pollen is deposited above. ${ }^{1}$ Not only when the flower is closed, but also when it is expanded, which in fine weather is the case from eight A.M. to five P.M., these two appendages run parallel to the ovary, in contact with, and, as it were, embracing

1 The part played by these structures in the fecundation of the atigma, and especially in the autogamic fecundation which occurs when the flower remains closed, cannot be described here in detail. 


\section{I08 Flowers and their Unbidden Guests.}

it. The base of the ovary therefore which they thus grasp completely occludes the two nectar-pits. Here again an insect, if it would get at the nectar, must force the two appendages from their contact with the ovary.

Another and similar case is that of Ophelia Wilfordii Kern. In this flower the nectar is secreted in an appendage, situated above the base of the petal and hollowed out into a kind of groove. The anterior and narrower part of this groove is closed in by its margins being elevated into ridges which converge above it, these margins being moreover set with short interdigitating fringes; the posterior part of the nectar-groove, just above the claw of the petal, is not covered in by a similar formation, but has its edges in close contact with the ovary. Insects therefore that would reach the nectar must first separate the petals from the ovary by force.

The closure of the cavity in which the nectar is secreted or stored is sometimes effected by the stigma, but not nearly so frequently as by the ovary. In such cases the stigma is of considerable size, and is flattened out so as to cover in the tube of the perianth like a lid. The finest examples of this kind of stigma are furnished by the group of gentians known as Cyclostigma, a group represented in our Alps by G. pumila, imbricata, verna, oestiva, bavarica, utriculosa, and nivalis. (Plate I. fig. 37 shows a flower of G. bavarica L. seen from above; and fig. 36 gives a lateral view of its 
stigma.) An insect that wishes to suck the nectar at the bottom of the tube must insert its proboscis by the margin of the stigma, and to do this must push away the folded corolla, by which the stigma is closely encircled; a task which is quite beyond the power of any but strong insects. ${ }^{1}$

We come now to the second group of formations mentioned at the beginning of this section, that, namely, in which the passage that leads to the nectar is not completely closed, but merely constricted-the constriction being effected by curvatures, swellings, dilatations, and aggregations of various parts.

There are two ways in which such constrictions benefit flowers. Either they completely exclude all such nectar-hunting animals as owing to their small dimensions would otherwise get at the honey without fecundating the stigma with pollen brought from other flowers, in which case they prevent an unprofitable

1 [There are, it may be noticed, some flowers where the nectar is perfectly accessible to insects, though they will in getting at it touch neither stigma nor anthers. Such, e.g., is the case with Marcgraavia nepenthoides as described by Belt (Nicaragua, p. 129). There are even plants, as the palosandre (ib. p. 130), where the nectar is accessible to very small insects, while larger ones are shut out. But in these cases the insects, though they touch neither anther nor stigma, indirectly conduce to allogamy. For as they are attracted' by the nectar, so in their turn they attract humming-birds, which feed on them; and these birds act as the immediate agents of cross-fertilisation. The larger insects are excluded from the palosandre, as the consumption by them of the honey would be a waste, since it is only small insects that furnish food to humming-birds.-EDrror.] 


\section{IO Flowers and their Unbidden Guests.}

expenditure of the nectar; or they compel those visitors whose size is suited to the mechanism of the flower, and who would therefore conduce to allogamy, to make their entrance in the exact way by which this advantageous result can be insured. The formations in question may therefore in this latter case be classed with those thorns and hair-like trichomes, which we designated as "path-pointers" in the two last chapters.

In this constriction of the passage which leads to the nectar we find again the same variety as to the methods employed as when the nectar-cavity is closed completely. Sometimes it is effected by tubercles, gibbosities, and various deformations of the perianth, or of excrescences of the perianth; sometimes by the crowding together of some or other of the floral organs; sometimes by the interposition of stout ovaries; sometimes by the thickening and dilatation of the filaments. - One method which repeatedly recurs, and of which Narcissus juncifolius (Plate II. fig. 57, longitudinal section of flower) and Enothera grandiflora (Plate II. fig. 51, longitudinal section of flower) may be selected as examples, is the contraction of the lower part of the perianth to one or more narrow channels. These however, though narrow, are yet wide enough to allow large insects to pass their long thin trunks down to the nectary, while smaller insects with shorter proboscis are completely excluded. In one of the two flowers selected as examples (Narcissus 
juncifolius), the channel is formed by the perianth; in the other (Enothera grandiflora) by the calyx ; while in Euphrasia longiflora, Fedia graciliflora, Crucianslla gilanica, Primula longiflora, Pedicularis tubiflora, Asperula longiflora, and many other flowers, it is the corolla which serves the purpose, being reduced in its lower part. to a long straight tube of such narrow dimensions as often to be impervious to a proboscis of more than 0.2 to $0.3 \mathrm{~mm}$. in diameter. In all the above instances, the leaves, out of which the tube is ideally composed, are coherent. But in Matthiola varia DC. (Plate II. fig. 63) the tubular channel is formed by petals which are not coherent but merely overlap, in combination with the sepals, which are stiff, erect, and closely apposed; while the small hole which serves as mouth to the channel is made by the uppermost petal being rolled into the shape of a funnel.

Frequently again it is by ridge-like processes of the perianth that the narrow passages are formed. In Lilium martagon, for instance (Plate II. fig. 42, a whole perianth leaf; fig. 43 ,transverse section of a perianth leaf), the nectaries run down the centre of the perianth-leaves, and are each enclosed by a pair of raised borders, which incline towards each other, meet, and form a very narrow canal in which the nectar is completely hidden, and which is only accessible to a thin proboscis. Ridge-like processes are found also on the petals of Linum viscosum and Linum catharticum, and of many species of Gera- 


\section{2 Flowers and their Unbidden Guests.}

nium, e.g., Geranium Robertianum. Here there is a single ridge on each petal. These ridges jut out towards the centrally-placed ovary with its surrounding stamens, and are closely pressed against it like so many buttresses. This results, as shown in the transverse section of a flower of this species (Plate II. fig. 62), in the formation of five narrow passages leading directly to the nectar, which is secreted by the base of the filaments at the bottom of the flower.

In many cases the self-same saccular pouch of the perianth that secretes or stores the nectar is also so developed as to constitute the narrow passage. The socalled spurs which are found in the most widely separated families, sometimes on the calyx, as in Tropæolum, sometimes on the perianth, as in Platanthera, sometimes on the corolla, as in Epimedium macranthum, are for the most part of this character. Gymnadenia odoratissima, of which a representation is given at Plate II. fig. 54 (longitudinal section of flower), may be quoted as an example. Frequently again these nectariferous pouches are twisted in a spiral manner. This makes them still more inaccessible to the smaller insects, while it does not interfere in the very least degree with such as have a proboscis that can be coiled up. Such, for instance, is the case in Aquilegia and Aconitum (Plate II. fig. 44, petal of Aconitum paniculatum), where the limb of the petal is deeply saccate, and the resulting pouch rolled back in a spire. Another and analogous 


\section{Constricted Entrance to Nectar-cavity. I I 3}

plan, by which the perianth is made to serve the same purpose as when provided with these straight and twisted passages and spurs, is its constriction at some or other spot. This may be seen in many Asperifolize and Primulaceæ, for instance in the several species of Androsaceæ, where it is the corolla that is thus constricted. (Plate II. fig. 46, longitudinal section of flower of Androsace glacialis.)

In the same category must be classed the swellings and tubercles that occur in such variety on the perianth, round about the entrance to the nectary. These present such an endless multiformity that it is impossible here to give an exhaustive account of them. And this so much the more, as the attempt to describe them would in each case involve a detailed consideration of other correlated structures in the flower. I shall therefore merely select a couple of typical cases out of the vast mass of material, cases which I have attempted to illustrate by drawings; and even in dealing with these I shall limit my remarks to the form and significance of the tubercles and swellings, without discussing any other structural arrangements which may be correlated with them.

One of the simplest arrangements is that of which Nigritella angustifolia mayserve as an example (Plate II. fig. 48, front view of flower ; fig. 47, longitudinal section of flower,in which the tips of the perianth were deficient). The nectar is here secreted by a saccular pouch of the 


\section{4 Flowers and their Unbidden Guests.}

labellum. The entrance to this, in itself far from wide, is still further narrowed, and this considerably, by a swelling at the mouth of the pouch. This swelling or fold forms an oblique bar at the back part of the labellum, itself narrowed into a funnel, and reduces the diameter of the entrance to half a millimetre. This effectually prevents most wingless insects from creeping in and getting at the nectar; and even amongst flying insects only such are apparently adapted to the flower as have a thin suctorial trunk, in using which they would unavoidably carry off the adhesive pollinia, and forthwith transport them in their roving flight to other flowers.

In the various species of Galeopsis the corolla presents two projections at its mouth. I have tried to give a representation of these in Plate II., fig. 56 (Galeopsis grandiflora). The corolla-tube is $23 \mathrm{~mm}$. in length, and in its lower half is not more than 2-3 mm. in width; but the upper half widens out and forms a funnel, which is pretty nearly $4 \mathrm{~mm}$. in diameter at its anterior opening, that is at the throat of the corolla. The width of the mouth of the corolla on the other hand, that is the distance which separates the margin of the upper lip, and therefore the anthers and stigma which it conceals, from the flat median portion of the lower lip, is no more than $2.5 \mathrm{~mm}$. If then the corolla were made of very firm tissue it would be impossible for a humble-bee, on visiting the flower, to thrust its head and thorax, 
which is from 8 to $10 \mathrm{~mm}$. in thickness, between the upper and lower lips into the wider throat, and thence pass its trunk down the remaining narrow part of the tube to the nectar. But the limb of the corolla admits a considerable amount of dilatation when vigorously pushed. For its junction with the tube is marked above by a transverse bulging line, which forms the axis of a joint on which the upper lip can move up and down. No sooner does a humble-bee thrust its head in at the mouth of the flower than the upper lip is raised like a lid, and with it of course the underlying elastic and flexible filaments, as also the style. Consequently the humble-bee comes unavoidably into successive contact with the stigma and the pollen, which is stored up in the protected anthers. As to the smaller flying insects, all such as are not more than 2.5 in thickness, can steal in at the centre of the outer opening, make their way thence to the funnel-shaped expansion of the tube, and, finding there no "weel" nor similar obstacle to stop them, can carry off the nectar from the lower and narrower part of the tube; and all this without any necessity of raising the upper lip, an act which would indeed be beyond, their strength. If, however, its body be but $2.5 \mathrm{~mm}$. in thickness, the insect is large enough, supposing only that it makes its entrance by passing over the middle lobe of the lower lip, to rub against stigma and anthers, and thus, as it flies from 


\section{6 Flowers and their Unbidden Guests.}

flower to flower, to promote intercrossing. Should it, however, not pass in by the mid-lobe, but make its approach from the side, it will be under the necessity of crossing over one of the two hollow pegshaped projections which are developed on the lower lip; or possibly as these hollow projections-which have given the plant in Germany the name of Hohlzahn-form fair landing-places, the insect may alight directly upon one of them, and then pass down by its hinder slope into the recesses of the flower. But as the apex of each of these projections is not more than $2.5 \mathrm{~mm}$. distant from the anthers and the stigma, insects of this thickness, in climbing over them, will rub against the stigma and the pollen. Suppose, however, that there were no hollow projections; suppose that in place of them there were actual furrows, as there are in the same position in so many other Labiatz. The distance between the anthers and the spot where the projections stood would now be not merely 2.5 $\mathrm{mm}$. but $4 \mathrm{~mm}$. or more. Small insects, therefore, with a body not more than $2.5 \mathrm{~mm}$. in thickness could reach the tube and carry off the nectar, without ever touching the pollen, without therefore conducing to allogamy, or repaying to the plant the price of its honey.

Another very striking instance of a corolla contracted by tubercles is furnished by the flowers of Scutellaria. In Scutellaria albida L. (Plate II. fig. 58, longitudinal. section of corolla; fig. 59, central view, lower lip re- 
moved, magnified 5 times), each of the two lateral petals presents a large bulge at the mouth of the tube. These bulges have their convexities turned towards the centre of the aperture, which they block up to such an extent that a small hole, scarcely $2 \mathrm{~mm}$. in width, is all that is left between them. Insects, however, in entering into the flower, push these two bulges asunder; and the consequence is that the loose pollen which has been discharged from the anthers under the upper lip, and has been deposited on the cushion-like upper surface of the arched bulgings, is displaced from this position, and showered down on the back of the insect. The insect in its further roving soon carries it to some other flower. Supposing these bulges not to exist, no insect would rub against the pollen, unless that part of its body which has to be introduced into the tube were at least $4 \mathrm{~mm}$. in thickness ; but as it is, insects of only half these dimensions can push apart the two bulgings, and in so doing will get besprinkled with pollen, and will therefore be just as useful as larger insects in promoting intercrossing. Such is the arrangement in Scutellaria. In Rhinanthus and Bartsia the entrance seems to be narrowed in another way, namely, by the three petals that form the lower lip retaining in the flower the same involuted position they had in the bud, and thus barricading the entrance in its lower part. In Calceolaria (Plate II. fig. 52, lateral view of a flower of Calceolaria Pavonii Benth.) the whole lower 


\section{8 Flowers and their Unbidden Guests.}

lip is rolled inwards in a spiral of more than a circle, and by the cohesion and sacculation of its parts is converted into a pouch, the so-called "calceolus," or slipper. The tongue-like extremity of the lip is concealed inside this pouch, and on it is a small depression which secretes nectar. The entrance to the pouch is rendered so tortuous by the very peculiar curvature of the lip, that it becomes simply impossible to most insects to get at the nectar. Strong and heavy humble-bees alone can rifle it; and even they accomplish this, not by making their way into the pouch, but by fixing themselves on the upper external surface of the "calceolus." The impulse ,given by the weight of their bodies makes the lower lip descend, producing a downward motion like that of a lower jaw; this motion being regulated by a pair of strong elastic bands, that extend from the pouch to the base of the corolla. The tongue-like nectary, already described, of course accompanies the pouch, of which it forms the extremity, in this semi-circular gyration; and though it was hitherto concealed inside the pouch immediately below the narrow entrance, is now exposed at the opening, and becomes readily accessible to the bee. The humble-bees, however, cannot take advantage of this without coming into contact with stigma and pollen in due succession, and thus promoting intercrossing among these proterogynous flowers. Insects that are without the requisite size or strength or 
weight to produce the necessary motion of the calceolus, and that therefore would touch neither stigma nor pollen, have no possible means of getting to the nectar.

In all these cases it is by curvature of the perianth, or of its appendages, that the narrowing of the passage leading to the nectary is effected. There are, however, many other cases where the same result is obtained by special developments of the andrœcium; and among them are some where the resulting forms are of extreme elegance. Such, for instance, are those where the filaments, thickened, or expanded into a petaloid condition, and adherent to the inner surface of the perianth, send out processes which jut into the central space of the tube, and partition it out into a number of precisely similar passages. These passages, which are usually five or six in number, stand in a circle round the central ovary; so that a transverse section of the flower gives the impression of a five-barrelled revolver. Such passages are, as a rule, very narrow, and allow nothing thicker than a proboscis to penetrate to the nectar, to which they lead. But it is only insects that have this proboscis that are welcome guests to these "revolverflowers;" for they alone are of such suitable size and weight as to repay their share in the feast by promoting allogamy. Other insects, whose visits would confer no such advantage, are shut out from the nectar 


\section{20 Flowers and their Unbidden Guests.}

by the length and narrowness of the passages by which alone it can be approached. This "revolver" formation is specially observable in sundry Gentianeæ, as also in many species of Convolvulus (C. siculus, C. tricolor, C. arvensis, C. sepium, etc.). The plant, however, which I have selected for illustration is Aphyllanthes monspeliensis (Plate II. fig. 55, transverse section of upper part of flower). Here the six stout broad filaments are internally in close apposition to the central style, while externally they are adherent to ridge-like processes given off from the mid-rib of each of the six free but overlapping petals. I have also given drawings from another plant, Gentiana firma Neilr. var. (Plate II. fig. 61), to illustrate the same kind of formation. Here there are five dilated filaments, closely apposed to the five sides of the central ovary. The petals cohere so as to form a tubular corolla, but at the points of coherence their commissures form ridges, which project internally and are adherent to the filaments. Similar arrangements, though without the same regularity and elegance, are also common in Caryophyllaceæ and Cruciferæ; for in many plants from these orders the long thin claws of the petals, together with the filaments, so completely fill up the space between the ovary and the firm upright closely approximated sepals, that only very narrow passages are left, which though they lead to the nectar are yet quite impenetrable by unbidden guests. 


\section{Drop-bar Arrangement.}

A very peculiar arrangement, which must here be noticed, is found in the flowers of Chelone and Pentastemon, and may not inappropriately be called the "drop-bar arrangement." 1 The Pentastemon gentianoides, so widely diffused as an ornamental plant, will serve as an example. (Plate I. fig. 34, longitudinal section; fig. 35, transverse section near base of flower.) The nectar in this flower is very abundant, and is secreted by the basal parts of the two shorter stamens, which are inserted on the corolla to the right and left respectively of the ovary. The nectar is secreted on the outer side of the stamens, that is on the side turned from the ovary and towards the corolla, and completely fills up the pouch-like spaces which lie between the latter and the secreting surfaces. It is impossible for the nectar to trickle out from these lateral spaces in a downward direction, because the dilated stamens are in close apposition with the inner surface of the corolla by their lower edges. But, on the other hand, there is a free communication between the two lateral pouches and the space above the ovary; and, as a matter of fact, this upper space, which is $3 \mathrm{~mm}$. in width, and over-arched by the corolla, is invari-

1 [I know of no English equivalent for the German Schlagbaum, and have therefore invented the term drop-bar. By it is meant an arrangement in common use in Germany as a barrier or toll-bar; consisting of a horizontal bar attached by one end to an upright, and moveable on that end up and down in a vertical direction.EDITOR.] 
I 22 Flowers and their Unbidden Guests.

ably found full of nectar so long as the flower is in blossom. As the bell-shaped flower is 11-16 mm. wide at the mouth, and as the anthers and stigma are closely apposed to the upper wall of the corolla, insects of all varieties of size, with bodies of from 1-10 mm. in thickness, can make their entrance, and, for all that has yet been mentioned, might carry off the nectar from the above-described space without necessarily touching the stigma and anthers; but the nectar is admirably protected against all such guests by means of the fifth and uppermost stamen, which is inserted upon the corolla about 6-7 $\mathrm{mm}$. from the bottom. This is converted into a "drop-bar," and has its thickened and dilated base placed immediately in front of the nectar-cavity, covering the opening so completely that only a small fissure, scarcely $1 \mathrm{~mm}$. in width, is left open on either side. This bar runs obliquely across the flower, crossing therefore the base of the other filaments and the style, and fixes its free end, which is thickened but forms no pollen, against the lower wall of the corolla, like a buttress. By this arrangement insects of sufficient size to be brought, when visiting the flower, into due contact with stigma and pollen are allowed to get at the nectar, inasmuch as they can insert their trunk into the narrow orifices on either side of the bar, while smaller and therefore unwelcome visitors are completely shut out.

In many cases the ovary and the filaments, which 
cling round the ovary in a compact body, so completely fill up the whole space within the perianth, that no opening is left except a very narrow passage, frequently merely a tiny hole or a minute fissure. Through such openings invited guests can introduce their proboscis, while unbidden ones are completely excluded from the nectar. Such an arrangement is found in very many Leguminosæ (Trifolium, Lotus, Anthyllis, Hippocrepis, Onobrychis, Medicago, etc.), where there is merely a small triangular aperture on the right and left of the upper filament near the bottom of the flower (Plate I. fig. 33, Hippocrepis comosa, seen from above, after removing the standard). Such again in the genus Viola, consisting of flowers too well known to require further description; such also in the magnificent large-flowered species of Amaryllis. The structure of the latter, so far as we are at present interested, will be understood by reference to the drawings of Amaryllis belladonna, which I have selected for illustration (Plate I. fig. 39, transverse section of flower; fig. 38, longitudinal section through nectary). The perianth of this flower, not far above its base, gives off an outgrowth, which in shape of a broad band encloses the bundle formed by the style and the six thick and closely approximated filaments. Only at one point, on the upper surface of the bundle, does this outgrowth, that elsewhere is in closest contact with 


\section{24 Flowers and their Unbidden Guests.}

the bundle, form a fold. This fold encircles a narrow passage, having an external orifice no more than $0.8-1.0 \mathrm{~mm}$. in diameter, and communicating internally with a cavity, $7 \mathrm{~mm}$. in length by $6 \mathrm{~mm}$. in width, placed behind the outgrowth. This cavity contains abundant. nectar, secreted by a disk that surrounds the base of the style; and into it large flying insects can readily introduce their proboscis through the above-mentioned narrow passage, while no access is possible to small, and therefore unprofitable, visitors. A very minute insect, less even than $0.8 \mathrm{~mm}$. in diameter, might, it is true, creep in through the passage; but were it to do so, it would be drowned in the copious nectar, which completely fills the relatively large cavity.

In many cases it is not the androcium nor the corolla, but the calyx, the epicalyx, and the bracts, that by their contorted growth, by their dilatation, or by their being crowded together, protect the nectar from being unprofitably expended. In many Sileneæ, for instance, the calyx is inflated to such an extent that the nectary comes to be farther off from the calyx than from the mouth of the corolla. It is thus rendered impossible for certain insects to get at the nectar by biting laterally through the perianth. It has long been known, and the fact is common enough in the flora of our country, that many Hymenoptera, and especially humble-bees, instead of making their entrance by the 
mouth of the corolla, try to get at the nectar, which they smell ${ }^{1}$ inside the flowers, by biting a hole through the leafy investments of the nectary and inserting their proboscis. This they are especially prone to do when the passage which leads to the nectar is not a perfectly open one, but is covered in by projecting parts that must be pushed aside before access can be obtained.

1 I have already briefly alluded to the fact that it is by amell that humble or other bees are attracted to the nectar. The clearest evidence of this is furnished by those cases where the bees, usually humble-bees, obtain the nectar in a manner prejudicial to the plant ; as occurs, for instance, with species of Aconitum, Gentiana, Rhododendron, and Pedicularis; flowers to which $I$ shall have to come back in the final chapter. Not only the nectar, but the parts that secrete and store it, are quite out of sight of the humblebees, even when they have settled on the flower; and yet they proceed forthwith to bite a hole through the perianth at the precise spot which offers the shortest road to the nectar. The nectar of flowers, it is true, makes as a rule no impression on our olfactory. nerves; but this by no means excludes the possibility of its being perceptible to insects even at some distance. When Sphinx convolvuli is seen flying with the rapidity of an arrow to the flowers of Lonicera etrusca or Caprifolium, nay mors, directing its flight towards them from a distance at which they must be quite out of its range of vision, it cannot be doubted that it is the perfume from the corolla, which even our olfactory nerves can recognise at some distance, that has furnished the attraction; and we nust draw the same inference when we see the same phenomena with flowers that contain nectar and yet are to our senses without scent and without attractive coloration. Place yourself near a hedge where the bees are swarming about the open flowers of Ampelopsis hederacea, and you will soon be convinced of this. The observations to be recorded in the next section, respecting the flowers of certain Caryophyllaceæ, render it, moreover, highly probable that the perceptibility of the nectar by certain insects is often subject to some condition of periodicity; just as there are many flowers whose corollas develop a perfume perceptible to our own olfactory nerves only at certain fixed hours in the day. 


\section{26 Flowers and their Unbidden Guests.}

This kind of visit, however, in which a hole is gnawec and the nectar sucked out laterally, would of course br a most unwelcome one to the flower, which would losi all the advantages of cross-fertilisation, as a reward fo: which it offered its nectar. But let the calyx be in. flated merely to such a degree that its wall shall lie a a greater distance from the nectary than can be traversed by the proboscis of a humble-bee, and al danger of this injurious mode of access will be avoided and the bee compelled to avail itself of the natura: entrance, at the margins of which are placed the anther: and the stigmas. ${ }^{1}$

The same result as is obtained in the foregoing instance by the inflation of the calyx into a bladder-like form can also be arrived at in another way, namely, by the calyx, or the bracts that surround the flower, being formed of very tough tissue - so tough that it can witk difficulty be gnawed into a hole even by a strong humble. bee. This, in the majority of cases, is the only interpretation to be found for those stiff hard calyxes and bracts. which are usually made of dry membranous tissue, but are sometimes so thickened as almost to resemble

1 [This use of an enlarged calyx as presenting an additional im. pediment to lateral gnawing was, to the best of my belief, first suggested by myself (Pop. Sc. Review, 1870, pp. 47 and 168). According, however, to H. Müller, the flower which I instanced, viz., Pedicularis, is not one to which this explanation applies. A further use to which an inflated calyx is at times subservient has been pointed out by F. Hildebrand (Verbreit. der Pflanzen. s. 64.) It aids in the dispersal of the seeds.-EDITor.] 
cartilage. The Dianthus prolifer, of which I give drawings (Plate III. fig. 114, a single flower ; fig. 113, a complete inflorescence), will serve as an example of this tolerably extensive class of protective appliances. In this flower the perianth (calyx as well as corolla) is made of a very delicate tissue, and is not protected externally either by viscidity or by hair-like structures. The nectar, moreover, in the recesses of the flower is at such a very short distance from the thin calyx, that it could be easily got at by gnawing laterally through the perianth. This unprofitable expenditure is, however, prevented by, the arrangement and character of the bracts. These are formed of a dry membrane, almost like parchment, and closely invest the fascicled flower-heads up to the very mouths of the individual flowers; and so tough are they, that humble-bees or ants might work away for ever with their jaws, and yet make no impression upon them.

That the crowding together of foliar organs would also act as an impediment, and stop insects from thus gnawing holes in the side of the perianth, is self-evident; and I am therefore inclined to believe, that the development of an epicalyx may be subservient to this among other uses. In many cases the nectar has no fewer than four foliaceous strata to protect it laterally, namely, the corolla, the calyx, the epicalyx, and the bract; so that it becomes excessively difficult, if not 


\section{28 Flowers and their Unbidden Guests.}

absolutely impossible, for an insect to bite out a hole and so get at the honey from the side.

This section has been mainly devoted to the consideration of cases where the protection is furnished by parts of the flower, and where the animals, from which the nectar is to be protected, are flying ones. But before bringing the section to an end, I may notice that the leaves also often act in the same way, by curvature, dilatation, crowding together ; the insects, however, thus excluded from the nectar being creeping ones. The leaves that effect this present much variety in their form and their aggregation. First to be mentioned in this relation are those leaves that embrace the stem all round, and form a kind of collar about it. In some plants, e.g. in Melianthus, the collar is formed by the stipules; in others (Bupleurum rotundifolium, Smyrnium perfoliatum, Lepidium perfoliatum) by the laminæ of alternating leaves; but most frequently of all by the cohesion of opposite leaves, as in numerous Gentianeæ and Caprifoliaceæ. ${ }^{1}$ All such leaves are somewhat curved towards their margin, and the curvature is such that the convex surface is turned upwards, while the smooth margin is more or less bent downwards. I have assured myself not only by observation but by experiment that wing-

I [I have found Chlora perfoliata a capital plant on which to experimentalise with ants. When placed on the slippery glaucous leaves of this plant the ants invariably fall off, tumbling down the "couloir" at the connate bases, which I suspect is formed with this special purpose.--EDIToR.] 
less insects, and notably ants, find it impossible to mount upwards over such leaves as these. The little creatures run up the stem, and may even not unfrequently traverse the under surface of the leaves, if not too smooth; but the reflexed and slippery margin is more than the best climbers among them can get over, and if they attempt it they invariably fall to the ground. There is no necessity for the lamina of the leaf to be very broad; even narrow leaves, as for instance those of Gentiana firma Neilr. var. (of which I have given a lateral view on Plate I. fig. 1 , and a transverse section in fig. 2), are enough for the purpose, supposing, of course, that the margin is bent backwards in the way described.

The perianth-leaves also, when curved and bent in appropriate fashion, can act in the same manner, and repel the attempts of unbidden creepers to make their way into the recesses of the flower. I placed some small and by no means timid ants, of a kind (Lasius niger) which under ordinary circumstances show themselves to be capital climbers, on the flowers of Cyclamen europoeum (Plate I. fig. 6). At first they tried to make their escape downwards by the peduncle; but, as I had put the flower-stalk in water, they turned back and managed to re-cross the calyx and get back to the corolla. After some useless clambering about the reflexed tips of the petals, they at last reached their curved margins, and here all their skill was baftled, 


\section{I30 Flowers and their Unbidden Guests.}

and they fell inevitably either into the water or to the ground.

But of all flowers none present such difficulty of access to small and wingless animals as do the pendulous. No ant, for instance, ever gets inside the hanging flowers of Galanthus nivalis (Plate I. fig. 5). I may therefore fairly infer that the nodding peduncles of small pendulous flowers, as also the drooping axes of twining plants, are developments that protect the nectar from the unprofitable visits of creeping insects and thus confer a benefit on the flowers.

7. Temporary Suspension of the Functions of those Parts of the Flower which attract Insects.

The majority of those plants whose flowers only open after sunset have a very short flowering period, limited to a single night. A flower opens one evening, remains open far into the night, or, perhaps, till dawn, and then closes never to open again. Far rarer are the species in which each flower repeats this evening opening and this morning closure for several successive days. One of the best-known examples is Hesperis tristis, a plant belonging to the Cruciferæ; but the family which presents by far the largest proportion of species with flowers of this kind is the Caryophyllaceæ, and as examples I may cite certain Sileneæ, which I 
have made the subject of special investigation, viz., Silene paradoxa L., S. longiflora Ehrh., S. ciliata Pourr., S. vallesia L., S. saxifraga L., S. Kitaibelii Vis., and $S$. nutans.

In all these plants each flower lasts, unless exposed to any unusual disturbance, three days and three nights. On the first day, when the perianth has opened late in the afternoon, the anthers of those five stamens which are opposite to the sepals come forward, so as to be visible at the mouth of the corolla between the claws of the petals, their loculi, however, being as yet closed. Their filaments now lengthen very rapidly, occupying from one to two hours in the process; and by the time the sun has gone down and twilight set in, the five anthers on their straight stiff filaments are seen to stand more or less in advance of the aperture, the loculi to have opened, and the whole anther to be covered with pollen. This condition lasts till the forenoon of the following, that is of the second, day. The stamens then bend outwards, and the anthers fall off or remain hanging like shrivelled empty bags at the end of the reflexed filaments. In the course of this afternoon the filaments of the five other stamens, those namely which are opposite to the petals, lengthen in their turn; the still-closed anthers appear as before towards evening at the aperture, and again by dusk they are to be seen, opened and pollen-covered, projecting on their stiff straight filaments beyond the mouth of the corolla. On the third 


\section{Flowers and their Unbidden Guests.}

day these stamens, like their predecessors, bend backwards, and at the same time the anthers, as a rule, fall off; and now, with the coming on of evening, the long S-shaped twisted silky stigmas, which hitherto were immature and hidden in the bottom of the flower, make their advance.

With this lengthening and bending of the stamens and stigmas goes hand in hand the opening and shutting of the corolla. With the approach of dusk the bifid limbs of the petals spread out in a flat surface, and fall back against the calyx. In this position they remain through the night, and not till the following morning do they begin (more quickly in sunshine and with a mild temperature, more slowly with a cloudy sky and in cold wet weather) to curl themselves up in an incurved spire, while at the same time they form longitudinal creases, and look as though they were gathered in or wrinkled. Thus the mouth of the flower comes to be surrounded by five rolled-up bodies, which at a hasty glance would lead one to think that the flower was already faded; but no sooner does evening return than the wrinkles disappear, the petals become smooth, uncurl themselves, and fall back against the calyx, and the corolla is again expanded.

The coloration of all these Caryophyllaceæ is very . peculiar. The inner surface of the petal is white, while the outer or under side is greenish, or of a dirty yellow or brownish tinge, or livid red, or almost ash- 
grey; in short, is invariably of some or other indefinite and inconspicuous colour. When therefore the petals are unfolded and their inner surface displayed, the white colour makes them very visible even in the twilight; whereas in the daytime, when they are curled up, and their under side alone exposed to view, the dull tint makes them very inconspicuous, in spite of the fuller light, and conveys the impression of the flower being already withered and past. (Plate III. fig. 115, flower of Silene nutans at midnight; fig. 116, the same flower at midday.)

In conclusion, one fact is still to be noticed, namely, that these Caryophyllaceæ are entirely without fragrance during the daytime, whilst in the evening, simultaneously with the opening and spreading out of their petals, they begin to exhale an aromatic odour. The scent of Silene longiflora is especially strong. Still more powerful is that of Silene mutans, which reminds one strongly of the smell of hyacinths; indeed so striking is this likeness that my children, who often came upon these flowers in their evening walks round my house at Trins, in the Gschnitz Valley, used to call them wild hyacinths. Some plants of Silene nutans which I had put into pots and placed in my bedroom, in order to be able to observe them more conveniently at night, filled the room with such a strong and almost overpowering odour, that I was obliged to carry them into another adjoining room. This odour, which is 


\section{34 Flowers and their Unbidden Guests.}

exhaled from eight o'clock in the evening till about three in the morning, together with the white colour of the petals, which is most striking in the dusk, attracts numerous insects that search for nectar in the evening or by night. Such of these insects as are wingless are altogether debarred from access by the viscid matter on the peduncles ; ${ }^{1}$ but flying insects are highly welcome, and to them the honey at the bottom of the flower is willingly offered in exchange for the cross-fertilisation to which they conduce. In the daytime it is quite otherwise. No insect, winged or not, is now welcome to the nectar. The filaments are at this time rolled back, and the anthers have fallen off, or, if still hanging to the filaments, are shrivelled and empty. There is now no pollen in the flowers to be rubbed off, and therefore there can be no fecundation of the stigma. Should the nectar therefore be consumed, it would be expended in vain; and the flowers moreover would be at this further disadvantage, that when evening came on they would be nectarless, and therefore would remain unvisited.

Now to prevent the nectar from being thus stolen without profit, and to protect the flowers from such insects as are active in the sunshine, no better means could be devised than those which are in fact adopted,

1 See pp. 60,61. Silene nutans is also very remarkable on another account, namely, as producing tetramorphic flowers. This, however, is a point which I shall have an opportunity of dealing with elsewhere. 
namely, that the organs which serve to attract insects shall suspend their activity for a time, or, in other words, that the function of attraction shall be in abeyance throughout the day. This literally happens in the flowers of the above-named Caryophyllaceæ, which, during the daytime, display only the dirty and inconspicuous under-side of their petals, and exhale no perfume.

It is evident that this arrangement is not without its due result. For, as already remarked, these flowers are much frequented by such flying insects as are active in the evening and in the night, but remain entirely unnoticed and unvisited by the numerous species that buzz about in sunshine!

\section{Diversion of Visitors from the Flower.}

Though we are doubtless justified in calling the substances discharged by glandular cells, or groups of cells, "excretory matter," yet this designation is only true in a certain sense, and must not be supposed to imply that the substances are of no use to the plants, and that after they are once discharged they possess no further functional significance. The observations recorded in the preceding pages show with abundant sufficiency how important a part may be played by these so-called excretions; and I would here only add the remark that even the oxalate of lime, 


\section{Flowers and their Unbidden Guests.}

which is discharged in not a few species of plants, and especially in many of our Alpine saxifrages, from special organs on the edges of the leaves, is not without its functional significance. For the purposes however of the present inquiry we are concerned with no other secretions than such as are resinous, mucilaginous, sweet, or saccharine. These terms, resinous, mucilaginous, sweet, and saccharine, indefinite as they may sound, must nevertheless as yet be employed, inasmuch as they furnish the best basis for a division of these glandular bodies into groups; and, so far as nomenclature is concerned, that division seems to me the most acceptable by which the glands that secrete resin, bassorin, and the mixture of mucilage and resin known as blastocol, are called colleters, while those which discharge a sweet-tasting saccharine fluid are called nectaries. It may be accepted as a very general rule that the latter are developed within the flowers, the former on the leaves. But no rule is without exception, and plants are not wanting which have nectaries on their leaves. The number of these plants appears, indeed, to be by no means large; at any rate, up to the present time few such cases are known; but the possibility always remains that further investigations may discover many more. Those which have been longest known are: Vicia faba, $V$. sepium, and V. sativa, Acacia longifolia, Prunus avium and $P$. laurocerasus, Catalpa syringoefolia, Impatiens tricornis, Ricinus; Vibur- 
num tinus, and $V$. opulus, and Clerodendron fragrans, in all of which the leaves undoubtedly secrete nectar.

In some of these, again, the secretion is produced by special groups of epidermal cells, placed on the under side of the leaf or stipules, and transformed into glandular tissue, as is the case, for instance, in Clerodendron, Prunus laurocerasus, and the above-mentioned species of Vicia; while in others the nectar is secreted by disk-shaped or knob-headed trichomes, which are found springing from the surface of the leaf or of the petiole, as is the case in Catalpa, Viburnum opulus, and Prunus armeniaca.

In Impatiens tricornis the two small stipules of each leaf are entirely transformed into nectaries. One of these is very small and stunted; the other, on the contrary, forms a fleshy disk, slightly convex above, and below shaped into a semi-globular protuberance, which is partly adherent to the base of the petiole, partly to the epidermis of the stem, and lies transversely in front of the axil from which the flower-stalk springs. (See Plate III. fig. 117; also fig. 118, which represents a transverse section of such a transformed stipule.) The nectar secreted by the tissue of this fleshy disk collects in the form of a drop on the apex of the semi-globular breast-shaped swelling on the under side of the disk. Any insects that creep along the stem must, if they would get at the flower, of necessity pass over this disk with its drop of nectar; thus what 


\section{38 Flowers and their Unbidden Guests.}

they would have sought, and moreover would have found, in the flower, is already offered them here in rich abundance. The creeping insects are not fastidious. Nectar in one place is the same to them as nectar in another. They are content with that which is first offered, and so do not trouble themselves to climb farther up to the flowers. In Impatiens tricornis the stipules are so frequented by Myrmica loevinodis $\mathrm{Nyl}$. that I have often seen three of these ants upon a single stipule; and yet, though I have examined hundreds of plants of this species, and though its nectariferous flowers have no other protection whatsoever to keep out these little creatures, I have never seen a single ant inside a blossom. They would, indeed, be very unwelcome guests, inasmuch as they could reach the nectariferous spur without coming into contact with the pollen, or, at a later stage of the flowering, with the stigma. They would thas consume the nectar without profit, and not only so, but by diminishing the attraction would limit and hinder the visits of those insects, which, being larger and coming on the wing, would in entering the flower necessarily come into due and successive contact with the pollen and the stigma.

As with Impatiens tricornis, so is it with other plants where nectar is secreted on the leaves. Though these leaf-formations may present no mechanical hindrance nor offer any insurmountable barrier to small creeping ants, they yet serve to divert such visitors from the 
flowers, and detain them from further advance. I do not therefore hesitate to interpret all nectar-glands that are found on leaves as means of protection against the unwelcome, because unprofitable, visits of creeping insects. $^{\text {I }}$

1 [Kerner makes no mention here of nectar-glands found neither inside the flower nor on the leaves, but, as sometimes happens, on the calyx. Fritz Muiller (Nature, Nov. 29, 1877), doubts whether the calyx-glands of Malpighiacex serve to protect the flowers from crawlers. In one species, at any rate (Bunchosia gaudichaudiana), he has found that they serve the aame purpose as nectaries inside a flower; attracting bees, which in gnawing them get coated with pollen on their under surface. Mr. Darwin points out that a similar observation has been made by $\mathrm{Mr}$. Farrer in respect of Coronilla_-EDITOR.] 


\section{CHAPTER V.}

\section{CONCLUDING REMARKS.}

TrE foregoing pages will suffice to show that the relations between the forms of plants and those of animals that feed on them are far more multifarious than has hitherto been supposed; and more especially that numerous formations which occur on the leaves and stem are far from being devoid of functional signifcance, inasmuch as through them flowers are protected against the disadvantageous assaults of certain animals. Where the attacking animals are wanting, there these defensive appliances are also, of course, meaningless. Such formations, therefore, are to be regarded as means of protection only when the plants are growing in their original habitat in the district, that is, where the species to which they belong has arisen. In any other situation these developments may perhaps not serve as defences, nay they may be of direct disadvantage, or at any rate may be a mere superfluity extraneous to the economy of the plant; and it is self-evident that such unprofitably, because uneconomically, organised plants, being placed under conditions not concordant with their 
structure, will be driven from the scene by more advantageously organised competitors. ${ }^{1}$

If, for example, a species of plant spreads into a district. where it finds itself exposed to new kinds of attack, or if, in a district where the species arose, and where until now the external conditions have been suitable to it, these external conditions alter, it may happen that this species will become rarer and rarer, and gradually quite die out. By these alterations of external conditions we are not, however, simply to understand changes of climate; for no less important are the changes which may occur within a given area in the animal world. Quite independently of the changes which occur in their area of distribution, animals as well as plants are subject to variation; and individual varieties may arise with new characters, that under the special

1 That structures which, owing to external conditions, have become useless or even prejudicial to a plant, thereon undergo gradual degradation or abortion, is a notion which must be most decidedly rejected. The so-called process of "adaptation" is never a direct one, never comes simply in response to a want. In other words, external conditions can never occasion an inheritable change of form, whether advantageous or the contrary, can neither determine the development of an organ nor its abortion. Structural peculiarities, advantageous and disadvantageous, present themselves in individual varieties, quite independently of any direct influence of external conditions. When the peculiarity is an advantageous one, its possessor, being thereby well suited for the struggle with its local competitors, can maintain its position, can multiply, extend itself, and form the starting-point of a species. When, on the other hand, the peculiarity is one that, under the special local circunstances, confers no advantage, or is positively injurious, its possessor succumbs in the struggle for existence. 


\section{Flowers and their Unbidden Guests.}

external conditions are of advantage, and such varieties may form a starting-point for new species. But that which is of advantage to the attacking animal implies, as a rule, a corresponding disadvantage to the plant attacked; and therefore not only is it possible, but in the course of ages it has certainly happened innumerable times, that in consequence of the development of some or other individual advantageous variety of an animal into a species, that is in consequence of the multiplication of this advantageously organised form of animal within a certain district, some plants in this same district have been gradually exterminated, owing to the interference on the part of their new enemies with the formation of their flowers and seeds.

1 It must be borne in mind that there are species of plants which, though they are provided with some or other of the appliances described in this treatise, are nevertheless only imperfectly protected thereby from the attacks of those animals to which they are exposed at the present time. For instance, many of the nectariferous flowers of our own flora, such as Aconitum, Pedicularis, Gentiana, Rhododendron, Rhinanthus, are liable to have their corolla gnawed through, and their nectar rifled without profit to themselves (p. 125). Some of these species, nevertheless, maintain themselves, and this in abundance. The explanation of this is in the first place that the flowers are not entirely unvisited by the proper opening, and secondly, that, in default of allogamy by the agency of insects, the flowering process terminates in autogamy (e.g. Rhododendron, Rhinanthus). In several of these species, however, this is not the case ; and these, as for instance Aconitum paniculatum Lam., are at the present time rare; they produce, moreover, as a rule, no seed, are individually scarce, and may be fairly regarded as species on the way to extinction.

[It appears to me that the ordinary blue variety of Aconitum napellus is protected from this lateral gnawing and useless expenditure of nectar, at any rate to a great extent, by some or other distasteful 


\section{Resemblance between Plants of same District. 143}

It is not only the dying out of certain species that is thus to be explained by changes in the external conditions, and especially by changes in the animals to whose attacks they are exposed, but the same considerations account also for the further fact, that species of plants, which, having regard to other characters, we reckon as belonging to the most widely separated families and races, nevertheless, if growing under like external conditions, present similar peculiarities of structure. Only such structural developments as are of advantage are preserved, and only such individual varieties as arise with characters adapted to the environment, can become the starting-points for new species. As, however, the process of remodelling in adaptation

ingredient in its blue flower; for I gathered one year in Switzerland a hundred flower stems of this blue variety, and found not a single flower perforated; whereas, on similarly examining a hundred flower-stems of the white variety in the same district, I found every open flower with a hole in the side. This probably explains the much greater abundance of the blue variety. As regards Rhinanthus, I cannot but still think that the wide calyx is a considerable protection against lateral pilfering of nectar. I have examined a vast number of the flowers of Rhin. cristagalli, both in England and in Italy, and very rarely indeed have I found the corolla perforated. Doubtless these exceptional instances are enough to show that such perforation is not impossible. But there was no necessity for nature to make it an impossibility. Her object would be equally well attained if she made the lateral access more difficult than the normal one by the mouth; for the bee simply wishes to avoid trouble, and selects the easiest plan of getting at the nectar. But it cannot, I take it, be questioned, that the peculiar calyx of Rhinanthus is a considerable, though not absolutely insurmountable, impediment to the lateral perforation.-EDITOR.] 


\section{I44 Flowers and their Unbidden Guests.}

to new conditions may involve simultaneously species from the most various families of plants, there is no difficulty in understanding why, for instance, in one floral district numerous species from the most different orders are found armed with thorns, while in another there is a prevalence of flowers with very copious nectar, and why, in short, the character of the whole vegetation is often determined by the predominance of plants that resemble each other in some similar speciality of structure. This conformity however is, on the other hand, greatly limited by the extreme multifariousness presented both by the means of attraction and by the means of protection, and by the fact that one and the sarne result can be attained by formations of the most diverse kinds. This circumstance indeed that, though the dangers to be guarded against are identical, yet the means of defence may be provided equally well by the most different formations, explains how it is that several species of one and the same group are often to be found growing side by side without coming into direct competition with each other, inasmuch as each has its own special advantageous variety of organisation. Examples of this might be adduced in abundance, especially were we to consider the distribution of many Labiatæ, Caryophyllaceæ, Salicineæ, and Cirsiums; but by such discussions I should fear to exceed unwarrantably the limits of this treatise. I confine myself therefore to one single example, 


\section{Soldanella Alpina.}

namely, to Soldanella; and this example I select with the special object of showing that the development of certain protective appliances against uninvited guests may, as it appears to me, even give rise to the formation of new species.

Soldanella alpina L. is well known at the present day as one of the most widely diffused plants above the tree-line on the Pyrenees, Alps, Apennines, and Carpathians; and it therefore cannot be doubted that this species, as well as numerous others peculiar to the lofty mountains of South Europe, already existed in the region of these upheavals, at a time when glaciers still covered the deep valleys, where wheat and maize are now cultivated and where lofty trees flourish in abundance. With the transition from the climatal conditions of the ice age to those of the present milder period, the above-named plant, which up till then must have grown only in the lower situations, extended its area gradually farther upwards into regions that were now no longer covered with perpetual snow; while the situations it had hitherto occupied were at the same time invaded by a number of other immigrating species.

This advance of the boundary line of the distribution areas must however not be conceived of as a sudden occurrence, but as having been brought about as gradually as the change in the climatal conditions themselves. One plant maintained itself in the valleys side by side with the new immigrants for 


\section{I46 Flowers and their Unbidden Guests.}

a long period, nay sometimes has maintained itself up to the present day, and this without change in its form; a second in the same low-lying position gradually gave way before the new comers, better adapted than itself to the new conditions there prevailing, and found in compensation a fresh home in the higher regions, now become accessible to vegetable life; while a third extended its boundary into the region above, but at the same time managed also to maintain its position below, on the condition however of there developing into a new species.

Soldanella alpina belongs to the last of these three groups. At the present day it is to be found everywhere above the tree-line in the alpine region, in company with plants of very low organisation; and no sooner is the snow melted than it is to be seen coming into flower, preferentially at the very border of the melting snow-fields, ${ }^{1}$ on ground still soaking with ice-cold water. Within a day or two a shaft, destitute of hairs, and about $7 \mathrm{~cm}$. in height, bearing at its top one to three proterogynous flowers, develops itself at the expense of the nutritive material that has been stored up in reserve

1 I have pointed out elsewhere (Verh. d. naturw.-medic. Ver. in Innsbriick, May 15, 1872) that Soldanella alpina L. will grow under the snow at the expense of the reserve-substances stored up in its evergreen leaves, on ground still soaked with snow-water, and at a temperature scarcely one degree above zero ; and that the heat which it gives out in the process of respiration melts holes in the superincumbent snow, through which the flower-stalks then find issue. 


\section{Soldanella Alpina.}

in the evergreen leathery leaves. These flowers are assiduously visited by humble-bees, ${ }^{1}$ so that the advantages of cross-fertilisation are habitually obtained. Growing as this plant does in an alpine region, all protection of its nectar from creeping insects would be superfluous; for on the spot where it comes into flower there is as yet no animal life, and the wingless creatures from the neighbourhood are kept at a. distance by the snow-water with which the ground is soaked. Amongst the flying insects that might visit it there are, it is true, some of such small dimensions that they could make their way to the nectar by passing along the inner surface of the corolla between the filaments, and this without touching stigma or anther; but for their exclusion five small and delicate flaps, which extend over the nectar-pit like a diaphragm, are quite sufficient. The flowering process in Soldanella alpina occupies only a few days. The ripening of the seeds, on the contrary, takes a comparatively long time. It is however usually completed before all vegetation has come to an end in the alpine regions. It is only such individual plants as are prevented from flowering until August by excessive local accumulations of snow that fail altogether to bring their seeds to maturity.

Now let us suppose this plant to be subjected to a

1 In the alpine district of Trins in the Tirol I noticed that Soldanella alpina was visited very assiduously by Bombus terrestris, Proteus agrorum, lapidarius, and also by Apis mellifica. 


\section{48 Flowers and their Unbidden Guests.}

milder climate, where the period of vegetation is of greater length, and to be at the same time exposed to the competition of other immigrating species. As the Soldanella resembles most alpine plants in requiring the ground on which it grows to be thoroughly and equably soaked with water, it would now maintain itself best and longest in cool shady spots where the ground was wet; but even there it would be hard pressed by the encroachment on its habitat of mosses and other plants of luxuriant growth, and little by little most individuals of the species would certainly perish. Here and there a plant might still maintain a prolonged existence, but only when it had so varied from the original stock as to have a much taller stem, by which its flowers would be raised above the dense mass of luxuriant moss that covered the ground in the wood. Now the development of this bulkier stem would require a longer time; and the plant therefore would be unable to flower immediately after the winter snow had melted away, and had left the ground uncovered. It would, however, be unnecessary that it should continue any longer to do so, as the period of vegetation in the less elevated forest-region would be a longer one than higher up; so that the Soldanella, in spite of its later flowering, would yet have enough time to ripen its seeds fully before the end of autumn. Such a long-stalked variety would therefore be able to maintain itself, to multiply, and even to spread. But at the 
same time it would be exposed in its new position to an injurious influence which was quite unknown to the Soldanella alpina that in past ages had occupied the same district. For this long-stalked sub-species when it came into flower would now find animal life already in activity about it, and would be surrounded by creeping insects that could easily climb its stem, force their way into the flowers, and get at the nectar by breaking through the thin and weak membranous scales that covered in the nectary; so that the advantage of cross-fertilisation, which requires the intermediation of flying insects, would be completely lost. Under these circumstances there can be no doubt but that any variety which developed glandular and viscid trichomes on its peduncles, and stronger, and therefore less easily forced, coverings to its nectary, would enjoy much more favourable conditions for survival than such specimens as were without these protective appliances. And even supposing that at first individuals without these appliances might be found co-existing and intermixed with others that had them, yet the former would gradually become rarer and rarer, and at last would be entirely supplanted by scions of the new variety, better adapted to the new conditions.

Now some such variety must have developed itself somewhere or other within the ancient distribution area of Soldanella alpina, and have been the startingpoint for the establishment of a fresh species, namely 


\section{I5O Flowers and their Unbidden Guests.}

Soldanella montana Mikan., which at the present day takes the place of Soldanella alpina in the forestregion of the eastern Alps and of the Böhmerwald, as also of the mountain plateaux of the Sudetic and Carpathian ranges in Moravia' and Bohemia. This $S$. montana differs from $S$. alpina in having a tall stem, glandular peduncles, strong and elongated flaps over its nectar-cavity, and in flowering at a later period, counting from the end of winter. These characters it retains with much constancy even when cultivated; and if the two species are planted side by side, as has been done by me for the last twelve years in the botanical garden at Innsbrïck, the $S$. montana is found to begin flowering some two weeks later than the S. alpina, and not to open its buds until the latter is already out of bloom. ${ }^{1}$

There can be no doubt that a similar variety, presenting some or all of the above-mentioned characters of $S$. montana, can even make its appearance in the alpine region; and, as a matter of fact, I have repeatedly noticed in the Tirolean Alps, where S. montana does not grow, single plants of $S$. alpina with tall stems and with four flowers, and I have also found specimens in which the scales of the corolla were stronger and of greater length than usual. These

1 On an average of ten years' observations made in the botanical gardens at Innsbrück, S. alpina L. begins to flower on April 4th, S. montana Mik. on April 17th. 


\section{Soldanella Alpina and Montana. I5 I}

characters, however, advantageous as they are to the Soldanella of the forest-district, whose existence they render possible, are of no value to the Soldanella of the alpine region, and are even in some measure injurious to it. For the development of a longer stem, and of a larger number of flowers, implies more time; and on the mountain heights, where the period during which vegetation is possible is very limited, time is most precious. The taller the growth of a plant, thè later will it be in coming into flower; the longer also will the ripening of its seeds be delayed, and there will even be some risk of their never ripening at all. It need hardly, however, be said, that when individuals with these unsuitable characters make their appearance in the alpine region, they never become the starting-point for the development of a new species, but quickly vanish from the scene. And a similar extinction must be the fate of any variety with the characters of S. alpina, should such present itself amongst the progeny of S. montana in the forest-region.

INASBRUCK, Jan. 30, 1876. 


\section{EXPLANATION OF THE PLATES.}

Fig.

\section{Plate I.}

1. A pair of leaves on the flowering stem of Gentiana firma (Neilr. var.), magnified it times.

2. Transverse section of the flowering stem and of a pair of leaves of Gentiana firma (Neilr. var.), $\times 3$.

3. Transverse section of a radical leaf of Pinguicula alpina $\mathrm{L}$., $\times 2$.

4. Fragment from the upper surface and central part of a leaf of Pinguicula alpina L.; showing the two kinds of trichomes, $\times 60$.

5. Flower of Galanthus nivalis L. ; lateral view ; natural size.

6. Flower of Cyclamen europaum L. ; lateral view; natural size.

7. A piece of the bristly stem with a pair of leaves of Knautia dipsacifolia (Host); natural size.

8. Several of the partly overlapping involucril bracts of Centaurea cyanus $\mathbf{L}$, lateral view, $\times 3$.

9. Three marginal ligulate flowers from capitulum of Crepis paludosa (L.), and involucral bracts of the same covered with glandular trichomes, $\times 2$.

10. Lateral view of flower of Circaea alpina L., $\times \mathbf{5}$.

11. Longitudinal section of a flower of Saxifraga controversa Sternbg., $\times 7$.

12. Lateral view of flower of Linnoea boreatis L., $\times 2$.

13. Lateral view of the trichome-covered calyx and bracts of Linnoa borealis $\mathrm{L}, \times 10$. The corolla is cut off close above the ends of the sepals.

14. Longitudinal section of flower of Atragene alpina L., natural size. 

咅

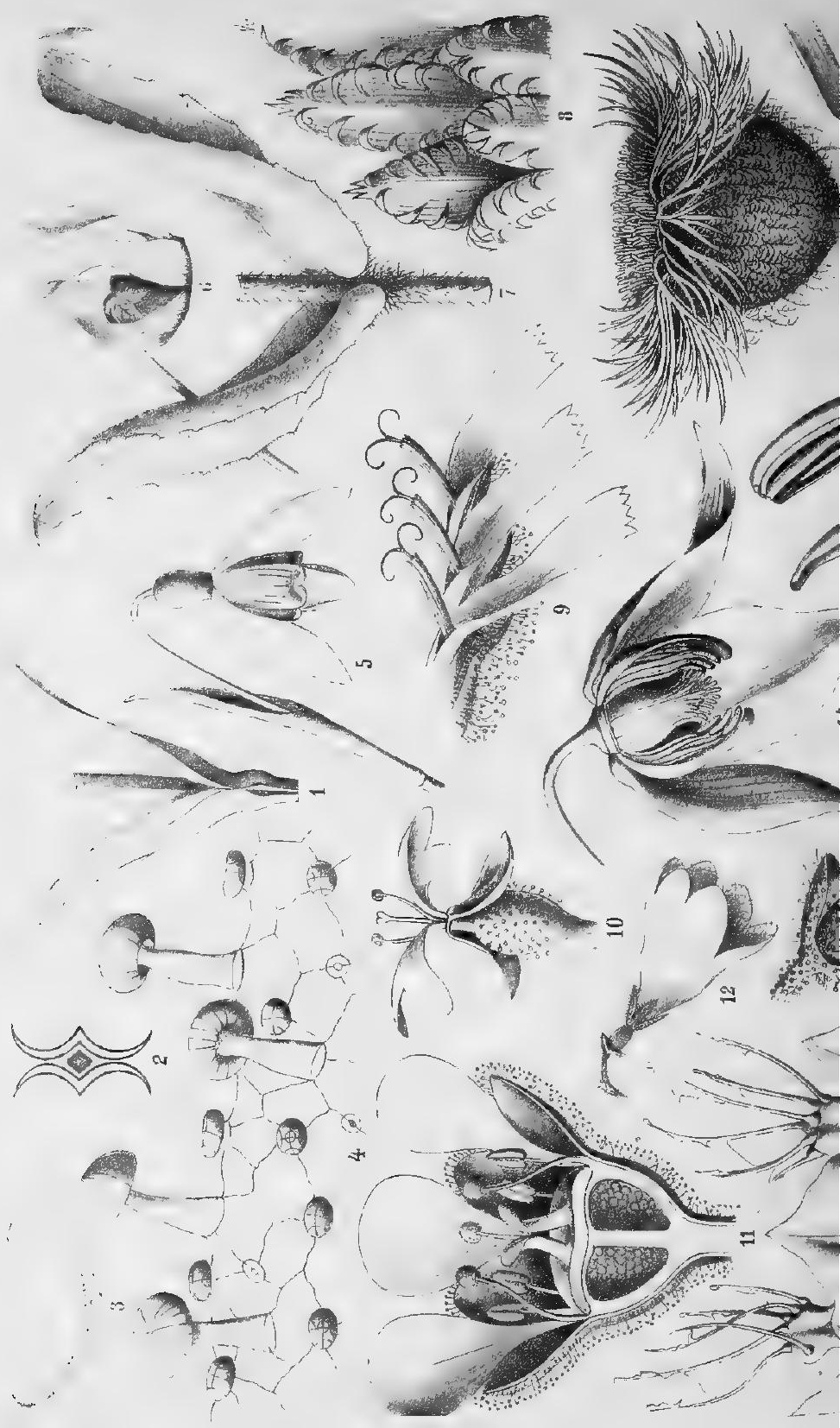




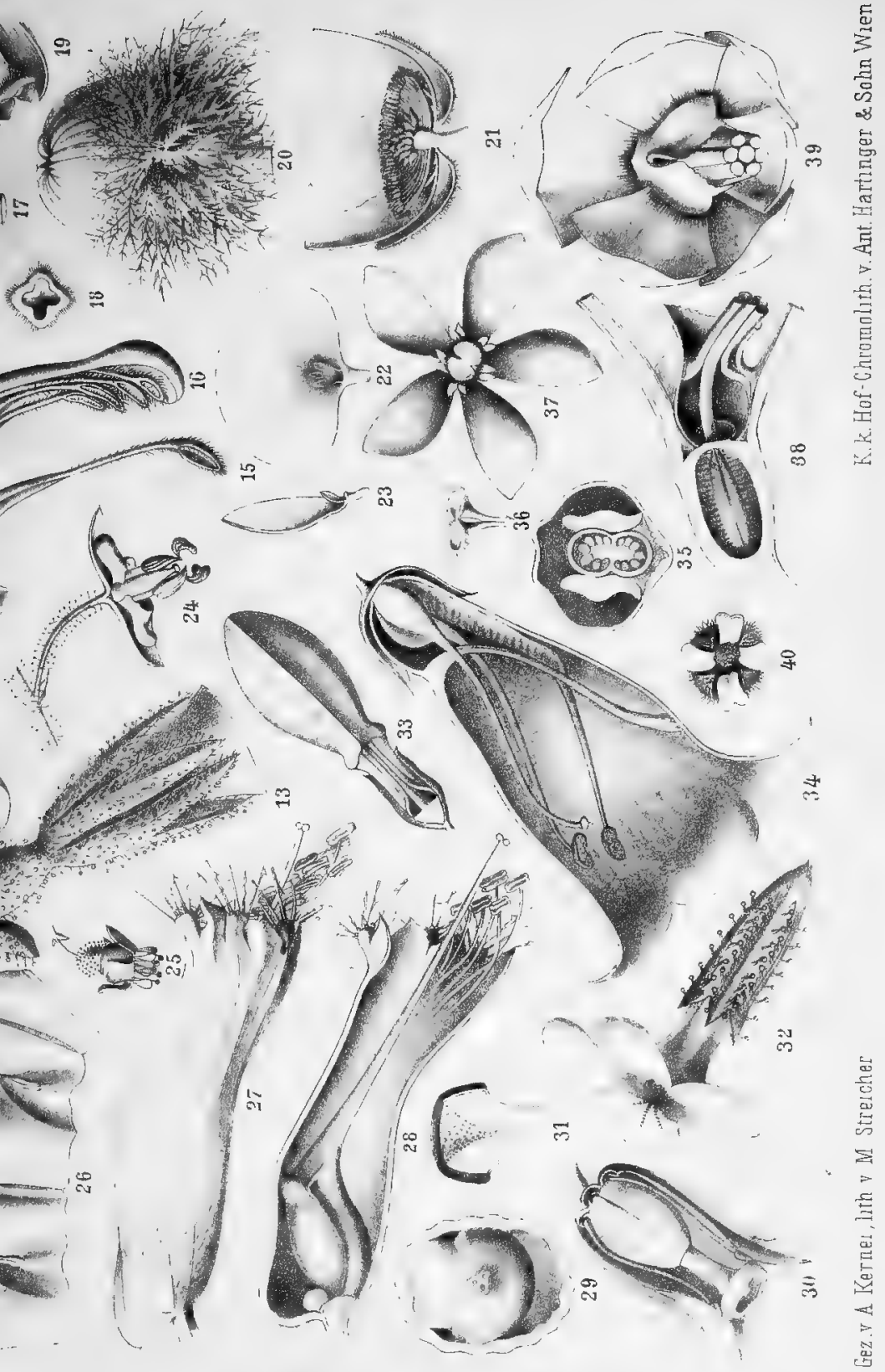



FIG.

15. A single stamen from flower of Atragene alpina L., showing the groove in the basal part of the filament in which nectar is secreted, $\times 2$.

16. Several stamens of Atragene alpina L., standing one behind the other, and covering each other, $\times 2$.

17. Lateral view of capitulum of Centaurea pseudophrygea C. A. Meyer. Natural size.

18. End of style of Monotropa hypopitys $\mathrm{L}$, Wallr, seen from above, $\times 2 \frac{1}{2}$.

19. Longitudinal section of the anterior part of flower of Monotropa hypopitys $\mathrm{L}_{\text {, }} \times 2 \frac{1}{2}$.

20. Lateral view of capitulum of Carlina vulgaris $\mathrm{L}$. The marginal flowers are in the position they assume at night, with their apices bent over towards each other. Natural size.

21. Longitudinal section of flower of Ranunculus glacialis $\mathbf{L}$., $\times 1 \frac{1}{2}$.

22. A single petal of Ranunculus glacialis $\mathrm{L}$, seen from above, $\times 1 \frac{1}{2}$.

23. Longitudinal section of a single petal of Ranunculus glacialis L., $\times 1 \frac{1}{2}$.

24. Longitudinal section of flower of Epimedium alpinum $\mathbf{L}_{\text {, }}$, the peduncle covered with glandular trichomes, $\times 2$.

25. Lateral view of flower of Ribes grossularia $\mathrm{L}$., natural size.

26. Part of flower of Cuphea micropetala H. B. K., $\times 6$, slit open. On the calyx-tube are inserted two lanceolate petals, and above each of these is a knob-shaped epiblasteme with bristly processes that secrete a viscid substance.

27. Lateral view of flower of Cuphea mieropetala H.B.K., $\times 2$.

28. Longitudinal section of flower of Cuphea micropetala H.B.K., $\times 2$.

29. Transverse section of flower of Cuphea micropetala H.B.K. The section is made across the triangular style and close above the ovary, $\times 3$.

30. Longitudinal section of flower of Monotropa glabra Bernh., $\times 2 \frac{1}{2}$. 
Fig.

31. Longitudinal section of the upper end of the style of Monotropa glabra Bernh, $\times 4$. The epiderm, which discharges viscid matter, is represented by the dark line.

32. Lateral view of tlower of Plumbago europoea $\mathrm{L}_{\text {., }} \times 3 \frac{1}{\text { s }}$. The calyx is covered with 10 rows of very viscid glandular trichomes.

33. Flower of Hippocrepis comosa $\mathbf{L}$, robbed of its standard; seen from above, $\times 3 \frac{1}{2}$.

34. Longitudinal section of flower of Pentastemon gentianoides (H. B.) $\times 1 \frac{1}{2}$.

35. Transverse section of flower of Pentastemon gentianoides (H. B.) The section is made near the base of the flower, across the axis of the ovary.

36. Lateral view of the stigma of Gentiana bavarica L., $\times 3$.

37. Flower of Gentiana bavarica $L_{\text {., }}$ seen from above, $\times 1 \frac{1}{2}$.

38. Longitudinal section of the nectar-cavity of flower of Amaryllis belladonna I. ; natural size.

39. Transverse section of flower of Amaryllis belladonna $\mathrm{L}$. The section is made across the flaments and the style, just in front of the entrance to the nectar-cavity. Natural size.

40. Flower of Alyssum calycinum $\mathbf{L}$, seen from above, $\times 4$.

\section{Pudte II.}

41. Lateral view of flower of Linaria alpina (L.), $\times 2 \frac{1}{2}$.

42. A segment of the perianth of Lilium martagon $\mathrm{I}_{\text {., }} \times 1$ 秃.

43. Transverse section of a segment of the perianth of Lilium martagon L., $\times 3$.

44. Lateral view of a petal of Aconitum paniculatum Lam., $\times 1 \frac{1}{2}$. 45. Longitudinal section of flower of Tricyrtes pilosa Wallich, $\times 2$.

46. Longitudinal section of flower of Androsace glacialis Hoppe, $\times 4$.

47. Longitudinal section of flower of Nigritella angustifolia Rich., $\times 6$. The tips of the perianth-lobes are cut off. 



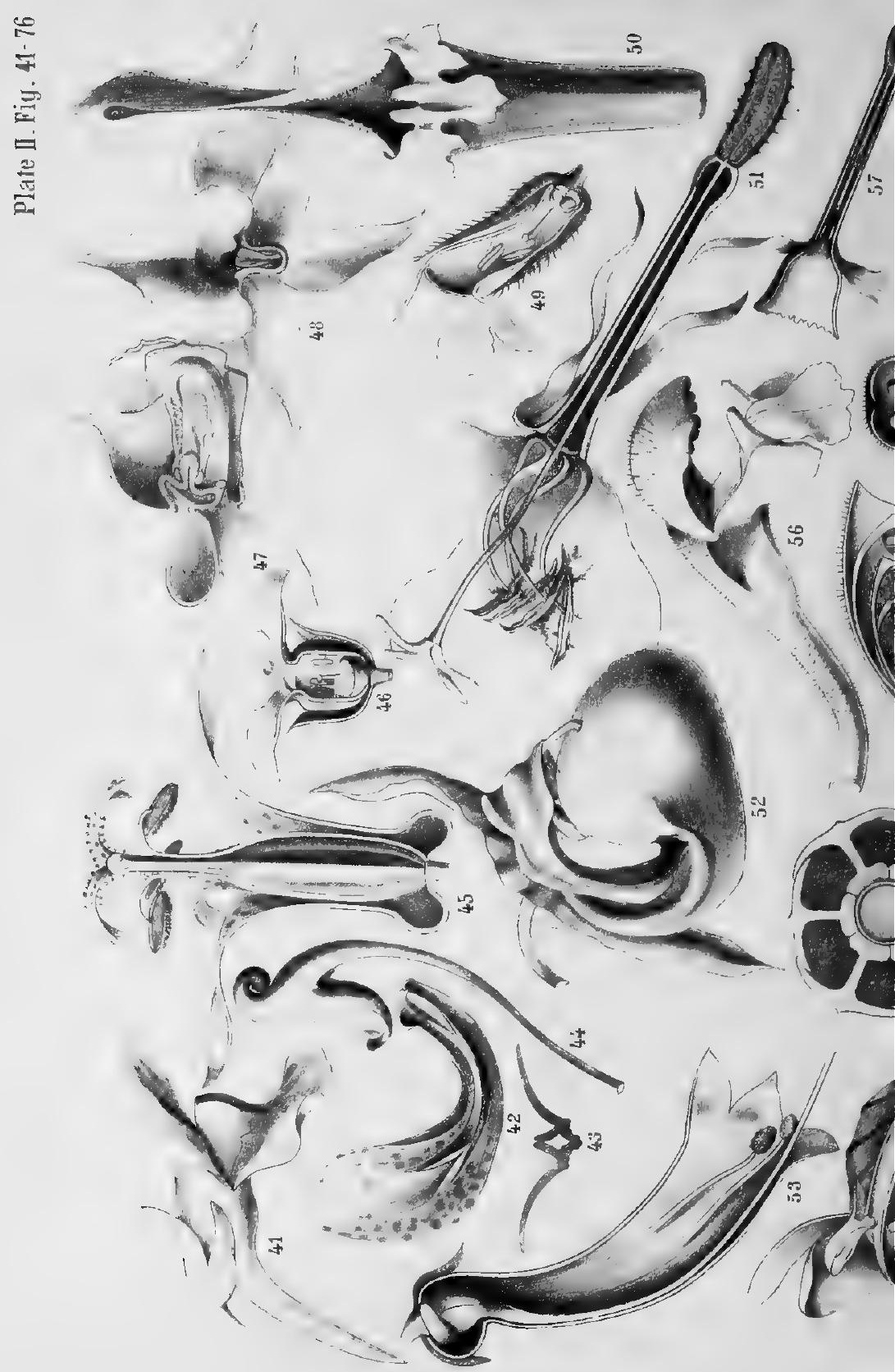



Fig.

48. Front view of flower of Nigritella angustifolia Rich., $\times 6$.

49. Longitudinal section of flower of Anchusa arvensis L., $\times 3$.

50. Front view of the corolla of Pedicularis recutita $\mathrm{L}_{\text {. }} \times 6$.

51. Longitudinal section of flower of CBnothera grandiflora Lam.; natural size.

52. Lateral view of flower of Calceolaria Pavonii Benth., $\times 2$.

53. Longitudinal section of flower of Phygelius capensis., $\times 1 \frac{1}{2}$.

54. Longitudinal section of flower of Gymnadenia odoratissima L.

55. Transverse section of the upper part of flower of Aphyllanthes monspeliensis $\mathrm{L}$., $\times 10$.

56. Lateral view of a corolla of Galeopsis grandiflora, $\times 2$.

57. Longitudinal section of flower of Narcissus juncifolius Reg., $\times 1 \frac{1}{2}$.

58. Longitudinal section of a corolla of Scutellaria albida $\mathrm{L}, \times 5$.

59. Front view of a corolla of Scutellaria albida $\mathbf{I}_{\mathbf{L}} \times \mathbf{5}$. The lower lip cut away.

60. Longitudinal section of flower of Cynoglossum pietum Ait., $\times 4$.

61. Transverse section of the lowest part of flower of Gentiana firma (Neili. var.) The section is made close above the nectar-cavity, across the axis of the ovary.

62. Transverse section of the lower part of flower of Geranium Robertianum L, $\times 6$.

63. Flower of Mattholo varia (Sibth. et $\mathrm{Sm}$ ), seen obliquely from above, $\times 2$.

64. Lateral view of flower of Gentiana ciliata I., natural size. .

65. One of the two inner petals of Hypecoum procumbens $\mathrm{L}_{\text {, }}$, seen from the side turned towards the ovary, $\times 2 \frac{1}{2}$.

66. Lateral view of flower of $H y p e c o u m$ procumbens $\mathrm{L}$., $\times 3$.

67. Longitudinal section of flower of Shoertia perennis $\mathbf{L}_{\mathbf{L}}, \times 3$.

68. Lower part of a petal of Serertia perennis $L_{\text {. }}$, with the two nectariferous epiblastemes, $\times 8$.

69. Longitudinal section of one of the nectariferous epiblastemes from the petals of Swertia perennis, $\times 10$.

70. Longitudinal section of a short-styled flower of Menyanthes trifoliata L., $\times 2$. 
Fra.

71. Front view of flower of Melampyrum pratense L., $\times 6$. The lower lip cut away.

72. Flower of Gentiana nana Wulf., seen from above, $\times 5$. The aperture of the flower is seen to be closed by eight fringed epiblastemes.

73. Longitudinal section of flower of Symphytum officinale L., $\times 2$.

74. Two stamens alternating with two prickly epiblastemes, from flower of Symphytum officinale $\mathrm{L}_{\text {, }} \times 3$.

75. Lateral view of flower of Tellima grandiflora Lindl., $\times 2$.

76. Longitudinal section of flower of Soldanella alpina $\mathrm{L}, \times 2$.

\section{Plate III.}

77. Lateral view of a petal of Nigella elata $\mathrm{L}_{\text {, }} \times 5$.

78. Longitudinal section of a petal of Nigella elata L., $\times 5$.

79. A petal of Nigella sativa L., seen from above, $\times 7$.

80. A petal of Nigella sativa $L$, robbed of its lid-shaped appendage, seen from above, $\times 7$.

81. Longitudinal section of flower of Passiflora vespertilio L., $\times 2$.

82. Front view of flower of Cuphea platycentra Planch., $\times 3$.

83. Longitudinal section of flower of Parnassia palustris L., $\times 2$.

84. A single nectary from flower of Parnassia palustris $L$, seen from the side turned towards the ovary, $\times 2$.

85. Longitudinal section of flower of Cobcea scandens Cav.; natural size.

86. Longitudinal section of the nectar-cavity of flower of Epilobium angustifolium L., $\times 2$. The petals cut off.

87. Longitudinal section of flower of Mamillaria glochidiata Mart., $\times 3$.

88. Longitudinal section of flower of Campanula barbata L., $\times 2$.

89. Stamen from flower of Campanula barbata. The dilated and hollowed base of the stamen is seen from the side turned towards the style, $\times 1 \frac{1}{2}$.

90. Longitudinal section of flower of Potentilla micrantha Ram., $\times 5$. 


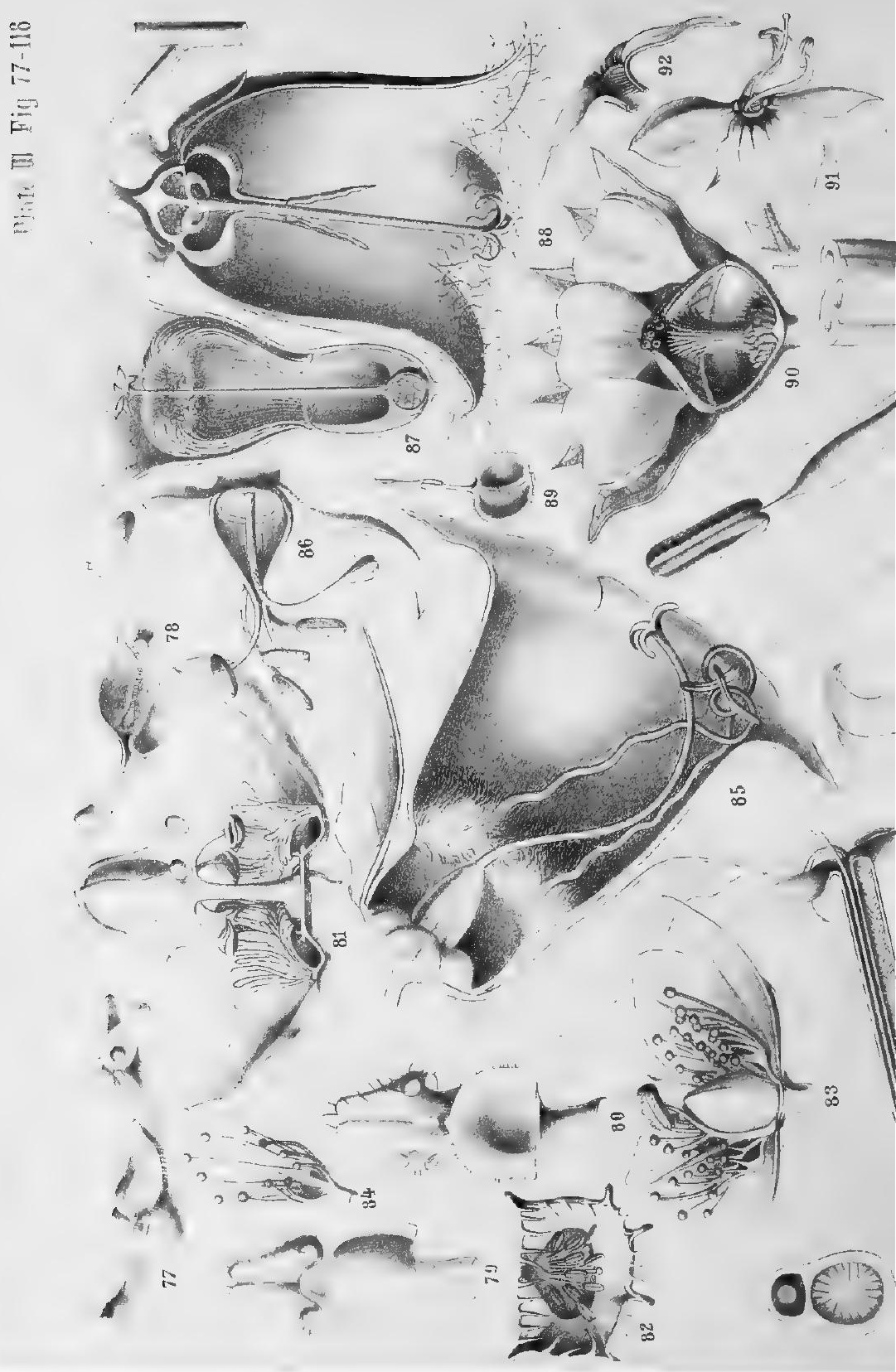



\section{Explanation of the Plates.}

Fig.

91. Lateral view of flower of Veronica Chamodrys $\mathrm{L} ., \times 3$.

92. Longitudinal section of the corolla of Veronica Chamcedrys I., $\times 3$.

93. Front view of flower of $V$ eronica officinalis $\mathrm{L} ., \times 4$.

94. Longitudinal section of flower of Veronica officinalis L., $\times 4$.

95. Side view of the lower half of the ovary, of a stamen, and of the lower part of a segment of the perianth of Tulipa silvestris L., $\times 2$.

96. Longitudinal section of flower of Lonicera alpigena $\mathrm{L}_{.}, \times 2$.

97. Longitudinal section of flower of Centranthus ruber (L.), $\times 4$.

98. Transverse section made across the middle of the corolla of Centranthus ruber (L.), $\times 12$.

99. Longitudinal section of flower of Horminum pyrenaicum L., $\times 2$.

100. Transverse section of flower of Horminum pyrenaicum $\mathbf{L}$. The section made just in front of the weel at the bottom of the corolla, $\times 2 \frac{1}{2}$.

101. Longitudinal section of flower of Phlox paniculata L, $\times 2$.

102. Longitudinal section of the lower part of flower of Phlox paniculata $\mathrm{L}$, $\times 6$.

103. Longitudinal section of flower of Vaccinium oxycoccos L., $\times 3$. 104. Transverse section of the whorl of stiff filaments of Vaccinium oxycoccos L., with their edges beset with trichomes, $\times 3$.

105. Transverse section of the corolla of Malva rotundifolia $\mathrm{I}_{\text {. }}$; the section is made near the base of the corolla, $\times 5$.

106. Longitudinal section of lower part of flower of $V$ inca herbacea W. K., $\times 4$. The tips of the petals cut off.

107. Style of flower of Vinca herbacea W. K., $\times 4$.

108. Stamen of Vinca herbacea W. K., seen from the side turned towards the style.

109. Longitudinal section of flower of Haplophyllum patavinum L., $\times 4$.

110. Longitudinal section of flower of Arctostaphylos uva ursi (L.), $\times 6$.

11. Longitudinal section of flower of Cirsium spinosissimum L., $\times 2$. 
Fra.

112. Longitudinal section of lowest part of flower of Daphne Blagayana Freyer., $\times 12$.

113. Inflorescence of Dianthus prolifer $\mathrm{L}_{\text {, }} \times \mathrm{I}_{\frac{1}{2}}$. The tough membranous bracts closely invest 5-7 crowded flowers, which, one after another, protrude their petals, stamens, and styles beyond the bracts, each opening and closing twice. Each flower occupies two days in blossoming. After this the parts of the flower which are above the bracts shrivel up, and another flower protrudes its petals, stamens, and style.

114. A single flower of an inflorescence of Dianthus prolifer on its first day of blossoming, $\times 1 \frac{1}{2}$.

115. Flower of Silene nutans L. as seen at midnight, natural size.

116. The same flower of Silene nutans $\mathrm{L}$. the following- midday, natural size.

117. Stipule of Impatiens tricornis Wallich., transformed into a nectary, seen from below. On the most convex part is a drop of nectar ; to the right of the nectary is the petiole; and behind the nectary is seen the forked peduncle, springing from the axil of the leaf ; $\times 10$.

118. Section of the stipule of Impatiens tricornis Wallich, having the function of a nectary, $\times 10$. 


\section{INDEX OF THE NAMES OF PLANTS.}

A.

Acacia longifolia W., 136.

Acer platanoides L., 59.

Aconitum, 28, 38, 112, 125, 142.

142. paniculatum Lam., 52, 112,

- vulparia Rchb., 52.

Aschmea, 40.

- ccerulea Beer., 41, 101.

Alchemilla vulgaris L., 37, 38.

Alisma, 44.

Allionia, 52.

Allosorus crispus (L.), 38.

Alnus, 49.

Alsine viscosa Schreb., 52.

Alyssum calycinum L., 96.

Amaryllis, 123.

— belladonna L., 123.

Ampelopsis hederacea L., 125.

Amygdalec, 103.

Anchusa arvensis, 83.

Androsace, 113.

- glacialis Hoppe, 113.

Angelonia grandiflora C. Hub., 58.

Anthyllis, 123.

- alpestris Kit., 20.

Antirrhinum, 100.

- majus, 23.

Aphyllanthes monspeliensis L., 120.

Aposeris foetida (L.), 29.

Aquilegia, 52, 112.

Arctostaphylos alpina L., 87.

- wva ursi (L.), 30, 87.

Aristolochia, 29.

Asarum, 29.

Asclepias, 68.

Asperifolia, 21, 71, 78, 83, 102.

Asperula longiflora W. K., 111.
Asperula odorata L., 29.

Atractylis, 75.

Atragene, 105.

- alpina L., 105.

Atropa belladonna L., 29, 88.

Azalea procumbens L., 30.

B.

Ballota, 29, 83.

Begonia manicata Vis., 28.

Betula, 49.

Billbergia, 40.

- pyramidalis Ldl., 41.

Bromeliacece, 41, 55.

Bupleurum rotundifolium L., 128.

Butomus, 44.

Cactece, 103.

Calaminthd alpina, 87.

Calceolaria, 117.

- Pavonii Benth, 117.

Campanula, 102, 103.

- barbata, 35, 81, 86, 103.

- Carpathica, 103.

- patula L., 103.

—_persicifolia L., 103.

- - pyramidalis L., 103.

- rapunculoides L., 103.

- spicata L., 103.

- trachelium L., 103.

Campanulacees, 37, 86.

Caprifoliacec, 128.

Carduns, 75.

Carex firma Host., 30.

Carlina vulgaris L., 71, 75.

Caryophyllacea, 12, 21, 52, 125, 130 ,

$132,135,144$.

Catalpa syringafolia Sims., 136,

137. 
Centaurea, 72.

- cyanus L., 72, 73, 75.

- pseudo-phrygia C.A.M., 37.

Centranthus angustifolius L., 89.

- ruber L., 24, 89.

Cerastium, 61.

Chelidonium, 29.

Chelone, 121.

Chenopodium Bonus Henricus L,, 38.

Circcea alpina L., 61.

Cirsium, 86, 144.

- eriophorum (L.), 98.

- spinosissimum (L.), 38, 86.

Cistus ladaniferus L., 52, 60.

- populifolius, 52 .

Clematis, 105.

Cleonia lusitanica L., 97.

Clerodendron fragrans W., 137.

Cobcea scandens Cav., 88.

Colchicum, 11, 29, 36.

Comarum palustre L., 48.

Oompositce, 21, 81, 86.

Conium, 29.

Convolvulus, 120.

- arvensis L., 120.

- sepium, 120.

- siculus L., 120.

- tricolor L., 120.

Corydalis, 100.

Crassulacea, 29.

Crepis paludosa (L.), 60.

- pulchra L., 44.

Crucianella gilanica Trin., 111.

Cruciferce, 21.

Cuphea micropetala H. B. K., 62, 64,65 .

— platycentra Planch., 18, 95. Cuscuta, 37.

Cyclamen, 29, 102.

- europøum, 129.

Cyclostigma, 108.

Cynarocephaloe, 75.

Cynoglossum pictum Ait., 100.

Cytisus alpinus Mill., 36.
D.

Daphne Blagayana Freyer., 88.

- striata Tratt., 30.

Datura, 28.

- stramonium L., 38.

Dianthus prolifer L., 127. viscidus M. B., 52.

Diclytra, 100.

Dictamnus, 52.

Digitalis ambigua Murs., 18.

Dipsacus laciniatus L., 41.

Dodecatheon, 102.

Drosophyllum lusitanicum (L.),

51.

Dryas, 103.

— octopetala L., 30.

E.

Empetrum, 30.

Epilobium angustifolium L., 102.

Epimedium alpinum L., 51.

Eremurus tauricus Stev., 18.

Erica, 102.

Erodium, 61.

Eryngium alpinum L., 75.

- campestre L., 38.

Euphorbia, 29.

Euphrasia, 36, 38, 81 .

_Lngiflora, Vahl., 111.

-_viscosa L., 52.

F.

Fedia graciliflora, 111.

Festuca alpestris R. Sch., 31.

Fumaria, 100.

G.

Galanthus nivalis L., 130.

Galeopsis, 114.

- grandiflora, 71, 114. pubescens, 71 . Tetrahit, 71.

Gaya simplex, 37.

Gentiana, 108, 120, 125, 129, 142. 
Gentiana cestiva, 108.

- bavarica, 18, 108.

—_iliata L., 81, 94.

- firma (Neilr. var.), 120, 129.

- germanica W., 18, 83.

— imbricata Froeb., 108.

- Iutea L., 43.

- nana Wulf., 82, 83.

- nivalis L., 108.

— pannonica Scop, 43.

—pumila L., 108.

- punctata L., 43.

—utriculosa L., 108.

- verna L., 108.

Gentianea, 84, 128.

Georginia, 36.

Geranium, 52, 61, 82, 87, 88, 112. - palustre L., 87.

- Robertianum L., 29, 112.

- silvaticum L., 52, 87.

Geum, 103.

Gladiolus, 102.

Globularia cordifolia L., 30.

- nudicaulis L., 30.

Gymnadenia odoratissima (L.), 36, 112.

\section{H.}

Haplophyllum patavinum (L.), 85.

Hedysarum obscurum L., 37.

Helleborus, 28.

Hemerocallis, 102.

Hesperis tristis L., 130.

Hippocrepis, 123.

- comosa L., 123.

Holosteum glutinosum M.B., 52.

Horminium pyrenaicum L, 83.

Hottonia, 44.

Hydrocharis, 44.

Hyoscyamus, 38.

Hypecoum, 107.

- procumbens L., 107.

Hypericum, 61.

I.

Impatiens tricomis Wall, , 137, 138.
Ipomcea violacece Hort., 88.

Iris tuberosa L., 18.

J.

Juglans, 49.

Juncus bufonius L., 30. trifidus L., 30.

$\mathrm{K}$.

Kentrophyllum, 75.

Knartia dipsacifolia Host, 72.

L.

Labiatce, 52, 61, 71, 75, 83, 144.

Lactuca, 29, 68.

- augustana, 67.

- sativa L., 67.

Lagoecia cuminoides L., 97.

Lamium, 29, 83.

Lamprococcus, 40.

-Weilbachii C. Koch., 41.

Lapsana communis L., 44.

Lathrowa, 37.

Ledum, 52.

palustre, 60.

Leonurus, 77, 83.

- heterophyllus, 76, 83.

Lepidium draba, L., 29.

- perfoliatum L., 128.

Lilies, 36, 84.

Lilium chalcedonicum L., 84.

- martagon L., 111.

Linaria, 100.

- alpina L., 100.

- vulgaris L., 29.

Linncea, 10.

- borealis, 10, 51, 61 .

Linum catharticum L., 111. viscosum L., 52, 111.

Listera ovata R. Br., 52.

Lonicera alpigena L., 87.

— caprifolium L., 125.

- etrusca Santi, 125. nigra $\mathrm{L}_{\text {. }}, 87$.

sempervirens L., 87. 
Lonicera xylosteum L., 87.

Lotus, 123.

Lychnis viscaria L, , 52, 53, 60.

Lycium barbarum L., 88.

Lycopus, 87, 90.

\section{M.}

Malvacece, 85.

Malva rotundifolia, 85.

Mallows, 36.

Mamillaria glochidiata Mart., 103, 104.

Marrubium, 10.

- peregrinum L., 38, 88.

Matthiola varia S. Sm., 111.

Medicago, 123.

Melampyrum, 77.

- pratense L., 77.

Melianthus, 23, 106.

Mentha, 90.

Menyanthes trifoliata L., 87.

Mesembryanthemea, 103.

Milfoil, 37.

Monotropa, 37.

— glabra Bernh., 65.

— hypopitys L., 86.

\section{N.}

Narcissus juncifolius Requ., 110.

Nardus stricta L., 30, 38.

Neottia, 37.

Nicandra physaloides (L.), 102.

Nigella, 101.

-_ damascena L., 97.

- elata L., 101.

- sativa L., 101.

Nigritella angustifolia Rich., 36.

Nuphar, 44.

Nymphoea, 44.

\section{o.}

Enothera grandiflora Lam., 110. Onobrychis, 123.

Ophelia, 84.

Ophetia Wilfordii A. Kern, 108.

Opuntia, 103.
Origanum, 90.

Orobanche, 37, 81 .

P.

Paderota ageria L., 87.

_ bonarota L., 87.

Pcoonia, 28.

Papaver, 29.

Parnassia, 36.

- palustris L., 91.

Passiflora, 84.

- vespertilio L., 84 .

Pedicularis, 12, 20, 76, 77, 81, 111,

$125,142$.

_- foliosa L., 76.

- jacquini Koch, 20.

- incarnata Jacqu., 20.

— EEderi Vahl, 76.

- recutita L., 76.

- rosea Jacqu., 76.

— tubiflora Fisch., 111. verticillata L., 76.

Pentastemon, 15, 121.

__ gentianoides (H.B.), 15, 121.

Persica, 103.

Phlomis, 83.

Phlox paniculata L., 83.

Phygelius capensis, 23, 106.

Physalis atriplicifolia Jacqu., 85.

Phyteuma, 102.

- hemispharicum L., 36.

Phytolacca, 29.

Pinguicula, 55, 57.

- alpina L., 55, 57.

- grandiflora Lam., 55.

—_ leptoceras Rchb., 55. vulgaris L., 55.

Pinks, 36.

Pirola uniflora, L., 36.

Plantago major L., 30.

Platanthera, 112. bifolia L., 36.

Plumbago, 10, 51. europcea L., 50, 61.

Polemonium cceruleum L., 88. 


\section{Index of the Names of Plants.}

Polygonum amphibium L., 44, 46, 49.

Polytrichum, 39.

Populus, 49.

Potentilla, 104.

- mierantha Ram., 104.

Primula, 113.

- glutinosa Wulf., 18, 55.

- hirsuta All., 55.

- longiflora All., 111.

— minima L., 87.

— tiroliensis Schott., 55.

-_ villosa Jacqu., 55.

- viscoвa All., 55.

Prunella, 83.

Prunus, 61.

- avium L., 136.

— laurocerasus L., 137.

- _- armeniaca, 137.

Pulicaria viscosa L., วิ2, 137.

R.

Ramondia, 102.

Ranunculacere, 105.

Ranunculus, 104.

- glacialis L., 37, 104, 107.

Rhinanthus, 142.

- angustifotius Gmel., 97.

Rhododendron, 30, 125, 142.

- ferrugineum L., 38, 87.

- hirsutum L., 87.

Ribes grossularia L., 61 .

Ricinus, 136.

Robinia viscosa Vent., 51.

Rosaceo, 103.

Rumex alpinus L., 38.

S.

Sagittaria, 44.

Salicinere, 144.

Salix daphnoides Vill., 69.

—_ pentandra L., 59.

Salvia, 51.

Sambucus ebulus L., 29.

Saponaria glutinosa M. B., 58.
Saponaria porrigens L., 58.

Saxifraga controversa Sternbg. 61.

Saxifragece, 21, 52, 61.

Scabiosa, 37.

Serophulariacece, 52, 75, 83.

Scutellaria, 116, 117.

- albida L., 116.

Sedum dasyphyllum L., 61 .

Sempervivum arachnoideum L.,

98.

Senecio cordatus Koch., 37.

- doronicum L., 37. viscosus L., 58.

Silenece, 52, 130.

Silene ciliata Pourr., 131.

— inaperta L., 53.

- Kitaibelii Vis., 131.

-..- longiflora Ehrh., 131, 133.

__ muscipula L., 52, 53.

- noctiflora L., 58.

— nutans L., 53, 54, 133, 134.

- paradoxa L., 131.

— saxifraga, L., 131.

_ vallesia L., 131.

- - viscosa Pers., 52.

— viscosissima Ten., 52.

Smyrnium perfoliatum Mill., 128.

Solanacene, 102.

Solanum, 28.

Soldanella, 144.

- alpina L., 145-151.

__- montana Mik., 149-15l.

Spergula, 61.

Stachys, 83.

Stellavia cerastoides L., 61.

Sternbergia, 11.

Stratiotes, 44.

Swertia, 84 .

- perennis L., 84.

Symphytum, 78.

- officinale L., 78.

T.

Tellima grandiflora Ldl., 81, 94, 95. 
Thesium, 81.

Thistles, 38.

Thymus, 90.

— serpyllum L., 81.

Tillandsia, 40.

Tricyrtes pilosa Wall., 106.

Trifolium, 123.

- alpinum L., 37.

— badium Schreb., 10.

Trisxago, 81.

Tropceolum, 94, 112.

- majus L. 94.

Tulipa silvestris L., 88.

U.

Utricularia, 44.

$\mathrm{V}$.

Vaccinium oxycoccos L., 86. Vitis Idoea L., 30.
Veratrum, 29.

Verbascum, 37.

Verbena officinalis L., 83.

Verbenacece, 83.

Veronica, 83.

Veronica Chamadrys L., 84. officinalis L., 84.

Viburnum Opulus L., 137. Tinus L., 137.

Vicia, 137. faba L., 136.

_ sativa L., 136.

- sepium L., 136.

Villarsia, 44.

Vinca herbacea W.K., 89.

Viola, 123. odorata, 36.

Vriesia psatticina Morr., 4l, 55.

$\mathrm{X}$.

Xanthium spinosum L., 38. 


\section{A LIST OF \\ C. KEGAN PAUL AND CO'S $P U B L I C A T I O N S$.}




\section{A LIST OF \\ C. KEGAN PAUL AND CO.'S PUBLICATIONS.}

ABBEY (Henry).

Ballads of Good Deeds, and Other Verses. Fcap. 8vo. Cloth gilt, price $5 s$.

ABDULLA (Hakayit). Autobiography of a Malay Munshi. Translated by J. T. Thomson, F. R. G. S. With Photolithograph Page of Abdulla's MS. Post 8vo. Cloth, price 12s.

ADAMS (A. L.), M.A., M.B., F.R.S., F.G.S.

Field and Forest Rambles of a Naturalist in New Brunswick. With Notes and Observations on the Natural History of Eastern Canada. Illustrated. 8vo. Cloth, price I4s.

ADAMS (F. O.), F.R.G.S.

The History of Japan. From the Earliest Period to the Present Time. New Edition, revised. 2 volumes. With Maps and Plans. Demy 8vo. Cloth, price 21s. each.

ADAMS (W, D.).

Lyrics of Love, from Shakespeare to Tennyson. Selected and arranged by. $\$$ cap. 8vo. Cloth extra, gilt edges, price $3^{s} .6 d$.

Also, a Cheap Edition. Fcap. 8vo. Cloth, price $2 s .6 d$.

ADAMS (John), M.A.

St. Malo's Quest, and other Poems. Fcap. 8vo. Cloth, 55 .

\section{ADON.}

Through Storm \& Sunshine. Illustrated by $M$. E. Edwards, A. T. H. Paterson, and the Author. Crown 8vo. Cloth, price 7s. $6 d$.

A. J. R.

Told at Twilight; Stories in Verse, Songs, \&ec. Fcap. 8vo. Cloth, price $3 s .6 z^{*}$.
A. K. H. B.

A Scotch Communion Sunday, to which are added Certain Discourses from a University City. By the Author of "The Recreations of a Country Parson." "Second Edition. Crown 8vo. Cloth, price ss.

ALBERT (Mary).

Holland and her Heroes to the year 1585. An Adaptation from "Motley's Rise of the Dutch Republic. Small crown 8vo. Cloth, price, 45.60 .

ALLEN (Rev. R.), M.A. Abraham ; his Life, Times, and Travels, 3,800 years ago. Second Edition. With Map. Post 8vo. Cloth, price 6s.

ALLEN (Grant), B.A. Physiological $\mathbb{E}$ sthetics. Large post 8vo. $g s$.

AMOS (Prof. Sheldon). Science of Law. Third Edition. Crown 8vo. Cloth, price 5s. Volume $\mathbf{X}$. of The International Scientific Series.

ANDERSON (Rev, C.), M.A. New Readings of Old Parables. Demy 8vo. Cloth, price 4s. $6 d$.

Church Thought and Church Work. Edited by. Second Edition. Demy 8vo. Cloth; price 7s. $6 d$.

The Curate of Shyre. Second Edition. 8vo. Cloth, price 7s. $6 d$.

ANDERSON (Col. R. P.).

Victories and Defeats. An Attempt to explain the Causes which have led to them. An Officer's Manual. Demy 8vo. Cloth, price I4s. 
ANDERSON (R. C.), C.E. Tables for Facilitating the Calculation of every Detail in connection with Earthen and Masonry Dams. Royal 8vo. Cloth, price $\delta_{2} 25$.

ANSON (Lieut.-Col. The Hon. A.), V.C., M.P.

The Abolition of Purchase and the Army Regulation Bill of 187r. Crown 8vo. Sewed, price Is. Army Reserves and Militia Reforms. Crown 8vo. Sewed, price $r s$.

Story of the Supersessions. Crown 8vo. Sewed, price $6 d$.

ARCHER (Thomas).

About my Father's Business. Work amidst the Sick, the Sad, and the Sorrowing. Crown 8vo. Cloth, price $5 s$.

ARGYLE (Duke of).

Speeches on the Second Reading of the Church Patronage (Scotland) Bill in the House of Lords, June 2, 1874; and Earl of Camperdown's Amendment, June 9, 1874, placing the Election of Ministers in the hands of Ratepayers. Crown 8vo. Sewed, price Is.

Army of the North German Confederation.

A Brief Description of its Organization, of the Different Branches of the Service and their role in War, of its Mode of Fighting, \&c., \&c. Translated from the Corrected Edition, by permission of the Author, by Colonel Edward Newdigate. Demy 8vo. Cloth, price $5 s$.

AUBERTIN (J.J.).

Camoens' Lusiads. Portuguese Text, with Translation by. With Map and Portraits. 2 vols. Demy 8vo. Price zos.

Aunt Mary's Bran Pie. By the author of "St. Olave's." Illustrated. Cloth, price $3^{s .} 6 d$.

Aturora.

A Volume of Verse. Fcap. 8vo. Cloth, price $5 s$.

BAGEHOT (Walter).

Some Articles on the Depreciation of Silver, and Topics connected with it. Demy 8vo. Price ss.
BAGEHOT (Walter)-continued. Physics and Politics; or, Thoughts on the Application of the Principles of "Natural Selection" and "Inherítance" to Political Society. Fourth Edition. Crown 8vo. Cloth, price 45 .

Volume II. of The International Scientific Series.

The English Constitution. A New Edition, Revised and Corrected, with an Introductory Dissertation on Recent Changes and Events. Crown 8vo. Cloth, price 7s. $6 \%$.

Lombard Street. A Description of the Money Market. Seventh Edition. Crown 8vo. Cloth, price $75.6 d$.

BAGOT (Alan).

Accidents in Mines : their Causes and Prevention. Crown 8 vo. Cloth, price $6 s$.

BAIN (Alexander), LL.D.

Mindand Body: the Theories of their relation. Fifth Edition. Crown 8vo. Cloth, price $4 s$.

Volume IV. of The International Scientific Series.

BAKER (Sir Sherston, Bart.). Halleck's International

Law; or Rules Regulating the Intercourse of States in Peace and War. A New Edition, revised, with Notes and Cases. 2 vols. Demy 8 vo. Cloth, price $38 s$.

BALDWIN (Capt. J. H.), F.Z.S. The Large and Small Game of Bengal and the North-Western Provinces of India. 4to. With numerous Illustrations. Second Edition. Cloth, price zIs.

BANKS (Mrs. G. L.). God's Providence House. New Edition. Crown 8vo. Cloth, price $3 s .6 d$.

BARING (T. C.), M.A., M.P. Pindar in English Rhyme. Being an Attempt to render the Epinikian Odes with the principal remaining Fragments of Pindar into English Rhymed Verse. Small Quarto. Cloth, price 7s.

BARLEE (Ellen).

Locked Out: a Tale of the Strike. With a Frontispiece. Royal I6mo. Cloth, price is. 6d. 
BARNES (William).

An Outline of English Speechcraft. Crown 8vo. Cloth, price $4 s$.

BARTLEY (George C. T.). Domestic Economy : Thrift in Every Day Life. Taught in Dialogues suitable for Children of all ages. Small crown 8vo. Cloth, limp, 2.5 .

BAUR (Ferdinand), Dr. Ph.

A Philological Introduction to Greele and Latin for Students. Translated and adapted from the German of. By C. KEgan Paul, M.A. Oxon., and the Rev, E. D. STONE, M.A., late Fellow of King's College, Cambridge, and Assistant Master at Eton. Crown 8vo. Cloth, price $6 s$.

BAYNES (Rev. Canon R, H.) At the Communion Time. A Manual for Hojly Communion. With a preface by the Right Rev. the Lord Bishop of Derry and Raphoe. Cloth, price xs. $6 d$.

* * Can also be had bound in French morocco, price $2 s .6 d$. ; Persian morocco, price $3 s$. ; Calf, or Turkey morocco, price 3s. $6 d$.

Home Songs for Quiet Hours. Fourth and cheaper Edition. Fcap. 8vo. Cloth, price $2 s, 6 d$. This may also be had handsomely bound in morocco with gilt edges.

BECKER (Bernard H.).

The Scientific Societies of London. Crown 8vo. Cloth, price $5 s$.

BELLINGHAM (Henry), Barrister-at-Law.

Social Aspects of Catholicism and Protestantism in their Civil Bearing upon Nations. Translated and adapted from the French of M. le Baron de Haulleville. With a Preface by $\mathrm{His}$ Eminence Cardinal Manning. Crown 8vo. Cloth, price $6 s$.

BENNETT (Dr. W. C.).

Narrative Poems \& Ballads. Fcap. 8vo. Sewed in Coloured Wrapper, price Is.
BENNETT (Dr. W. c.)-conlinued.

Songs for Sailors. Dedicated by Special Request to $H$. R. H. the Duke of Edinburgh. With Steel Portrait and Illustrations. Crown 8vo. Cloth, price $3 s .6 d$.

An Edition in Illustrated Paper Covers, price is.

Songs of a Song Writer. Crown 8vo. Cloth, price 6s.

BEN NIE (Rev. J. N.), M.A.

The Eternal Life. Sermons preached during the last twelve years. Crown 8vo. Cloth, price $6 s$.

BERNARD (Bayle).

Samuel Lover, the Life and Unpublished Works of. In 2 vols. With a Steel Portrait. Post 8vo. Cloth, price 2xs.

BERNSTEIN (Prof.).

The Five Senses of Man. With gr Illustrations. Second Edition. Crown 8vo. Cloth, price 5 .

Volume XXI, of The International Scientific Series.

BETHAM - EDWARDS (Miss M.).

Kițty. With a Frontispiece. Crown 8 vo. Cloth, price $6 s$.

BISCOE (A. C.).

The Earls of Middleton, Lords of Clermont and of Fettercairn, and the Middleton Family. Crown 8vo. Cloth, price ros. $6 d$.

BISSET (A.)

History of the Struggle for Parliamentary Government in England. 2 vols. Demy 8vo. Cloth, price 24s.

BLASERNA (Prof. Pietro).

The Theory of Sound in its Relation to Music. With numerous Illustrations. Crown 8vo. Cloth, price $5 s$.

Volume XXII. of The International Scientific Series.

Blue Roses ; or, Helen Malinofska's Marriage. By the Author of "Véra." 2 vols. Fifth Edition. Cloth, gilt tops, r2s.

*** Also a Cheaper Edition in 1 vol. With frontispiece. Crown 8vo. Cloth, price $6 s$. 
BLUME (Major W.).

The Operations of the German Armies in France, from Sedan to the end of the war of $1870-$ 7x. With Map. From the Journals of the Head-quarters Staff. Translated by the late E. M. Jones, Maj. zoth Foot, Prof. of Mil. Hist., Sandhurst. Demy 8vo. Clöth, price gs.

BOGUSLAWSKI (Capt. A. von). Tactical Deductions from the War of I870-7I. Translated by Colonel Sir Lumley Graham, Bart., late I8th (Royal Irish) Regiment. Third Edition, Revised and Corrected. Demy 8vo. Cloth, price $7 s$.

BONWICK (J.), F.R.G.S.

Egyptian Belief and Modern Thought. Large post 8 vo. Cloth, price ros. $6 d$.

Pyramid Facts and Fancies, Crown 8vo. Cloth, price 5s.

The Tasmanian Lily. With Frontispiece. Crown 8vo. Cloth, price 5 s.

Mike Howe,the Bushranger of Van Diemen's Land. . With Frontispiece. Crown 8vo. Cloth, price 5 .

BOSWELL (R. B.), M.A., Oxon. Metrical Translations from the Greek and Latin Poets, and other Poems. Crown 8vo. Cloth, price $5 s$.

BOWEN (H. C.), M. A.

Studies in English, for the use of Modern Schools. Small Crown 8vo. Cloth, price is. $6 \dot{d}$.

BOWRING (L.), C.S.I.

Eastern Experiences. Illustrated with Maps and Diagrams.

Demy 8vo. Cloth, price $16 s$.

BOWRING (Sir John).

Autobiographical Recollections. With Memoir by Lewin B. Bowring.

Demy 8vo. Price 14s.

BRADLEY (F. H.).

Ethical Studies. Critical Essays in Moral Philosophy. Large post 8vo. Cloth, price 9s.
BRADLEY (F. H.)-continued. Mr. Sidgwick's Hedonism : an Examination of the Main Argument of "The Methods of Ethics." Demy 8vo., sewed, price 2s. $6 d$.

Brave Men's Footsteps.

By the Editor of "Men who have Risen." A Book of Example and Anecdote for Young People. With Four Illustrations by C. Doyle. Third Edition. Crown 8vo. Cloth, price 3 s. $6 d$.

BRIALMONT (Col. A.).

Hasty Intrenchments. Translated by Lieut. Charles A. Empson, R.A. With Nine Plates. Demy 8vo. Cloth, price $6 s$.

BROOKE (Rev. J. M. S.), M. A. Heart, be Still. A Sermon preached in Holy Trinity Church, Southall. Imperial $32 \mathrm{mo}$. Sewed, price $6 d$.

BROOKE (Rev. S. A.), M. A.

The Late Rev. F. W. Robertson, M.A., Life and Letters of. Edited by.

I. Uniform with the Sermons. 2 vols. With Steel Portrait. Price 7s. $6 d$.

II. Library Edition. 8vo. With Two Steel Portraits. Price I2s.

III. A Popular Edition, in $x$ vol. 8vo. Price 6s.

Theology in the English Poets. - Cowper, Coleridge, WORDSWORTH, and BURNS. Third Edition. Post 8 vo. Cloth, price gs.

Christ in Modern Life. Eleventh Edition. Crown 8vo. Cloth, price $7 s .6 d$.

Sermons. First Series. Ninth Edition. Crown 8vo. Cloth, price 6s. Sermons. Second Series. Third Edition Crown 8vo. Cloth, price $7 s$.

The Fight of Faith. Sermons preached on various occasions. Third Edition. Crown 8vo. Cloth, price $7 s, 6 d$.

Frederick Denison Maurice: The Life and Work of. A Memorial Sermon. Crown 8 vo. Sewed, price rs. 
BROOKE (W. G.), M.A.

The Public Worship

Regulation Act. With a Classified

Statement of its Provisions, Notes, and Index. Third Edition, revised and corrected. Crown 8vo. Cloth, price $3 s$. $6 d$.

Six Privy Council Judgments-r850-1872. Annotated by. Third Edition. Crown 8vo. Cloth, price $9 s$.

BROUN (J. A.).

Magnetic Observations at Trevandrum and Augustia Malley. Vol. I. 4to. Cloth, price $5_{3}$.

The Report from above, separately sewed, price $2 \mathrm{t} s$.

BROWN (Rev. J. Baldwin), B.A. The Higher Life. Its Reality, Experience, and Destiny. Fourth Edition. Crown 8vo. Cloth, price 7s. $6 d$.

Doctrine of Annihilation in the Light of the Gospel of Love. Five Discourses. Third Edition. Crown 8vo. Cloth, price 2s. $6 d^{\prime}$.

BROWN (J. Croumbie), LL.D.

Reboisement in France; or, Records of the Replanting of the Alps, the Cevennes, and the Pyrenees with Trees, Herbage, and Bush. Demy 8vo. Cloth, price izs. $6 d$.

The Hydrology of Southern Africa. Demy 8vo. Cloth, price Ios. $6 d$.

BRYANT (W. C.)

Poems. Red-line Edition. With 24 Illustrations and Portrait of the Author. Crown 8vo. Cloth extra, price $7 s .6 d$.

A Cheaper Edition, with Frontispiece. Small crown 8 vo. Cloth, price 3s. $6 d$.

BUCHANAN (Robert).

Poetical Works. Collected Edition, in 3 vols, with Portrait. Crown 8\%o. Cloth, price 6s. each.

Master-Spirits. Post 8vo. Cloth, price Ios. $6 d$.

BULKELEY (Rev, H. J.).

Walled in, and other Poems. Crown 8vo. Cloth, price 5s.
BURCKHARDT (Jacob).

The Civilization of the Period of the Renaissance in Italy. Authorized translation, by S. G. C. Middlemore. 2 vols. Demy 8 vo. Cloth, price 24s.

BURTON (Mrs. Richard).

The Inner Life of Syria, Palestine, and the Holy Land. With Maps, Photographs, and Coloured Plates. 2 vols. Second Edition. Demy 8vo. Cloth, price 24s.

BURTON (Capt. Richard F.).

The Gold Mines of Midian and the Ruined Midianite Cities. A Fortnight's Tour in North Western Arabia. With numerous Illustrations. Second Edition. Demy 8vo. Cloth, price $18 s$.

\section{CALDERON.}

Calderon's Dramas: The Wonder-Working Magician-Life is a Dream-The Purgatory of St. Patrick. Translated by Denis Florence MacCarthy. Post 8vo. Cloth, price Ios.

CARLISLE (A. D.), B. A. Round the World in 1870 . A Volume of Travels, with Maps. New and Cheaper Edition. Demy 8vo. Cloth, price $6 s$.

CARNE (Miss E. T.).

The Realm of Truth. Crown 8vo. Cloth, price 5s. $6 d$.

CARPENTER (E.).

Narcissus and other Poems. Fcap. 8vo. Cloth, price 5 s.

CARPENTER (W. B.), LL.D., M.D., F.R.S., \&c.

The Principles of Mental Physiology. With their Applications to the Training and Discipline of the Mind, and the Study of its Morbid Conditions. Illustrated. Fourth Edition. 8vo. Cloth, price I2s.

CAVALRY OFFICER.

Notes on Cavalry Tactics, Organization, \&c. With Diagrams. Demy 8vo. Cloth, pricerzs. 
CHAPMAN (Hon. Mrs. E. W.). A Constant Heart. A Story. a vols. Cloth, gilt tops, price r2s.

Children's Toys, and some Elementary Lessons in General Knowledge which they teach. Illustrated. Crown 8vo. Cloth, price $5 s$.

CHRISTOPHERSON (The late Rev, Henry), M.A.

Sermons. With an Introduction by John Rae, LL.D., F.S.A. Second Series. Crown 8vo, Cloth, price 6s.

CLERK (Mrs. Godfrey).

'Ilâm en Nâs. Historical

Tales and Anecdotes of the Times of the Early Khalifahs. Translated from the Arabic Originals, Illustrated with Historical and Explanatory Notes. Crown 8vo. Cloth, price $7 s$.

CLERY (C.), Capt.

Minor Tactics, With 26 Maps and Plans. Third and revised Edition, Demy 8vo. Cloth, price $16 s$.

CLODD (Edward), F.R.A.S.

The Childhood of the World : a Simple Account of Man in Early Times. Third Edition. Crown 8vo. Cloth, price $3 s$.

A Special Edition for Schools. Price Is.

The Childhood of Religions. Including a Simple Account of the Birth and Growth of Myths and Legends. Third Thousand. Crown 8vo. Cloth, price $5 s$.

A Special Edition for Schools. Price Is. $6 d$.

COLERIDGE (Sara).

Pretty Lessons in Verse for Good Children, with some Lessons in Latin, in Easy Rhyme. A New Edition. Illustrated. Fcap. 8vo. Cloth, price 3 s. $6 d$.

Phantasmion. A Fairy Tale. With an Introductory Preface by the Right Hon. Lord Coleridge, of Ottery St. Mary. A New Edition. Illustrated. Crown 8vo. Cloth, price $7 s .6 d$.
COLERIDGE (Sara)-continued.

Memoir and Letters of Sara

Coleridge, Edited by her Daughter.

With Index. 2 vols. With Two

Portraits. Third Edition, Revised and Corrected. Crown 8vo. Cloth, price $24 s$.

Cheap Edition. With one Portrait.

Cloth, price 7s. 6 d.

COLLINS (Mortimer).

Inn of Strange Meetings, and other Poems. Crown 8vo. Cloth, price $5^{s}$.

COLLINS (Rev. R.), M.A.

Missionary Enterprise in the East. With special reference to the Syrian Christians of Malabar, and the results of modern Missions. With Four Illustrations. Crown 8 vo. Cloth, price $6 s$.

CONGREVE (Richard), M.A., M.R.C.P.L.

Human Catholicism. Two

Sermons delivered at the Positivist School on the Festival of Humanity, 87 and 88 , January $I_{2} 1875$ and 7876 . Demy 8vo. Sewed, price is.

Religion of Humanity; the Annual Address delivered at the Positivist School, Ig, Chapel-street, Lamb's Conduit-street, W.C., on the Festival of Humanity, January $I$, 1878 .

COOKE (M. C.), M.A., LL.D.

Fungi; their Nature, Influences, Uses, \&cc. Edited by the Rev. M. J. Berkeley, M. A., F. L. S. With Illustrations. Second Edition. Crown 8vo. Cloth, price 5 s.

Volume XIV, of The International Scientific Series.

\section{COOKE (Prof. J. P.)}

The New Chemistry. With 3 Illustrations. Third Edition. Crown 8vo. Cloth, price $5 s$.

Volume $1 \mathrm{X}$. of The International Scientific Series.

Scientific Culture. Crown 8vo. Cloth, price Is.

COOPER (T.T.), F.R.G.S,

The Mishmee Hills: an Account of a Journey made in an Attempt to Penetrate Thibet from Assam, to open New Routes for Commerce. Second Edition. With Four Illustrations and Map. Post 8 vo. Cloth, price sos. 62 . 
Cornhill Library of Fiction (The). Crown 8vo. Cloth, price 35. $6 d$, per volume.

Half-a-Dozen Daughters. By J. Masterman.

The House of Raby, By Mrs. G. Hooper.

A Fight for Life. By Moy Thomas.

Robin Gray. By Charles Gibbon.

One of Two; or, A LeftHanded Bride. By J. Hain Friswell.

God's Providence House. By Mrs. G. L. Banks.

For Lack of Gold. By Charles Gibbon.

Abel Drake's Wife. By John

Saunders.

Hirell. By John Saunders.

CORY (Lieut. Col. Arthur).

The Eastern Menace; or,

Shadows of Coming Events.

Crown 8vo. Cloth, price $5 s$.

Ione. A Poem in Four Parts.

Fcap. 8vo. Cloth, price 5 s.

Cosmos.

A Poem. Fcap. 8vo. Cloth, price 3s. $6 d$.

CóX (Rev. Sir G. W.), Bart.

A History of Greece from the Earliest Period to the end of the Persian War. 2 vols. Demy 8ro, Cloth, price $36 s$.

The Mythology of the Aryan Nations, \& vols. Demy 8vo. Cloth, price $28 s$.

A General History of Greece from the Earliest Period to the Death of Alexander the Great, with a sketch of the subsequent History to the present time. Crown 8vo. Cloth, price $7 s .6 \bar{d}$.

Tales of Ancient Greece. Third Edition. Small Crown 8vo. Cloth, price $6 s$.

School History of Greece. With Maps. Fcap. 8vo. Cloth, price 3s. $6 d$.

The Great Persian War from the Histories of Herodotus. New Edition. Fcap. 8vo. Cloth, price, $3^{s}, 6 d$.

A Manual of Mythology in the form of Question and Answer. Third Edition. Fcap. 8vo. Cloth, price $3^{s}$.
CoX (Rev. Samuel).

Salvator Mundi ; or, Is Christ the Saviour of all Men? Fifth Edition. Crown 8vo. Cloth, price $5 s$

CRESSWELL (Mrs. G.).

The King's Banner. Drama in Four Acts. Five Illustrations. 4to. Cloth, price Ios, $6 d$.

CROMPTON (Henry). Industrial Conciliation. Fcap. 8vo. Cloth, price 2s. $6 d$.

CUMMINS (H. I.), M. A. Parochial Charities of the City of London. Sewed, price Is.

CURWEN (Henry).

Sorrow and Song: Studies of Literary Struggle. Henry Mürger -Novalis-Alexander Petöf-Honoré de Balzac-Edgar Allan Poe - André Chénier. 2 vols. Crown 8vo. Cloth, price $\mathbf{r}_{5}$.

DANCE (Rev. C. D.).

Recollections of Four Years in Venezuela. With Three Illustrations and a Map. Crown 8vo. Cloth, price 7s. $6 d$.

D'ANVERS (N. R.).

The Suez Canal: Letters and Documents descriptive of its Rise and Progress in $1854-56$. By Ferdinand de Lesseps. Translated by. Demy'8vo. Cloth, price ros. $6 d$. Little Minnie's Troubles. An Every-day Chronicle. With Four Illustrations by W. H. Hughes. Fcap. Cloth, price $3 s, 6 d$.

Pixie's Adventures; or, the Tale of a Terrier. With 2I Illustrations. $16 \mathrm{mo}$. Cloth, price $45.6 d$.

DAVIDSON (Rev. Samuel), D.D., LL.D.

The New Testament, translated from the Latest Greek Text of Tischendorf. A new and thoroughly revised Edition. Post 8vo. Cloth, price ros. $6 d$.

Canon of the Bible: Its Formation, History, and Fluctuations. Second Edition. Small crown 8vo. Cloth, price ${ }^{5}$ s. 
DAVIES (G. Christopher).

Mountain, Meadow, and Mere: a Series of Outduor Sketches of Sport, Scenery, Adventures, and Natural History. With Sixteen Illustrations by Bosworth W. Harcourt. Crown 8vo. Cloth, price 6s.

Rambles and Adventures of Our School Field Club. With Four Illustrations. Crown 8vo. Cloth, price 5s.

DAVIES (Rev. J. L.), M.A.

Theology and Morality.

Essays on Questions of Belief and Practice. Crown 8vo. Cloth, price 7s. $6 d$.

DAWSON (George), M.A.

Prayers, with a Discourse on Prayer. Edited by his Wife. Fifth Edition, Crown 8vo. Price $6 s$.

Sermons on Disputed Points and Special Occasions. Edited by his Wife. Second Edition. Crown 8vo. Cloth, price 6s.

Sermons on Daily Life and Duty. Edited by his Wife. Second Edition. Crown 8vo. Cloth, price $6 s$.

DE L'HOSTE'(Col. E. P.).

The Desert Pastor, Jean Jarousseau. Translated from the French of Eugène Pelletan. With a Frontispiece. New Edition. Fcap. 8vo. Cloth, price $3 s .6 d$.

DE REDCLIFFE (Viscount Stratford), P.C., K.G., G.C.B.

Why am I a Christian? Fifth Edition. Crown 8vo. Cloth, price $3 s$.

DE TOCQUEVILLE (A.).

Correspondence and Conversations of, with Nassau William Senior, from 1834 to 1859 . Edited by M: C. M. Simpson. 2 vols. Post 8 vo. Cloth, price a1s.

DE VERE (Aubrey).

Alexander the Great. A Dramatic Poem. Small crown 8vo. Cloth, price $5 s$.

The Infant Bridal, and Other Poems. A New and Enlarged Edition. Fcap. 8vo. Cloth, price $7 s, 6 d$.
DE VERE (Aubrey).-continued. The Legends of St. Patrick, and Other Poems. Small crown 8vo Cloth, price 5s.

St. Thomas of Canterbury. A Dramatic Poenz. Large fcap. 8vo. Cloth, price $5 s$.

Antar and Zara : an Eastern Romance. INISFAIL, and other Poems, Meditative and Lyrical. Fcap. 8vo. Price 6s.

The Fall of Rora, the Search after Proserpine, and other Poems, Meditative and Lyrical. F cap. 8vo. Price 6s.

\section{DENNIS (J.).}

English Sonnets. Collected and Arranged. Elegantly bound. Fcap. 8vo. Cloth, price $3^{s .6 d \text {. }}$

\section{DOBSON (Austin).}

Vignettes in Rhyme and Vers de Société. Third Edition. Fcap. 8vo. Cloth, price 5s.

Proverbs in Porcelain. By the Author of "Vignettes in Rhyme" Second Edition. Crown 8vo. 6s.

DOWDEN (Edward), LI.D.

Shakspere : a Critical Study of his Mind and Art. Third Edition. Large Post 8vo. Cloth, price r2s.

Studies in Literature, $17^{89}$ I877. Large Post 8vo. Cloth, price I2s.

Poems. Second Edition. Fcap. 8vo. Cloth, price 5.

DOWNTON (Rev. H.), M.A.

Hymns and Verses. Original and Translated. Small crown 8 vo. Cloth, price $3 s, 6 d$.

DRAPER (J W.), M.D., LL.D. History of the Conflict between Religion and Science. Eleventh Edition. Crown 8vo. Cloth, price $5 s$.

Yolume XIII. of The International Scientific Series. 
DREW (Rev, G. S.), M.A. Scripture Lands in connection with their History. Second Edition. 8vo. Cloth, price ros. $6 d$.

Nazareth: Its Life and Lessons. Third Edition. Crown 8vo. Cloth, price $5 s$.

The Divine Kingdom on Earth as it is in Heaven. 8vo. Cloth, price ros. $6 d$.

The Son of Man: His Life and Ministry. Crown 8vo. Cloth, price $7 s .6 d$.

DREWRY (G. O.), M.D.

The Common-Sense Management of the Stomach. Fourth Edition. Fcap. 8vo. Cloth, price $2 s, 6 d$.

DREWRY (G. O.), M. D., and BARTLETT (H. C.), Ph.D., F.C.S.

Cup and Platter : or, Notes on Food and its Effects. Small 8vo. Cloth, price 2s. $6 d$.

DRUM MOND (Miss).

Tripps Buildings. A Study from Life, with Frontispiece. Small crown 8vo. Cloth, price 3s. $6 d$.

DURAND (Lady).

Imitations from the German of Spitta and Terstegen.

Fcap. 8vo. Cloth, price 4 s.

DU VERNOIS (Col. von Verdy).

Studies in leading Troops. An authorized and accurate Translation by Lieutenant $H$. J. T. Hildyard, 7ist Foot. Parts I. and

II. Demy 8vo. Cloth, price $7 s$.

EDEN (Frederick).

The Nile without a Dragoman. Second Edition. Crown 8vo. Cloth, price 7s. 6d.

EDMONDS (Herbert).

Well Spent Lives : a Series of Modern Biographies. Crown 8vo. Price 5 s.

EDWARDS (Rev. Basil).

Minor Chords; Or, Songs for the Suffering: a Volume of Verse Fcap. 8vo. Cloth, price 35. $6 d$. ; paper, price $25.6 d$.
ELLIOT (Lady Charlotte).

Medusa and other Poems. Crown 8vo. Cloth, price $6 s$.

ELLIOTT (Ebenezer), The Corn Law Rhymer.

Poems. Edited by his son, the Rev. Edwin Elliott, of St. John's, Antigua. 2 vols. Crown 8 vo. Cloth, price $28 s$.

ELSDALE (Henry).

Studies in Tennyson's Idylls. Crown 8vo. Cloth, price 5s.

ENGLISH CLERGYMAN. An Essay on the Rule of Faith and Creed of Athanasius. Shall the Rubric preceding the Creed be removed from the Prayerbook? Sewed. 8vo. Price is.

Epic of Hades (The). By a New Writer. Author of "Songs of Two Worlds." Fourth and finally revised Edition. Fcap. 8vo. Cloth, price 7s. $6 d$.

\section{Eros Agonistes.}

Poems. By E. B. D. Fcap. 8vo. Cloth, price $35.6 d$.

Essays on the Endowment of Research.

By Various Writers.

List of Contributors.

Mark Pattíson, B. D.

James S. Cotton, B. A.

Charles E. Appleton, D. C. L.

Archibald $\mathrm{H}$. Sayce, M. A.

Henry Clifton Sorby, F. R. S.

Thomas K. Cheyne, M. A.

W. T. Thiselton Dyer, M. A.

Henry Nettleship, M. A.

Square crown octavo. Cloth, price ros. $6 d$.

EVANS (Mark).

The Gospel of Home Life. Crown 8vo. Cloth, price $45.6 \%$. The Story of our Father's Love, told to Children; being a New and Enlarged Edition of Theology for Children. With Four Illustrations. Fcap. 8vo. Cloth, price $35.6 d$.

A Book of Common Prayer and Worship for Household Use, compiled exclusively from the Holy Scriptures, Fcap. 8vo. Cloth, price $2 s .6 d$. 
EX-CIVILIAN.

Life in the Mofussil: or, Civilian Life in Lower Bengal. 2 vols. Large post 8vo. Price r4s.

EYRE (Maj.-Gen. Sir V.), C.B., K.C.S.I., \&c.

Lays of a Knight-Errant in many Lands. Square crown 8vo. With Six Illusirations. Cloth, price $7 s .6 d$.

FARQUHARSON (M.).

I. Elsie Dinsmore. Crown 8vo. Cloth, price $3 s .5 \%$.

II. Elsie's Girlhood. Crown Svo. Cloth, price 3s. 6d.

III. Elsie's Holidays at Roselands. Crown 8vo, Cloth, price $3 s .6 d$.

FERRIS (Henry Weybridge). Poems. Fcap. 8vo. Cloth, price $5 s$.

Folkestone Ritual Case (The). The Argument, Proceedings Judgment, and Report, revised by the several Counsel engaged. Demy 8 vo. Cloth, price 25s.

FOOTMAN (Rev, H.), M.A.

From Home and Back; or, Some Aspects of Sin as seen in the Light of the Parable of the Prodigal. Crown 8vo. Cloth, price 55.

FOWLE (Rev. Edmund). Latin Primer Rules made Easy. Crown 8vo. Cloth, price $3 s$.

FOWLE (Rev, T. W.), M.A. The Reconciliation of Religion and Science. Buing Essays on Immortality, Inspiration, Miracles, and the Being of Christ. Demy 8vo. Cloth, price ros. $6 d$.

FOX-BOURNE (H. R.). The Life of John Locke, 3632-r704. 2 vols. Demy 8vo. Cloth, price $28 s$.

FRASER (Donald).

Exchange Tables of Sterling and Indian Rupee Currency, upon a new and extended system, embracing Values from One $\mathrm{Far}$ thing to One Hundred Thousand Pounds, and at Rates progressing, in Sixteenths of a Penny, from xs. 9d, to 2s. $3 d$. per Rupee. Royal 8vo. Cloth, price ros. $6 d$.
FRISWELL (J. Hain).

The Better Self. Essays for Home Life. Crown 8vo. Cloth, price $6 s$.

One of Two; or, A LeftHanded Bride. With a Frontispiece. Crown 8vo. Cloth, price $3^{s .} 6 d$.

FYTCHE (Lieut.-Gen. Albert), C.S.I., late Chief Commissioner of British Burma.

Burma Past and Present, with Personal Reminiscences of the Country. With Steel Portraits, Chromolithographs, Engravings on Wood, and Map. 2 vols. Demy 8vo. Cloth, price $30 s$.

GAMBIER (Capt. J. W.), R.N. Servia. Crown 8vo. Cloth, price 5.

GARDNER (H.).

Sunflowers. A Book of Verses. Fcap, 8vo. Cloth, price $5^{5}$.

GARDNER (J.), M.D.

Longevity: The Means of Prolonging Life after Middle Age. Fourth Edition, revised and enlarged. Small crown 8vo. Cloth, price 45 .

\section{GARRETT (E.).}

By Still Waters. A Story for Quiet Hours. With Seven Illustrations. Crown 8vo. Cloth, price $6 s$.

G. H. T.

Verses, mostly written in India. Crown 8vo. Cloth, price $6 s$.

GIBBON (Charles).

For Lack of Gold. With a Frontispiece. Crown 8 vo. Illustrated Boards, price $2 s$.

Robin Gray. With a Frontispiece. Crown 8vo. Illustrated boards, price $2 s$.

GILBERT (Mrs.).

Autobiography and other Memorials. Edited by Josiah Gilbert. Third Edition. With Portrait and several Wood Engravings. Crown 8vo. Cloth, price $7 s .6 d$. 
GILL (Rev. W. W.), B.A.

Myths and Songs from the South Pacific. With a Preface by F. Max Müller, M.A., Professor of Comparative Philology at Oxford. Post 8vo. Cloth, price gs.

\section{GODKIN (James).}

The Religious History of Ireland: Primitive, Papal, and Protestant. Including the Evangelical Missions, Catholic Agitations, and Church Progress of the last half Century. 8vo. Cloth, price $x 2 s$.

GOETZE (Capt. A, von). Operations of the German Engineers during the War of 1870-187x. Published by Authority, and in accordance with Official Documents. Translated from the German by Colonel G. Graham, V.C., C.B., R.E. With 6 large Maps. 'Demy 8vo. Cloth, price ars.

\section{GODWIN (William).}

William Godwin: His Friends and Contemporaries. With Portraits and Facsimiles of the handwriting of Godwin and his Wife. By C. Kegan Paul, 2 vols. Demy 8vo. Cloth, price $28 s$.

The Genius of Christianity Unveiled. Being Essays never before published. Edited, with a Preface, by C. Kegan Paul. Crown 8 vo. Cloth, price $7 s .6 d$.

GOLDIE (Lieut. M. H. G.) Hebe : a Tale. Fcap. 8vo. Cloth, price 5 s.

GOODENOUGH (Commodore J. G.), R.N., C.B., C.M.G.

Memoir of, with Extracts from his Letters and Journals. Edited by his Widow. With Steel Engraved Portrait. Square 8vo. Cloth, 5s. ** Also a Library Edition with Maps, Woodcuts, and Steel Engraved Portrait. Square post 8vo Cloth, price $\mathrm{I}_{4} \mathrm{~s}$.

\section{GOODMAN (W.).}

Cuba, the Pearl of the Antilles. Crown 8vo. Cloth, price 7s. $6 d$.
GOULD (Rev. S. Baring), M.A.

The Vicar of Morwenstow: a Memoir of the Rev. R. S. Hawker. With Portrait. Third Edition, revised. Square post 8 vo. Cloth, ros. $6 d$.

GRANVILLE (A. B.), M.D., F.R.S., \&c.

Autobiography of A. B. Granville, F. R. S., etc. Edited, with a brief account of the concluding years of his life, by his youngest Daughter, Paulina B. Granville. vols. With a Portrait. Second Edition. Demy 8vo. Cloth, price 32s.

GREY (John), of Dilston.

John Grey (of Dilston): Memoirs. By Josephine E. Butler. New and Revised Edition. Crown 8vo. Cloth, price $3 s .6 d$.

GRIFFITH (Rev. T.), A.M. Studies of the Divine Master. Demy 8vo. Cloth, price I2s.

GRIFFITHS (Capt. Arthur). Memorials of Millbank, and Chapters in Prison History. With Illustrations by R. Goff and the Author. 2 vols. Post 8 vo. Cloth; price $2 \mathrm{I} s$.

GRIMLEY (Rev. H. N.), M.A., Professor of Mathematics in the University College of Wales.

Tremadoc Sermons, chiefly on the SPIRITUAL Body, the UNSEEN World, and the Divine Humanity. Second Edition. Crown 8vo. Cloth, price $6 s$.

GRÜ NER (M. L.).

Studies of Blast Furnace Phenomena. Translated by L. D. B. Gordon, F.R.S.E., F.G.S. Demy 8 vo. Cloth, price $7 s .6 d$.

GURNEY (Rev. Archer). Words of Faith and Cheer. A Mission of Instruction and Suggestion. Crown 8vo. Cloth, price 6s.

First Principles in Church and State. Demy 8vo. Sewed, price Is. $6 d$. 
HAECKEL (Prof. Erast).

The History of Creation. Translation revised by Professor E. Ray Lankester, M.A., F.R.S. With Coloured Plates and Genealogical Trees of the various groups of both plants and animals. 2 vols. Second Edition. Post 8vo. Cloth, price 32s.

The History of the Evolution of Man. With numerous Illustrations. 2 vols. Post 8vo.

HAKE (A. Egmont).

Paris Originals, with twenty etchings, by Léon Richeton. Large post 8 vo. Cloth, price $\mathrm{r} 4 \mathrm{~s}$.

Halleck's International Law or Rules. Regulating the Intercourse of States in Peace and War. A New Edition, revised, with Notes and Cases. 2 vols. Demy 8 vo. Cloth, price $38 s$.

HARCOURT (Capt. A. F. P.). The Shakespeare Argosy. Containing much of the wealth of Shakespeare's Wisdom and Wit, alphabetically arranged and classified. Crown 8vo. Cloth, price $6 s$.

HARDY (Thomas). A Pair of Blue Eyes. New Edition. Crown 8 vo. Cloth, price $6 s$.

HARRISON (Lieut.-Col. R.). The Officer's Memorandum Book for Peace and War. Second Edition. Oblong $32 \mathrm{mo}$. roan, elastic band and pencil, price 3s. 6 d. ; russia, $5^{s}$.

HAWEIS (Rev. H. R.), M.A. Current Coin. MaterialismThe Devil-Crime-DrunkennessPauperism-Emotion-RecreationThe Sabbath. Third Edition. Crown 8vo. Cloth, price $6 s$.

Speech in Season. Fourth Edition. Crown 8vo. Cloth, price gs.

Thoughts for the Times. Tenth Edition. Crown 8vo. Cloth, price $7 s .6 d$.
HAWEIS(Rev. H. R.)-continued. Unsectarian Family Prayers, for Morning and Evening for a Week, with short selected passages from the Bible. Second Edition. Square crown 8vo. Cloth, price $3 s .6 d$.

HAYMAN (H.), D.D., late Head Master of Rugby School.

Rugby School Sermons. With an Introductory Essay on the Indwelling of the Holy Spirit. Crown 8vo. Clath, price $75.6 d$.

HELLWALD (Baron F, von).

The Russians in Central Asia. A Critical Examination, down to the present time, of the Geography and History of Central Asia. Translated by Lieut.-Col. Theodore Wirgman, LL.B. Large post 8vo. With Map. Cloth, price I2s.

HELVIG (Major H.).

The Operations of the Bavarian Army Corps. Translated by Captain G. S. Schwabe. With Five large Maps. In 2 vols. Demy 8vo. Cloth, price $24 s$.

Tactical Examples: Vol. I. The Battalion, price I5s. Vol.II. The Regiment and Brigade, price sos. $6 d$. Translated from the German by Col. Sir Lumley Graham. With numercus Diagrams. Deny 8vo. Cloth.

HERFORD (Brooke).

The Story of Religion in England. A Book for Young Folk. Crown 8vo. Cloth, price $5 s$.

HEWLETT (Henry G.).

A Sheaf of Verse. "Fcap. 8 vo. Cloth, price $3 s .6 d$.

HINTON (James).

Life and Letters of. Edited by Ellice Hopkins, with an Introduc. tion by Sir W. W. Gull, Bart., and Portrait engraved on Steel by C. $H$. Jeens. Crown 8vo. Cloth, 8s. 6d.

The Place of the Physician. To which is added Essays on THE LAW OF HUMAN LIFE, AND ON THE RELATION BETWEEN ORGANIC AND INORGANIC WORLDS. Second Edition. Crown 8vo. Cloth, price $3 s .6 d$. 
HINTON (James),-continued. Physiology for Practical Use. By various Writers. With 50 Illustrations. 2 vols. Second Edition: Crown 8vo. Cloth, price ras. $6 d$.

An Atlas of Diseases of the Membrana Tympani. With Descriptive Text. Post 8vo. Price $£ 66 s$.

The Questions of Aural Surgery. With Illustrations. a vols. Post 8vo. Cloth, price I2s. $6 d$.

H. J. C.

The Art of Furnishing. A Popular Treatise on the Principles of Furnishing, based on the Laws of Common Sense, Requirement, and Picturesque Effect. Small crown 8 vo. Cloth, price $3^{s}$. $6 d$.

HOCKLEY (W. B.).

Tales of the Zenana; or, A Nuwab's Leisure Hours. By the Author of "Pandurang Hari." With a Preface by Lord Stanley of Alderley. 2 vols. Crown 8vo. Cloth, price $2 x s$.

Pandurang Hari; or, Memoirs of a Hindoo. A Tale of Mahratta Life sixty years ago. With a Preface by Sir H. Bartle E. Frere, G.C.S.I., \&c. Crown 8vo. Cloth, price $6 s$.

HOFFBAUER (Capt.).

The German Artillery in the Battles near Metz. Based on the official reports of the German Artillery. Translated by Capt. E. O. Hollist. With Map and Plans. Demy 8vo. Cloth, price 2rs.

HOLMES (E. G. A.).

Poems. Fcap. 8vo, Cloth, price $5 s$.

HOLROYD (Major W, R. M.).

Tas-hil ul Kālām; or, Hindustani made Easy. Crown 8vo. Cloth, price $5 s$.

HOOPER (Mary).

Little Dinners: How to Serve them with Elegance and Economy. Thirteenth Edition. Crown 8vo. Cloth, price $5 s$.
HOOPER (Mary).-continued.

Cookery for Invalids, Per. sons of Delicate Digestion, and Children. Crown 8vo. Cloth, price 3s. $6 d$.

Every-Day Meals. Being Economical and Wholesome Recipes for Breakfast, Luncheon, and Supper. Second Edition. Crown 8vo. Cloth, price 5s.

HOOPER (Mrs. G.).

The House of Ràby. With a Frontispiece. Crown 8vo. Cloth, price $3 s, 6 d$.

HOPKINS (Ellice).

Life and Letters of James Hinton, with an Introduction by Sir W. W. Gull, Bart., and Portrait engraved on Steel by C. H. Jeens. Crown 8vo. Cloth, price 8s. 6d:

HOPKINS (M.).

The Port of Refuge; or, Counsel and Aid to Shipmasters in Difficulty, Doubt, or Distress. Crown 8vo. Second and Revised Edition. Cloth, price $6 s$.

HORNE (William), M.A.

Reason and Revelation : an Examination in to the Nature and Contents of Scripture Revelation, as compared with other Forms of Truth. Demy 8vo. Cloth, price rzs.

HORNER (The Misses).

Walks in Florence. A New and thoroughly Revised Edition. 2 vols. crown 8vo. Cloth limp. With Illustrations.

Vol. I,-Churches, Streets, and Palaces. Ios. 6d. Vol. II.-Public Galleries and Museums. 5s.

HOWARD (Mary M.).

Beatrice Aylmer, and other

Tales. Crown $8 \mathrm{vo}$. Cloth, price $6 s$.

HOWARD (Rev. G. B.).

An Old Legend of St. Paul's. Fcap. 8vo. Cloth, price 4s. $6 d$.

HOWELL (James).

A Tale of the Sea, Sonnets, and other Poems. Fcap. 8vo. Cloth, price 5s.

HUGHES (Allison). Penelope and other Poems. Fcap. 8vo. Cloth, price 4s. 6d. 
HULL (Edmund C. P.).

The European in India. With a Medical Guide for ANgloINDIANS. By R. R. S. Mair, M.D., F.R.C.S.E. Third Edition, Revised and Corrected. Post 8vo. Cloth, price $6 s$.

HUMPHREY (Rev. W.).

Mr. Fitzjames Stephen and Cardinal Bellarmine. Demy 8 vo. Sewed, price Is.

\section{IGNOTUS.}

Culmshire Folk. A Novel. New and Cheaper Edition. Crown 8vo. Cloth, price $6 s$.

\section{INCHBOLD (J. W.).}

Annus Amoris. Sonnets. Foolscap 8vo. Cloth, price $4 s, 6 d$.

\section{INGELOW (Jean).}

The Little Wonder-horn. A Second Series of "Stories Told to a Child." With Fifteen Illustrations. Small 8vo. Cloth, price 2s. $6 d$.

Indian Bishoprics. By an Indian Churchman. Demy 8vo. 6d.

\section{International Scientific Series (The).}

I. The Forms of Water in Clouds and Rivers, Ice and Glaciers. By J. Tyndall, LL.D., F.R.S. With 25 Illustrations. Seventh Edition. Crown 8vo. Cloth, price $5 s$.

II. Physics and Politics; or, Thoughts on the Application of the Principles of "Natural Selection" and "Inheritance" to Political Society. By Walter Bagehot. Fourth Edition. Crown 8vo. Cloth, price 4s.

III. Foods. By Edward Smith, M.D., LL.B., F.R.S. With numerous Illustrations. Fifth Edition. Crown 8vo. Cloth, price 5 s.

IV. Mind and Body: The Theories of their Relation. By Alexander Bain, LL.D. With Four Illustrations. Fifth Edition. Crown 8vo. Cloth, price $4 s$.

V. The Study of Sociology. By Herbert Spencer. Sixth Edition. Crown 8 vo. Cloth, price 5 s.
International Scientific Series (The)-continued.

VI. On the Conservation of Energy. By Balfour Stewart, M.A., LL.D., F.R.S. With $\mathrm{r}_{4}$ Illustrations. Fourth Edition. Crown 8vo. Cloth, price $5 s$.

VII. Animal Locomotion; or, Waiking, Swimming, and Flying. By J. B. Pettigrew, M.D., F.R.S., etc. With $\times 30$ Illustrations. Second Edition. Crown 8vo. Cloth, price $5 s$.

VIII. Responsibility in Mental Disease. By Fenry Maudsley, M. D. Third Edition. Crown 8vo. Cloth, price $5 s$.

IX. The New Chemistry. By Professor J. P. Cooke, of the Harvard University. With $3 \mathrm{I}$ Illustrations. Fourth Edition. Crown 8 vo. Cloth, price $5^{s}$.

$X$. The Science of Law. By Professor Sheldon Amos. Third Edition. Crown 8vo. Cloth, price 5s.

XI. Animal Mechanism. A Treatise on Terrestrial and Aerial Locomotion. By Professor E. J. Marey. With II7 Illustrations. Second Edition. Crown $8 v o$. Cloth, price $5 s$.

XII. The Doctrine of Descent and Darwinism. By Professor Oscar Schmidt (Strasburg University). With 26 Illustrations. Third Edition. Crown 8vo. Cloth, price 5s.

XIII. The History of the Conflict between Religion and Science. By J. W. Draper, M.D., LL.D. Eleventh Edition. Crowi 8vo. Cloth, price $5 s$.

XIV. Fungi; their Nature, Influences, Uses, \&c. By M. C. Cooke, M.A., LI.D. Edited by the Rev. M. J. Berkeley, M.A., F.L.S. With numerous Illustrations. Second Edition. Crown 8vo. Cloth, price $5^{5}$.

XV. The Chemical Effects of Light and Photography. By Dr. Hermann Vogel (Polytechnic Academy of Berlin). With roo Illustrations. Third and Revised Edition. Crown 8vo. Cloth, price $5 s$. 
International Scientific Series (The)-continued. XVI. The Life and Growth of Language. By William Dwight Whitney, Professor of Sanskrit and Comparative Philology in Yale College, New Haven. Second Edition. Crown 8vo. Cloth, price

XVII. Money and the Mechanism of Exchange. By W. Stanley Jevons, M.A., F.R.S. Third Edition. Crown 8vo. Cloth, price $5 s$.

XVIII. The Nature of Light: With a General Account of Physical Optics. By Dr. Eugene Lommel, Professor of Physics in the University of Erlangen. With I88 Illustrations and a table of Spectra in Chromo-lithography. Second Edition. Crown 8vo. Cloth, price 5 s.

XIX. Animal Parasites and Messmates. By Monsieur Van Beneden, Professor of the University of Lotrvain, Correspondent of the Institute of France. With $8_{3}$ Illustrations. Second Edition. Crown 8vo. Cloth, price $5^{5}$.

XX. Fermentation. By Professor Schützenberger, Director of the Chemical Laboratory at the Sorbonne. With 28 Illustrations. Second Edition. Crown 8vo. Cloth, price $5 s$.

XXI. The Five-Senses of Man. By Professor Bernstein, of the University of Halle. With gr Iilustrations. Second Edition. Crown 8vo. Cloth, price 5 .

XXII. The Theory of Sound in its Relation to Music. By Professor Pietro Blaserna, of the Royal University of Rome. With numerous Illustrations. Second Edition. Crown 8 vo. Cloth, price 5 s.

XXIII. Studies in Spectrum Analysis. By J. Norman Lockyer. F.R.S. With six photographic IIlustrations of Spectra, and numerous engravings on wood. Crown 8vo. Second Edition. Cloth, price 6s. $6 d$.

\section{Forthcoming Volumes.}

Prof. W. Kingdon Clifford, M.A. The First Principles of the Exact Sciences explained to the Non-mathematical.
International Scientific Series (The).

Forthcoming Vols. -continued.

W. B. Carpenter, LL.D., F.R.S. The Physical Geography of the Sea.

Sir John Luввоск, Bart., F.R.S. On Ants and Bees.

Prof. W. T. Thiselton Dyer, B.A., B.Sc. Form and Habit in Flowering Plants.

Prof. Micha.el Foster, M.D. Protoplasm and the Cell Theory.

H. Charlton Bastian, M.D., F.R.S. The Brain as an Organ of Mind.

Prof, A. C. Ramsay, LI.D., F.R.S. Earth Sculpture: Hills, Valleys, Mountains, Plains, Rivers, Lakes ; how they were Produced, and how they have been Destroyed.

P. BERT (Professor of Physiology, Paris). Forms of Life and other Cosmical Conditions.

Prof. T. H. Huxlex. The Crayfish: an Introduction to the Study of Zoology.

The Rev. A Secchr, D.J, late Director of the Observatory at Rome. The Stars.

Prof. J. Rosenthal, of the University of Eriangen. General Physiology of Muscles and Nerves.

Prof. A. De Quatrefages, Membre de I'Institut. The Human Race.

Prof. Thurston. The Steam Engine. With numerous Engravings.

Francis Galton, F.R.S. Psycho. metry.

J. W. JUDD, F.R.S. The Laws of Volcanic Action.

Prof. F. N. Balfour. The Embryonic Phases of Animal Life.

J. Luys, Physician to the Hospice de la Salpetriexre. The Brain and its Functions. With Illustrations.

Dr. Cart Semper. Animals and their Conditions of Existence.

Prof. Wurtz. Atoms and the Atomic Theory. 
International Scientific Series (The).

Forthconting Vols. - continued.

George J. Romanes, F.L.S. Animal Intelligence.

Alfred W. Bennett. A Handbook of Cryptogamic Botany.

JACKSON (T. G.).

Modern Gothic Architecture. Crown 8vo. Cloth, price $5 s$.

JACOB (Maj.-Gen, Sir G. Le Grand), K.C.S.I., C.B.

Western India Before and during the Mutinies. Pictures drawn from life. Second Edition. Crown 8vo. Cloth, price $7 s .6 d$.

JENKINS (E.) and RAYMOND (J.), Esqs.

A Legal Handbook - for Architects, Builders, and Building Owners. Second Edition Revised. Crown 8vo. Cloth, price $6 s$.

JENKINS' (Rev. R. C.), M.A.

The Privilege of Peter and the Claims of the Roman Church confronted with the Scriptures, the Councils, and the Testimony of the Popes themselves. Fcap. 8vo. Cloth, price $3^{s .} 6 d$.

JENNINGS (Mrs. Vaughan).

Rahel: Her Life and Letters. With a Portrait from the Painting by Daffinger. Square post 8vo. Cloth, price 7s, $6 d$.

JEVONS (W. Stanley), M.A., F.R.S.

Money and the Mechanism of Exchange. 'Second Edition. Crown 8vo. Cloth, price 5s.

VolumeXVII. of The International Scientific Series.

JONES (Lucy).

Puddings and Sweets. Being Three Hundred and Sixty-Five Receipts approved by Experience. Crown 8vo., price 2s. $6 d$.

RAUFMANN (Rev. M.), B.A.

Socialism: Its Nature, its Dangers, and its Remedies considered. Crown 8vo. Cloth, price 7s. $6 d$.
KER (David).

The Boy Slave in Bokhara. A Tale of Central Asia. With Illustrations. Crown 8vo. Cloth, price $5 s$.

The Wild Horseman of the Pampas. Illustrated. Crown 8 vo. Cloth, price 5 s.

KING (Alice).

A Cluster of Lives. Crown 8vo. Cloth, price $7 s .6 d$.

KING (Mrs. Hamilton).

The Disciples. A Poem. Third Edition, with some Notes. Crown 8vo. Cloth, price 7s. $6 d$.

Aspromonte, and other Poems. Second Edition. Fcap. 8vo. Cloth, price $4 s, 6 d$.

KINGSLEY (Charles), M.A.

Letters and Memories of his Life. Edited by his WIFE. With 2 Steel engraved Portraits and numerous Illustrations on Wood, and a Facsimile of his Handwriting. Eleventh Edition. 2 vols., demy 8 vo. Cloth, price $3^{6 s}$.

All Saints' Day and other Sermons. Second Edition. Crown 8vo. Cloth, $7 s .6 d$.

Letters to Young Men on Betting and Gambling. 8vo. sewed, price $7 s .6 d$. per Ioo.

KNIGHT (A, F, C.).

Poems. Fcap 8vo. Cloth, price $5 s$.

LACORDAIRE (Rev. Père).

Life: Conferences delivered at Toulouse. A New and Cheaper Edition. Crown 8 vo. Cloth, price ${ }_{3}^{s}, 6 d$.

Lady of Lipari (The).

A Poem in Three Cantos. Fcap. 8vo. Cloth, price 5 s.

LAMBERT (Cowley), F.R.G.S.

A Trip to Cashmere and Ladâk. With numerous Illustrations. Crown 8vo. Cloth, $7 s .6 d$. 
LAURIE (J. S.).

Educational Course of Secular School Books for India: The First Hindustani Reader. Stifflinen wrapper, price $6 d$.

The Second Hindustani Reader. Stifflinen wrapper,price $6 d$.

The Oriental (English) Reader. Book I., price 6d.; II., price $7 \frac{\lambda}{2} d . ;$ III., price gd. ; IV., price Is.

Geography of India; with Maps and Historical Appendix, tracing the Growth of the British Empire in Hindustan. Fcap. 8vo. Cloth, price Is. $6 d$.

\section{LAYMANN (Capt.).}

The Frontal Attack of Infantry. Translated by Colonel Edward Newdigate. Crown 8vo. Cloth, price 2s. 6d.

L. D. $S$.

Letters from China and Japan. With Illustrated Title-page. Crown 8 vo. Cloth, price 7s. $6 d$.

LEANDER (Richard).

Fantastic Stories. Trans-

- lated from the German by Paulina B. Granville. With Eight full-page Illustrations by $M$. E. Fraser-Tytler. Crown 8vo. Cloth, price $5 s$.

LEE (Rev. F. G.), D.C.L.

The Other World; or, Glimpses of the Supernatural. 2 vols. A New Edition. Crown 8vo. Cloth, price ${ }_{5} 5$.

LEE (Holme).

Her Title of Honour. A Book for Girls. New Edition. With a Frontispiece. Crown 8vo. Cloth, price 5 s.

LENOIR (J.).

Fayoum; or, Artists in Egypt. A Tour with M. Gerrome and others. With 13 Illustrations. A New and Cheaper Edition. Crown 8vo. Cloth, price $3 s .6 d$.

LEWIS (Mary A.).

A Rat with Three Tales. With Four Illustrations by Catherine F. Frere. Cloth, price $5 s$.
LOCKER (F.).

London Lyrics. A New and

Revised Edition, with Additions and a Portrait of the Author. Crown 8 vo. Cloth, elegant, price $6 s$.

Also, an Edition for the People. F cap. 8vo. Cloth, price 2s. $6 d$.

LOCKYER (J. Norman), F.R.S.

Studies in Spectrum Ana. lysis ; with six photographic illustrations of Spectra, and numerous engravings on wood. Second Edition. Crown 8vo. Cloth, price 6s. 6d. Vol. XXIII. of the International Scientific Series.

LOM MEL (Dr. E.).

The Nature of Light: With a General Account of Physical Optics. Second Edition. With 188 Illustrations and a Table of Spectra in Chromo-lithography, Second Edition. Crown 8vo. Cloth, price $5 s$.

Volume XVIII. of The International Scientific Series.

LORIMER (Peter), D.D.

John Knox and the Church of England: His Work in her Pulpit, and his Influence upon her Liturgy, Articles, and Parties. Demy 8vo. Cloth, price I2s.

John Wiclif and his English Precursors, by Gerhard Victor Lechler. Translated from the German, with additional Notes. 2 vols. Demy 8vo. Cloth, price $21 s$.

LOTHIAN (Roxburghe). Dante and Beatrice from I282 to I2go. A Romance. 2 vols. Post 8vo. Cloth, price 24s.

LOVER (Samuel), R.H.A.

The Life of Samuel Lover, R. H. A. ; Artistic, Literary, and Musical.' With Selections from his Unpublished Papers and Correspondence. By Bayle Bernard. 2 vols. With a Portrait. Post 8vo. Cloth, price 2 Is.

LUCAS (Alice).

Translations from the Works of German Poets of the 18th and 19th Centuries. Fcap. 8vo. Cloth, price $5 s$. 
LYONS (R. T.), Surg.-Maj. Bengal Army.

A Treatise on Relapsing Fever. Post 8 vo. Cloth, price $7 s, 6 \vec{d}$.

MACAULAY (J.), M.A., M.D., Edin.

The Truth about Ireland: Tours of Observation in 1872 and I875. With Remarks on Irish Public Ouestions. Being a Second Edition of "Ireland in 1872 ," with a New and Supplementary Preface. Crown 8vo. Cloth, price $3 s, 6 d$.

MAC CLINTOCK (L.).

Sir Spangle and the Dingy Hen. Illustrated. Square crown 8vo., price $2 s .6 d$.

MAC DONALD (G.).

Malcolm. With Portrait of the Author engraved on Steel. Fourth Edition. Crown 8vo. Price 6s.

The Marquis of Lossie. Second Edition. Crown 8vo. Cloth, price $6 s$.

St. George and St. Michael. Crown 8vo. Cloth, 6s.

MAC KENNA (S. J.).

Plucky Fellows. A Book for Boys. With Six Illustrations. Second Edition. Crown 8vo. Cloth, price $3 s .6 d$.

At School with an. Old Dragoon. With Six Illustrations. Second Edition. Crown 8vo. Cloth, price 5.

MACLACHLAN (A. N. C.), M.A. William Augustus, Duke of Cumberland : being a Sketch of his Military Life and Character, chiefly as exhibited in the General Orders of His Royal Highness, 1745-1747. With Illustrations. Post 8 vo. Cloth, price I5s.

MACNAUGHT (Rev. John).

Cona Domini: An Essay on the Lord's Supper, its Primitive Institution, Apostolic Uses, and Subsequent History. Demy 8vo. Cloth, price I4s.

MAGNUSSON (Eirikr), M.A., and PALMER (E.H.), M.A.

Johan Ludvig Runeberg's Lyrical Songs, Idylls and Epigrams. Fcap. 8vo. Cloth, price 5 s.
MAIR (R. S.) M.D., F.R.C.S.E. The Medical Guide for Anglo-Indians. Being a Compendium of Advice to Europeans in India, relating to the Preservation and Regulation of Health. With a Supplement on the Management of Children in India. Second Edition. Crown 8vo. Limp cloth, price $3^{5.6} 6$.

MALDEN (H. E. and E. E.) Princes and Princesses. Illustrated. Small crown 8vo. Cloth, price 2s. 6d.

MANNING (His Eminence Cardinal).

Essays on Religion and Literature, By various Writers. Third Series. Demy 8vo. Cloth, price ras. $6 d$.

The Independence of the Holy See, with an Appendix containing the Papal Allocution and a translation. Cr. 8vo. Cloth, price $5 s$. The True Story of the Vatican Council. Crown $8 v 0$. Cloth, price 5 s.

MAREY (E. J.).

Animal Mechanics. A Treatise on Terrestrial and Aerial Locomotion. With II $_{7}$ Illustrations. Second Edition. Crown 8 vo. Cloth, price $5 s$.

Volume XI. of The International Scientific Series.

MARRIOTT (Maj.-Gen. W. F.), C.S.I.

A Grammar of Political Economy. Crown 8vo. Cloth, price $6 s$.

MASTERMAN (J.).

Worth Waiting for. A New Novel, 3 vols. Crown 8vo. Cloth. Half-a-dozen Daughters. With a Frontispiece. Crown 8vo. Cloth, price 3 s. $6 d$.

MAUDSLEY (Dr. H.).

Responsibility in Mental Disease. Second Edition. Crown 8vo. Cloth, price $5 s$.

Volume VIII. of The International Scientific Series.

MAUGHAN (W. C.).

The Alps of Arabia; or, Travels through Egypt, Sinai, Arabia, and the Holy Land. With Map. Second Edition. Demy 8vo. Cloth, price $5 s$. 
MAURICE (C. E.).

Lives of English Popular Leaders. No. I.-STEphen LANG. ToN. Crown 8vo. Cloth, price $7 s .6 d$. No. 2.-Tyler, Ball, and OldCASTle, Crown 8vo. Cloth, price 7s. $6 d$.

Mazzini (Joseph).

A Memoir. By E. A. V. Two Photographic Portraits. Second Edition. Crown 8vo. Cloth, price 5 s.

MEDLEY(Lieut.-Col.J.G.),R.E. An Autumn Tour in the United States and Canada. Crown 8vo. Cloth, price 5s.

MEREDITH (George).

The Ordeal of Richard Feverel. A History of Father and Son. In one vol. with Frontispiece. Crown 8vo. Cloth, price $6 s$.

MICKLETHWAITE (J. T.), F.S.A.

Modern Parish Churches:

Their Plan, Design, and Furniture.

Crown 8vo. Cloth, price $7 s, 6 d$.

MIDDLETON (The Lady).

Ballads. Square $16 \mathrm{mo}$. Cloth, price 3 s. $6 d$.

MILLER (Edward).

The History and Doctrines of Irvingism ; or, the so-called $\mathrm{Ca}$ tholic and Apostolic Church. 2 vols.

Large post 8vo. Cloth, price 25s.

MILLER (Robert).

The Romance of Love.

Fcap. 8vo. Cloth, price 5s.

MILNE (James).

Tables of Exchange for the Conversion of Sterling Money into Indian and Ceylon Currency, at Rates from Is. $8 d$. to $2 s$. $3 d$. per Rupee. Second Edition. Demy 8vo. Cloth, price $£ 225$.

MIVART (St. George), F.R.S. Contemporary Evolution : An Essay on some recent Social Changes. Post 8vo. Cloth, price 7s. $6 d$.

MOCKLER (E.).

A Grammar of the Baloochee Language, as it is spoken in Makran (Ancient Gedrosia), in the Persia-Arabic and Roman characters.

Fcap. 8vo. Cloth, price 5 s.
MOFFAT (Robert Scott).

The Economy of Consumption; an Omitted Chapter in Political Economy, with special reference to the Questions of Commercial Crises and the Policy of Trades Unions; and with Reviews of the Theories of Adam Smith, Ricardo, J. S. Mill, Fawcett, \&c. Demy 8vo. Cloth, price I8s.

The Principles of a Time Policy: being an Exposition of a Method of Settling Disputes between Employers and Labourers in regard to Time and Wages, by a simple Process of Mercantile Barter, without recourse to Strikes or Locks-out. Reprinted from "The Economy of Consumption," with a Preface and Appendix containing Observations on some Reviews of that book, and a Recriticism of the Theories of Ricardo and J. S. Mill on Rent, Value, and Cost of Production. Demy 8 vo. Cloth, price 3 s. $6 d$.

MOLTKE (Field-Marshal Von).

Letters from Russia.

Translated by Robina Napier. Crown 8vo. Cloth, price 6s.

MOORE (Rev. D.), M.A.

Christ and His Church. By the Author of "The Age and the Gospel," \&c. Crown 8vo. Cloth, price $3 s .6 d$.

MORE (R. Jasper).

Under the Balkans, Notes of a Visit to the District of Philippopolis in 1876 . With a Map and Illustrations from Photographs. Crown 8vo, Cloth, price $6 s$.

MORELL (J. R.)

Euclid Simplified in Method and Language. Being a Manual of Geometry. Compiled from the most important French Works, approved by the University of Paris and the Minister of Public Instruction. Fcap. 8vo. Cloth, price 2s. 6d.

MORICE (Rev. F. D.), M.A.

The Olympian and Pythian Odes of Pindar. A New Translation in English Verse. Crown 8vo. Cloth, price 7s. $6 d$.

MORLEX (Susan).

Aileen Ferrers. A Novel, 2 vols. Crown 8vo. Cloth.

Throstlethwaite. A Novel. 3 vols. Crown 8vo. Cloth. 
MORLEY (Susan)-continued. Margaret Chetwynd.

A Novel. 3 vols. Crown 8 vo. Cloth. MORSE (E. S.), Ph.D.

First Book of Zoology. With numerous Illustrations. Crown Svo. Cloth, price $5 s$.

MORSHEAD (E. D. A.)

The Agamemnon of IEschylus. Translated into English verse. With an Introductory Essay. Crown 8vo. Cloth, price $5 s$.

MOSTYN (Sydney).

Perplexity. A Novel. 3 vols. Crown 8vo. Cloth.

MUSGRAVE (Anthony).

Studies in Political Economy. Crown 8vo. Cloth, price 6s.

My Sister Rosalind.

A Novel. By the Author of "Chris. tiana North" and "Under the Limes." 2 vols. Cloth.

NAAKÉ (J. T.).

Slavonic Fairy Tales.

From Russian, Servian, Polish, and Bohemian Sources. With Four Illustrations. Crown 8vo. Cloth, price 5 s.

NEWMAN (J. H.), D.D.

Characteristics from the

Writings of Being Selections from his various Works. Arranged with the Author's personal approval. Third Edition. With Portrait. Crown 8vo. Cloth, price $6 s$.

* * A Portrait of the Rev. Dr. J. H. Newman, mounted for framing, can be had, price $25.6 d$.

NEW WRITER (A).

Songs of Two Worlds. Third Edition. Complete in one volume with Portrait. Fcap. 8vo. Cloth, price $7 s .6 d$.

The Epic of Hades. Fourth and finally revised Edition. Fcap. 8vo. Cloth, price $7 s .6 d$.

NICHOLAS (Thomas), Ph. D., F.G.S.

The Pedigree of the English People: an Argument, Historical and Scientific, on the Formation and Growth of the Nation, tracing Raceadmixture in Britain from the earliest times, with especial reference to the incorporation of the Celric Aborigines. Fifth edition. Demy 8vo. Cloth, price $16 s$.
NICHOLSON (Edward B.), Librarian of the London Institution.

The Christ Child, and other Poems. Crown 8vo. Cloth, price 4s. $6 d$.

NOAKE (Major R. Compton).

The Bivouac; or, Martial Lyrist, with an Appendix-Advice to the Soldier. Fcap. 8vo. Price 5s, 6d.

NOBLE (J. A.).

The Pelican Papers. Reminiscences and Remains of a Dweller in the Wilderness. Crown 8vo. Cloth, price $6 s$.

NORMAN PEOPLE (The).

The Norman People, and their Existing Descendants in the British Dominions and the United States of America. Demy 8vo. Cloth, price 2Is.

NORRIS (Rev. Alfred). The Inner and Outer Life Poems. Fcap, 8vo. Cloth, price $6 s$.

Northern Question (The); Or, Russia's Policy in Turkey unmasked. Demy8vo. Sewed, price Is.

Notes on Cavalry Tactics, Organization, \&c. By a Cavalry Officer. With Diagrams. Demy 8 vo. Cloth, price I2s.

NOTREGE (John), A.M.

The Spiritual Function of a Presbyter in the Church of England. Crown 8vo. Cloth, red edges, price $3 s$. $6 d$.

Oriental Sporting Magazine (The).

A Reprint of the first 5 Volumes, in 2 Volumes. Demy 8 vo. Cloth, price $28 s$.

Our Increasing Military Difficulty, and one Way of Meeting it. Demy 8vo. Stitched, price $\mathrm{r} s$.

PAGE (Capt. S. F.).

Disciplineand Drill. Cheaper Edition. Crown 8vo. Price Is.

PALGRAVE, (W. Gifford). Hermann Agha; An Eastern Narrative. Third and Cheaper Edition. Crown 8vo. Cloth, price $6 s$. 
PANDURANG HARI; Or, Memoirs of a Hindoo. With an Introductory Preface by Sir H. Bartle E. Frere, G.C.S.I., C.B. Crown 8vo. Price 6s.

PARKER (Joseph), D.D. The Paraclete: An Essay on the Personality and Ministry of the Holy Ghost, with some reference to current discussions. Second Edition. Demy 8vo. Cloth, price rzs,

PARR (Harriet). Echoes of a Famous Year. Crown 8vo. Cloth, price 8s. $6 d$.

PAUL (C. Kegan). Goethe's Faust. A New Translation in Rime. Crown 8vo. Cloth, price $6 s$.

William Godwin: His Friends and Contemporaries. With Portraits and Facsimiles of the Handwriting of Godwin and his Wife, 2 vols. Square post 8 vo. Cloth, price $28 s$.

The Genius of Christianity Unveiled. Being Essays by William Godwin never before published. Edited, with a Preface, by C. Kegan Paul. Crown 8vo. Cloth price $7 s$. $6 d$.

PAUL (Margaret Agnes).

Gentle and Simple: A Story. a vols. Crown $8 v o$. Cloth, gilt tops, price 12s.

PAYNE (John).

Songs of Life and Death. Crown 8vo Cloth, price 5 s.

PAYNE (Prof, J, F.).

Lectures on Education. Price $6 d$. each.

II. Fröbel and the Kindergarten System. Second Edition.

A Visit to German Schools : Elementary Schools in Germany. Notes of a Professional Tour to inspect some of the Kindergartens, Primary Schools, Public Girls Schools, and Sehools for Technical Instruction in Hamburgh, Berlin, Dresden, Weimar, Gotha, Eisenach, in the autumn of 1874 . With Critical Discussions of the General Principles and Practice of Kindergartens and other Schemes of Elementary Education. Crown 8vo. Cloth, price 45. $6 d$.
PEACOCKE (Georgiana).

Rays from the Southern

Cross : Poems. Crown 8vo. With Sixteen Full-page Illustrations by the Rev. P. Walsh. Cloth elegant, price ros. $6 d$.

PELLETAN (E.).

The Desert Pastor, Jean Jarousseau. Translated from the French. By Colonel E. P. De L'Hoste. With a Frontispiece. New Edition. Fcap. 8vo. Cloth, price 3s. $6 d$.

PENNELL (H. Cholmondeley).

Pegasus Resaddled. By the Author of "Puck on Pegasus," \&c. \&c. With Ten Full-page Illustrations by George Du Maurier. Second Edition. F cap, 4to. Cloth elegant, price I2s. $6 d$.

PENRICE (Maj. J.), B.A. A Dictionary and Glossary of the Ko-ran. With copious Grammatical References and Explanations of the Text. 4to. Cloth, price 2Is.

PERCIVAL (Rev. P.).

Tamil Proverbs, with their English Translation. Containing upwards of Six Thousand Proverbs. Third Edition. Demy 8vo. Sewed, price $g s$.

PESCHEL (Dr. Oscar).

The Races of $M$ an and their Geographical Distribution. Large crown 8vo. Cloth, price gs.

PETTIGREW (J. Bell), M.D., F.R.S.

Animal Locomotion; or, Walking, Swimming, and Flying. With $r_{3} 0$ Illustrations. Second Edition. Crown 8vo. Cloth, price 5 s.

Volume VII. of The International Scientific Series.

PFEIFFER (Emily).

Glan Alarch: His Silence and Song. A Poem. Crown 8vo. price $6 s$.

Gerard's Monument and Other Poems. Second Edition. Crown 8vo. Cloth, price $6 s$.

Poems. Crown 8vo. Cloth, price $6 s$. 
PIGGOT (J.), F.S.A., F.R.G.S. Persia-Ancient and Modern. Post 8vo. Cloth, price ros. $6 d$.

PLAYFAIR (Lieut.-Col.), Her Britannic Majesty's Consul-General in Algiers.

Travels in the Footsteps of Bruce in Algeria and Tunis. Illustrated by facsimiles of Bruce's original Drawings, Photographs, Maps, \&c. Royal 4to. Cloth, bevelled boards, gilt leaves, price $£_{33} 3$.

POOR (Henry V.).

Money and its Laws, embracing a History of Monetary Theories and a History of the Currencies of the United States. Demy 8vo. Cloth, price ars.

POUSHKIN (A. S.).

Russian Romance. Translated from the Tales of Belkin, etc. By Mrs. J. Buchan Telfer (néc Mouravieff). Crown 8vo, Cloth, price $7 s .6 d$.

POWER (H.).

Our Invalids : How shall we Employ and Amuse Them? Fcap. 8vo. Cloth, price $2 s .6 d$.

POWLETT (Lieut. N.), R.A.

Eastern Legends and Stories in English Verse. Crown 8vo. Cloth, price $5^{s}$.

PRESBYTER.

Unfoldings of Christian Hope. An Essay showing that the Doctrine contained in the Damnatory Clauses of the Creed commonly called Athanasian is unscriptural. Small crown 8vo. Cloth, price $45.6 d$.

PRICE (Prof. Bonamy).

Currency and Banking. Crown 8vo. Cloth, price $6 s$.

Chapters on Practical Political Economy. Being the Substance of Lectures delivered before the University of Oxford. Large post 8vo. Cloth, price I2s.
PROCTOR (Richard A.), B.A.

Our Place among Infinities.

A Series of Essays contrasting our little abode in space and time with the Infinities around us. To which are added Essays on "Astrology," and "The Jewish Sabbath." Third Edition. Crown 8vo. Cloth, price $6 s$.

The Expanse of Heaven. A Series of Essays on the Wonders of the Firmament. With a Frontispiece. Third Edition. Crown 8vo. Cloth, price $6 s$.

Proteus and Amadeus. A Correspondence. Edited by Aubrey DeVere. Crown $8 v 0$. Cloth, price 5 s.

PUBLIC SCHOOLBOY.

The Volunteer, the Militiaman, and the Regular Soldier. Crown 8vo. Cloth, price $5 s$.

Punjaub (The) and North Western Frontier of India, By an old Punjauber. Crown 8vo. Cloth, price $5 s$.

RAM (James).

The Philosophy of War.

Small Crown 8 vo. Cloth, price 3 s. $6 d$. READ (Carveth).

On the Theory of Logic: An Essay. Crown 8vo. Cloth, price $6 s$.

REANEY (Mrs. G. S.). Blessing and Blessed; a Sketch of Girl Life. With a frontispiece. Crown 8vo. Cloth, price 5 s. Waking and Working; or, from Girlhood to Womanhood. With a Frontispiece. Crown 8vo. Cloth, price $5^{5}$.

Sunshine Jenny and other Stories. Three Illustrations. Royal r6mo. Cloth, price $1 s, 6 d$.

Sunbeam Willie, and other Stories. Three Illustrations. Royal r6mo. Cloth, price rs. $6 d$.

RHOADES (James).

Timoleon. A Dramatic Poem. Fcap. 8vo. Clath, price $5 s$.

RIBOT (Prof. Th.).

English Psychology. Second Edition. A Revised and Corrected Translation from the latest French Edition. Large post 8vo. Cloth, price $9 s$. 
RIBOT (Prof. Th.)-continued. Heredity : A Psychological Study on its Phenomena, its Laws, its Causes, and its Consequences. Large crown 8vo. Cloth, price gs.

RINK (Chevalier Dr. Henry). Greenland : Its People and its Products. By the Chevalier Dr. HENRy Rink, President of the Greenland Board of Trade. With sixteen Illustrations, drawn by the Eskimo, and a Map. Edited by Dr. Robert Brown. Crown 8vo. Price Ios. $6 d$.

ROBERTSON (The Late Rev. F. W.), M.A., of Brighton.

Notes on Genesis. Third Edition. Crown 8vo., price $5 s$.

New and Cheaper Editions:-

The Late Rev. F. W. Robertson, M.A., Life and Letters of. Edited by the Rev. Stopford Brooke, M.A., Chaplain in Or. dinary to the Queen.

I. 2 vols., uniform with the Sermons. With Steel Portrait. Crown 8vo. Cloth, price $7 s, 6 d$.

II. Library Edition, in Demy 8vo, with Two Steel Portraits. Cloth price I2s.

III. A Popular Edition, in $\mathbf{r}$ vol. Crown 8vo. Cloth, price $6 s$.

Sermons. Four Series. Small crown 8vo. Cloth, price $3 s .6 d$. each.

Expository Lectures on St. Paul's Epistles to the Corinthians. A New Edition. Small crown 8vo. Cloth, price 5 s.

Lectures and Addresses, with other literary remains. A New Edition. Crown 8vo. Cloth, price 5s. An Analysis of Mr. Tennyson's "In Memoriam." (Dedicated by Permission to the PoetLaureate.) Fcap. 8vo. Cloth, price 2s. The Education of the Human Race. Translated from the German of Gotthold Ephraim Lessing. Fcap. 8vo. Cloth, price 2s. $6 d$.

The above Works can also be had half-bound in morocco.

* * A Portrait of the late Rev. F. W. Robertson, mounted for framing, can be had, price $2 s .6 d$.

\section{ROBINSON (A. Mary F.).} A Handful of Honey. suckle. Fcap. 8vo. Cloth, price $3^{s,} 6 d$.

ROSS (Mrs. E.), ("Nelsie Brook"). Daddy's Pet. A Sketch from Humble Life. With Six Illustrations. Royal $16 \mathrm{mo}$. Cloth, price is.

RUSSELL (E. R.).

Irving as Hamlet. Second Edition. Demy 8vo. Sewed, price Is.

RUSSELL (Major Frank S.).

Russian Wars with Turkey,

Past and Present. With Two Maps.

Second Edition. Crown 8vo., price 6s.

RUTHERFORD (John).

The Secret History of the

Fenian Conspiracy; its Origin, Objects, and Ramifications. 2 vols. Post 8vo. Cloth, price r8s.

SADLER (S. W.), R.N.

The African Cruiser. A Midshipman's Adventures on the West Coast. With Three Illustrations. Second Edition, Crown 8vo. Cloth, price $3 s .6 d$.

SAMAROW (G.).

For Sceptre and Crown. A Romance of the Present Time. Translated by Fanny Wormald. 2 vols. Crown 8vo. Cloth, price 15 s.

SAUNDERS (Katherine).

Gideon's Rock, and other Stories. Crown 8vo. Cloth, price $6 s$. Joan Merryweather, and other Stories. Crown 8 vo. Cloth, price 6s. Margaret and Elizabeth. A Story of the Sea. Crown 8vo. Cloth, price $6 s$.

SAUNDERS (John).

Israel Mort, Overman : a Story of the Mine. Crown 8vo. Price 6s.

Hirell. With Frontispiece. Crown 8vo. Cloth, price $3 s$. $6 d$. Cheap Edition. With Frontispiece, price $2 s$.

Abel Drake's Wife. With Frontispiece. Crown 8vo. Cloth, price $3 s .6 d$.

Cheap Edition. With Frontispiece, price $2 s$. 
SCHELL (Maj. von).

The Operations of the First Army under Gen. Von Goeben. Translated by Col. C. H. von Wright. Four Maps. Demy 8vo. Cloth, price gs.

The Operations of the First Army under Gen. Von Steinmetz. Translated by Captain E. O. Hollist. Demy 8vo. Cloth, price Ios. $6 d$.

SCHELLENDORF, (Maj.-Gen. B. von).

The Duties of the General

Staff. Translated from the German by Lieutenant Hare. Vol. I. Demy 8vo. Cloth, Ios. 6d.

SCHERFF (Maj. W, von).

Studies in the New Infantry Tactics. Parts I, and II. Translated from the German by Colonel Lumley Graham. Demy 8vo. Cloth, price $7 s .6 d$.

SCHMIDT (Prof. Oscar).

The Doctrine of Descent and Darwinism. With 26 Illustrations. Third Edition. Crown 8vo. Cluth, price 5.

Volume XII, of The International Scientific Series.

SCHÜTZENBERGER(Prof.F.).

Fermentation. With $\mathrm{Nu}$ merous Illustrations. Crown $8 \mathrm{vo}$. Cloth, price $5 s$.

Volume XX. of The International Scientific Series.

SCOTT (Patrick).

The Dream and the Deed, and other Poems. Fcap. 8vo. Cloth, price 5 s.

ScotT (W. T.).

Antiguities of an Essex Parish ; or, Pages from the History of Great Dunmow. Crown 8vo. Cloth, price $5^{s}$. Sewed, 4s.

SCOTT (Robert H.).

Weather Charts and Storm Warnings. Illustrated. Crown 8vo. Cloth, price $3 s .6 d$.

Seeking his Fortune, and other Stories. With Four Illustrations. Crown 8vo. Cloth, price $3^{s .6} 6$.
SENIOR (N. W.).

Alexis De Tocqueville. Correspondence and Conversations with Nassau W. Senior, from I833 to I859. Edited by M. C. M. Simpson. 2 vols. Large post 8 vo. Cloth, price $2 r s$.

Journals Kept in France and Italy. From 1848 to 1852 . With a Sketch of the Revolution of 1848. Edited by his Daughter, $M$. C. M. Simpson, 2 vols. Post 8 vo. Cloth, price 24s.

Seven Autumn Leaves from Fairyland. Illustrated with Nine Etchings. Square crown 8vo. Cloth, price $3^{s .} 6 d$.

SEYD (Ernest), F.S.S.

The Fall in the Price of Silver. Its Causes, its Consequences, and their Possible Avoidance, with Special Reference to India. Demy 8vo. Sewed, price 2s. $6 d$.

SHADWELL (Maj.-Gen.), C.B. Mountain Warfare. Illustrated by the Campaign of 1799 in Switzerland. Being a Translation of the Swiss Narrative compiled from the Works of the Archduke Charles, Jomini, and others. Also of Notes by General $H$. Dufour on the Campaign of the Valtelline in 1635 . With Appendix, Maps, and Introductory Remarks, Demy 8 vo. Cloth, price I6s.

SHAW (Flora L.).

Castle Blair: a Story of Youthful Lives. 2 vols. crown 8vo. Cloth, price I2s. Also, an edition in I vol. crown 8vo. $6 s$.

SHELLEY (Lady).

Shelley Memorials from Authentic Sources. With (now first printed) an Essay on Christianity by Percy Bysshe Shelley. With Portrait. Third Edition. Crown 8vo. Cloth, price 5 s.

SHERMAN (Gen. W. T.).

Memoirs of General W. T. Sherman, Commander of the Federal Forces in the American Civil War. By Himself. 2 vols. With Map. Demy 8vo Cloth, price 245. Copyright English Edition. 
SHILLITO (Rev, Joseph).

Womanhood : its Duties, Temptations, and Privileges. A Book for Young Women. Second Edition. Crown 8vo. Price $3 s .6 d$.

SHIPLEY (Rev. Orby), M.A. Church Tracts, or Studies in Modern Problems. By various Writers. 2 vols. Crown 8vo. Cloth, price 5s. each.

SHUTE (Richard), M.A.

A Discourse on Truth. Large Post 8vo. Cloth, price gs.

SMEDLEY (M. B.).

Boarding-out and Pauper Schools for Girls. Crown 8vo. Cloth, price $3 s, 6 d$.

SMITH (Edward), M.D., LL.B., F.R.S.

Health and Disease, as Influenced by the Daily, Seasonal, and other Cyclical Changes in the Human System. A New Edition. Post 8yo. Cloth, price $7 s .6 d$.

Foods. Profusely Illustrated. Fourth Edition. Crown 8vo. Cloth, price 5 s.

Volume III. of The International Scientific Series.

Practical Dietary for Families, Schools, and the Labouring Classes. A New Edition. Post 8vo. Cloth, price 3s. 6d.

Tubercular Consumption in its Early and Remediable Stages. Second Edition. Crown 8vo. Cloth, price $6 s$.

SMITH (Hubert).

Tent Life with English Gipsies in Norway. With Five full-page Engravings and Thirty-one smaller Illustrations by Whymper and others, and Map of the Country showing Routes. Third Edition. Revised and Corrected. Post 8vo. Cloth, price 21s.

Songs of Two Worlds. By the Author of "The Epic of Hades." Third Edition. Complete in one Volume, with Portrait. Fcap 8vo. Cloth, price $7 s .6 d$.
Songs for Music.

By Four Friends, Square crown 8vo. Cloth, price $5 s$.

Containing songs by Reginald A.

Gatty, Stephen H. Gatty, Greville J. Chester, and Juliana Ewing.

SPENCER (Herbert).

The Study of Sociology. Fifth Edition. Crown 8vo. Cloth, price 5 s.

Volume $\mathrm{V}$. of The International Scientific Series.

SPICER (H.).

Otho's Death Wager. A Dark Page of History Illustrated. In Five Acts. Fcap. 8vo. Cloth, price 5 s.

STAPLETON (John).

The Thames: A Poem. Crown 8vo. Cloth, price $6 s$.

STEPHENS (Archibald John), LL.D.

The Folkestone Ritual Case. The Substance of the Argument delivered before the Judicial Committee of the Privy Council. On behalf of the Respondents. Demy 8vo. Cloth, price $6 s$.

STEVENSON (Robert Louis).

An Inland Voyage. With Frontispiece by Walter Crane. Crown 8vo. Cloth, price 7s. 6 d.

STEVENSON (Rev. W. F.). Hymns for the Church and Home. Selected and Edited by the Rev. W. Fleming Stevenson.

The most complete Hymn Book published.

The Hymn Book consists of Three Parts :- I. For Public Worship.II. For Family and Private Worship. -III. For Children.

* * Published in various forms and prices, the latter ranging from $8 d$. to $6 s$. Lists and full particulars zuill be furrished on application to the Publishers.

STEWART (Prof. Balfour), M.A., LL.D., F.R.S.

On the Conservation of Energy. Fifth Edition. With Fourteen Engravings. Crown 8vo. Cloth, price 5s.

Volume VI. of The International Scientific Series. 
STONEHEWER (AgnES).

Monacell : A Legend of North Wales. A Poem. Fcap. 8ro. Cloth, price $3 s .6 d$.

STRETTON (Hesba). Author of "Jessica's First Prayer."

Michael Lorio's Cross and other Stories. With Two Illustrations. Royal x6mo. Cloth, price Is. $6 d$.

The Storm of Life. With Ten Illustrations. Twenty-first Thousand. Royal r6mo. Cloth,price is. $6 d$.

The Crew of the Dolphin. Illustrated. Fourteenth Thousand. Royal 16 mo. Cloth, price Is. $6 d$.

Cassy. Thirty-eighth Thousand. With Six Illustrations. Royal I6mo. Cloth, price is. $6 d$.

The King's Servants. Forty-third Thousand. With Eight Illustrations. Royal $16 \mathrm{mo}$. Cloth, price $I s .6 d$

Lost Gip. Fifty-ninth Thousand. With Six Illustrations, Royal $\pm 6 \mathrm{mo}$. Cloth, price rs. $6 d$.

** Also a handsomely bound Edition, with Twelve Illastrations, price 2s. $6 d$.

David Lloyd's Last Will. With Four Illustrations. Royal I6mo., price 2s. $6 d$.

The Wonderful Life. Thirteenth Thousand. Fcap. 8vo. Cloth, price 2s. $6 d$.

A Night and a Day. With Frontispiece. Twelfth Thousand. Royal $16 \mathrm{mo}$. Limp cloth, price $6 d$.

Friends till Death. With IIIustrations and Frontispiece. Twenty-fourth Thousand. Royal I6mo. Cloth, price Is. $6 d$; ; limp cloth, price $6 \dot{d}$.

Two Christmas Stories. With Frontispiece. Twenty-first Thousand. Koyal $16 \mathrm{mo}$. Limp cloth, price $6 d$.

Michel Lorio's Cross, and Left Alone. With Frontispiece. Fifteenth Thousand. Royal r6mo. Limp cloth, price $6 d$.
STRETTON (Hesba)-continued. Old Transome. With Frontispiece. Sixteenth Thousand. Royal t6mo. Limp cloth, price $6 d$. ** Taken from "The King's Servants."

The Worth of a Baby, and how Apple-Tree Court was won. With Frontispiece. Nineteenth Thousand. Royal r6mo. Limp cloth, price $6 d$.

STUBBS (Lieut.-Colonel F. W.) The Regiment of Bengal Artillery. The History of its Organization, Equipment, and War Services. Compiled from Published Works, Official Records, and various Private Sources. With numerous Maps and Illustrations. Two Vols. Demy 8 vo. Cloth, price $32 s$.

STUMM (Lieut. Hugo), German Military Attache to the Khivan Expedition.

Russia's advance Eastward. Based on the Official Reports of. Translated by Capt. C. E. H. Vincent. With Map. Crown 8vo. Cloth, price $6 s$.

SULLY (James), M.A.

Sensation and Intuition. Demy 8vo. Cloth, price ros. 6d.

Pessimism : a History and a Criticism. Demy 8vo. Price $14 s$.

Sunnyland Stories.

By the Author of "Aunt Mary's Bran Pie." Illustrated. Small 8vo. Cloth, price $3 s .6 d$.

Supernatural in Nature, The. A Verification of Scripture by Free Use of Science. Demy 8vo. Cloth, price I4s.

Sweet Silvery Sayings of Shakespeare. Crown 8vo. cloth gilt, price $7 s .6 d$.

SYME (David).

Outlines of an Industrial Science. Second Edition. Crown 8vo. Cloth, price 6s.

Tales of the $Z$ enana. By the Author of "Pandurang Hari." 2 vols. Crown 8vo. Cloth, price $21 s$. 
TAYLOR (Rev. J. W. A.), M.A. Poems. Fcap. 8vo. Cloth, price $5^{s .}$

TAYLOR (Sir H.).

Works Complete. Author's Edition, in 5 vols. Crown 8vo. Cloth, price $6 s$. each.

Vols. I. to III. containing the Poetical Works, Vols. IV. and V. the Prose Works.

TAYLOR (Col. Meadows), C.S.I., M.R.I.A.

A Noble Queen : a Romance of Indian History, 3 vols. Crown 8vo. Cloth.

Seeta. 3 vols. Crown 8vo. Cloth.

The Confessions of a Thug. Crown 8vo. Cloth, price 6 s.

Tara: a Mahratta Tale. Crown 8vo. Cloth, price 6 s.

TELFER (J. Buchan), F.R.G.S., Commander R.N.

The Crimea and TransCaucasia. With numerous Illustrations and Maps. 2 vols. Medium 8vo. Second Edition. Cloth, price $36 s$.

TEN NYSON (Alfred).

The Imperial Library Edition. Complete in 7 vols. Demy 8 vo. Cloth, price 63 I3s. 6d.; in Roxburgh binding, $t_{4} 7^{s} .6 d$.

Author's Edition. Complete in 6 Volumes. Post 8vo. Cloth gilt ; - or half-morocco, Roxburgh style :-

VoL. I. Early Poems, and English Idylls. Price 6s.; Roxburgh, 7s. $6 d$.

VoL. II. Locksley Hall, Lucretius, and other Poems. Price 6s. ; Roxburgh, 7s. 6d.

VOL. III. The Idylls of the King (Complete). Price 7s. 6d.; Roxburgh, 9s.

Vol. IV. The Princess, and Maud. Price 6s.; Roxburgh, 7s. $6 d$.

VOL. V. Enoch Arden, and In Memoriam. Price 6s.; Roxburgh, $7 s, 6 d$.
TENNYSON (Alfred)-continued. Vol.VI. Dramas. Price $7 s_{0}$; Roxburgh, 8s. $6 d$.

Cabinet Edition. I2 volumes: Each with Frontispiece. Fcap. 8vo. Cloth, price 2s, 6d, each.

Cabinet Edition. - 22 vols. Complete in handsome Ornamental Case. $32 s$.

Pocket Volume Edition. 13 vols. In neat case, $36 s$. Ditto, ditto. Extra cloth gilt, in case, 425 .

The Guinea Edition of the Poetical and Dramatic Works, complete in I2 volumes, neatly bound and enclosed in box. Cloth, price 21s. French morocco, price 3is. $6 d$.

The Shilling Edition of the Poetical and Dramatic Works, in $x 2$ vols., pocket size. Price Is, each.

The Crown Edition. Complete in I volume, strongly bound in cloth, price $6 s$. Cloth, extra gilt leaves, price $7 s$. $6 a^{\prime}$. Roxburgh, half morocco, price $8 s, 6 d$.

** Can also be had in a variety of other bindings.

\section{Original Editions:}

Poems. Smail 8vo. Cloth, price $6 s$.

Maud, and other Poems. Small 8vo. Cloth, price 3s. $6 d$.

The Princess. Small 8vo. Cloth, price 3s. 6al.

Idylls of the King. Small 8vo. Cloth, price $5 s$.

Idylls of the King. Complete. Small 8vo. Cloth, price 6s.

The Holy Grail, and other Poems. Small 8vo. Cloth, price 4s. $6 d$.

Gareth and Lynette. Small 8vo. Cloth, price $3^{s}$.

Enoch Arden, \&c. Small 8vo. Cloth, price $3 s .6 d$.

In Memoriam. Small 8vo. Cloth, price 4s. 
TEN NYSON (Alfred)-contirued. Queen Mary. A Drama. New Edition. Crown 8vo. Cloth, price $6 s$.

Harold. A Drama, Crown 8vo. Cloth, price 6s.

Selections from Tennyson's Works. Super royal I 6 mo. Cloth, price 3s. $6 d$. Cloth gilt extra, price ${ }_{4} s$.

Songs from Tennyson's Works. Super royal $16 \mathrm{mo}$, Cloth extra, price $3 s .6 d$.

Also a cheap edition. I6mo. Cloth, price 2s. $6 d$.

Idylls of the King, and other Poems. Illustrated by Julia Margaret Cameron. a vols, Folio Half-bound morocco, cloth sides, price $£ 66$ s. each.

Tennyson for the Young and for Recitation. Specially arranged. Fcap. 8vo. Price rs. $6 d$.

Tennyson Birthday Book. Edited by Emily Shakespear. 32mo. Cloth limp, $2 s$.; cloth extra, $3 s$.

THOMAS (Moy).

A Fight for Life. With Frontispiece. Crown 8vo. Cloth, price $35.6 d$.

THOMPSON (Alice C.).

Preludes. A Volume of Poems. Illustrated by Elizabeth Thompson (Painter of "The Roll Call "). 8vo. Cloth, price 7s. 6d.

THOMPSON (Rev. A. S.).

Home Words for Wan. derers. A Volume of Sermons. Crown 8vo. Cloth, price 6s.

Thoughts in Verse.

Small Crown 8vo. Cloth, price Is, $6 d$.

THRING (Rev. Godfrey), B.A. Hymns and Sacred Lyrics. Fcap. 8vo. Cloth, price $5 s$.

TODD (Ḧerbert), M.A.

Arvan; or, The Story of the Sword. A Poem. Crown 8vo. Cloth, price $7 s, 6 \bar{d}$.
TODHUNTER (Dr. J.)

Laurella; and other Poems.

Crown 8vo. Cloth, price $6 s .6 d$.

TRAHERNE (Mrs. A.).

The Romantic Annals of

a Naval Family. A New and

Cheaper Edition. Crown 8vo.

Cloth, price $5^{s}$.

TREMENHEERE (Lieut.-Gen. C. W.)

Missions in India: the System of Education in Government and Mission Schools contrasted. Demy 8 vo. Sewed, price $2 s$.

TURNER (Rev. C. Tennyson). Sonnets, Lyrics, and Translations. Crown 8vo. Cloth, price 4s. $6 d$.

TYNDALL (John), L.L.D.,F.R.S. The Forms of Water in Clouds and Rivers, Ice and and Glaciers, With Twenty-five Illustrations. Seventh Edition. Crown 8vo. Cloth, price 5s.

Volume I. of The International Scientific Series.

VAMBERY (Prof. A.).

Bokhara: Its History and Conquest. Second Edition. Demy 8vo. Cloth, price $18 s$.

VAN BENEDEN (Mons.).

Animal Parasites and Messmates. With 83 Illustrations. Second Edition. Cloth, price $5 s$.

Volume XIX. of The International Scientific Series.

VINCENT (Capt. C. E. H.). Elementary Military Geography, Reconnoitring, and Sketching. Compiled for Non-Commissioned Officers and Soldiers of all Arms. Square crown 8vo. Cloth, price $2 s .6 \dot{d}$.

VOGEL (Dr. Hermann).

The Chemical effects of Light and Photography, in their application to Art, Science, and Industry. The translation thoroughly revised. With roo Illustrations, including some beautiful specimens of Photography. Third Edition. Crown 8vo. Cloth, price $5 s$.

Volume XV, of The International Scientific Series. 
VYNER (Lady Mary).

Every day a Portion. Adapted from the Bible and the Prayer Book, for the Private Devotions of those living in Widowhood. Collected and edited by Lady Mary Vyner. Square crown 8vo. Cloth extra, price $5 s$.

WARTENSLEBEN (Count $H$. von).

The Operations of the South Army in January and February, 187x. Compiled from the Official War Documents of the Head-quarters of the Southern Army. Translated by Colonel C. $\mathrm{H}$. von Wright. With Maps. Demy 8vo. Cloth, price $6 s$.

The Operations of the First Army under Gen. von Manteuffel. Translated by Colonel C. $H$. von Wright. Uniform with the above. Demy 8vo. Cloth, price gs.

WATERFIELD, W.

Hymns for Holy Days and Seasons. 32mo. Cloth, price Is. $6 \dot{\alpha}$.

WAY (A.), M.A.

The Odes of Horace Literally Translated in Metre. Fcap. 8vo. Cloth, price 2s.

WELLS (Capt. John C.), R.N. Spitzbergen-The Gateway to the Polynia ; or, A Voyage to Spitzbergen. With numerous IIlustrations by Whymper and others, -and Map. New and Cheaper Edition. Demy 8vo. Cloth, price 6s.

WETMORE (W. S.).

Commercial Telegraphic Code. Second Edition. Post 4to. Boards, price $42 s$.

WHITAKER (Florence).

Christy's Inheritance. A London Story. Illustrated. Royal $56 \mathrm{mo}$. Cloth, price Is. $6 d$.

WHITE (A. D.), LL.D.

Warfare of Science. With Prefatory Note by Professor Tyndall. Second Edition. Crown 8vo. Cloth, price $3^{s}$. $6 d$.
WHITE (Capt. F. B. P.).

The Substantive Seniority Army List-Majors and Captains. 8vo. Sewed, price 2s. $6 d$.

WHITNEY (Prof. W. D.)

The Life and Growth of Language. Second Edition. Crown 8vo. Cloth, price 5s. Copyright Edition.

Volume XVI. of The International Scientific Series.

Essentials of English Grammar for the Use of Schools. Crown 8vo. Cloth, price $3 s .6 d$.

WhitTLE (J. L.), A.M.

Catholicism and the Vatican. With a Narrative of the Old Catholic Congress at Munich. Second Edition. Crown 8vo. Cloth, price $4 s .6 d$.

WICKHAM (Capt. E. H., R.A.)

Influence of Firearms upon Tactics: Historical and Critical Investigations. By an OFFICER OF SUPERIOR Rank' (in the German Armry). Translated by Captain E. H. Wickham, R.A. Demy 8vo. Cloth, price $7 s .6 d$.

WILBERFORCE (H. W.).

The Church and the Empires. Historical Periods. Prececed by a Memoir of the Author by John Henry Newman, D.D. of the Oratory. With Portrait. Post 8vo. Cloth, price ros. $6 d$.

\section{WILKINSON (T. L.).}

Short Lectures on the Land Laws. Delivered before the Working Men's College. Crown 8vo. Limp Cloth, price $2 s$.

WILLIAMS (A. Lukyn).

Famines in India; their Causes and Possible Prevention. The Essay for the Le Bas Prize, I875. Demy 8vo, Cloth, price 5s. 
WILLIAMS (Charles), one of the Special Correspondents attached to the Staff of Ghazi Ahmed Mouktar Paska.

The Armenian Campaign : Diary of the Campaign of 1877 in Armenia and Koordistan. With Two Special Maps. Large post 8vo. Cloth, price ros. $6 d$.

WILLIAMS (Rowland), D.D.

Life and Letters of, with Extracts from his Note-Books. Edited by Mrs. Rowland Williams. With a Photographic Portrait. a vols. Large post 8vo. Cloth, price 24s.

Psalms, Litanies, Counsels and Collects for Devout Persons. Edited by his Widow. New and Popular Edition. Crown 8vo. Cloth, price 3 s. $6 d$.

WILLIS (R., M.D.)

Servetus and Calvin: a Study of an Important Epoch in the Early History of the Reformation. 8vo. Cloth, price I6s.

\section{WILLOUGHBY (The Hon.} Mrs.).

On the North Wind Thistledown. A Volume of Poems. Elegantly bound. Small crown 8 vo. Cloth, price $7 s .6 d$.

WILSON (H. Schütz).

Studies and Romances. Crown 8vo. Cloth, price $7 s .6 d$.

WILSON (Lieut,-Col. C. T.). James the Second and the Duke of Berwick. Demy 8vo. Cloth, price I2s. $6 a$.

WINTERBOTHAM (Rev. R.), M.A., B.Sc.

Sermons and Expositions. Crown 8vo. Cloth, price $7 s .6 d$.

WOINOVITS (Capt. I.).

Austrian Cavalry Exercise. Translated by Captain W. S. Cooke. Crown 8vo. Cloth, price 75 .
WOOD (C. F.).

A Yachting Cruise in the South Seas. With Six Photographic Illustrations. Demy 8 vo. Cloth, price $7 s .6 d$.

WRIGHT (Rev. David), M.A.

Waiting for the Light, and other Sermons. Crown 8vo. Cloth, price $6 s$.

WYLD (R. S.), F.R.S.E.

The Physics and the Philosophy of the Senses; or, The Mental and the Physical in their Mutual Relation. Illustrated by several Plates. Demy 8 vo. Cloth, price I6s.

YONGE (C. D.).

History of the English Revolution of I688. Crown 8vo. Cloth, price $6 s$.

YOUMANS (Eliza A.).

An Essay on the Culture of the Observing Powers of Children, especially in connection with the Study of Botany. Edited, with Notes and a Supplement, by Joseph Payne, F. C. P., Author of "I Lectures on the Science and Art of Education," \&c. Crown 8vo. Cloth, price $2 s, 6 d$.

First Book of Botany. Designed to Cultivate the Observing Powers of Children. With 300 Engravings. New and Enlarged Edition. Crown 8vo. Cloth, price 5 s.

YOUMANS (Edward L.), M.D.

A Class Book of Chemistry, on the Basis of the New System. With zoo Illustrations. Crown 8vo. Cloth, price $5^{s}$.

\section{ZIMMERN (H.).}

Stories in Precious Stones. With Six Illustrations. Third Edition. Crown 8vo. Cloth, price 5s. 


\section{THE NINETEENTH CENTURY.}

A Monthly Reviere, edited by JAMEs KNowles, price 2s. $6 d$.

Vols. I and 2 (Price I4s. each) and Vol. 3 (Price I7s.) contain Contributions by the following Writers :

The Duke of Argyll.

Mr. Matthew Arnold.

Rabbi Hermann Adler.

Mr. Arthur Arnold.

Rev. J. Baldwin Brown.

Mr. Edgar Bowring.

Mr. Thomas Brassey, M.P.

Mr. Edgar A. Bowring.

Sir Thomas Bazley, Bart., M.P.

Professor George von Bunsen.

Rev. Dr. George Percy Badger.

Rev. Canon Barry.

Dr. H. Charlton Bastian.

Professor Clifford.

Dr. Carpenter.

Professor Colvin.

Mr. Grant Duff, M.P.

Mr. Edward Dicey.

Rev. R. W. Dale.

Mr. J. A. Froude.

Mr. Archibald Forbes,

Rt. Hon. W. E. Gladstone, M.P.

Bishop of Gloucester and Bristol.

Mr, W. R. Greg.

Professor Huxley.

Mr. Frederick Harrison.

Mr. George Jacob Holyoake.

Mr. R. H. Hutton.

Mr. Henry Irving.

Sir John Lubbock, M.P.

Cardinal Manning.
Rev. Dr. Martineau.

Rev. Malcolm MacColl.

Professor Henry Morley.

His Highness Midhat Pasha.

Professor Henry Morley.

Mr. A. H. Mackonochie.

Rt. Hon. Lyon Playfair, M.P.

Mr. George Potter.

Viscount Stratford de Redcliffe,

Professor Croom Robertson.

Rev. J. Guiness Rogers.

Professor Ruskin.

Mr. W. R. S. Ralston.

The Very Rev, the Dean of St. Paul's.

Lord Selborne.

Sir James Fitzjames Stephen.

Rt. Hon. James Stansfeld, M.P.

Mr. James Spediding.

Professor Godwin Smith.

Professor Tyndall.

Mr. Tennyson.

Sir Julius Vogel.

Dr. Ward.

Major Gen. Sir Garnet Wolseley.

The Very Rev. the Dean of Westminster.

The Right Rev. Chas. Wordsworth, Bishop of St. Andrew's.

Mr. Frederick Wedmore.

Sir Thomas Watson.

\&c. \&c.

\section{LONDON :}

C. KEGAN PAUL AND CO.,

I, PATERNOSTER SQUARE.

CHISWICK PRESS:-CHARLES WHITTINGHAM, TOOKS COURT, CHANCERY LANE. 






a

6.

B.t.

-

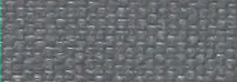

H.

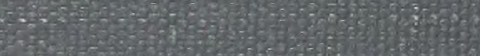

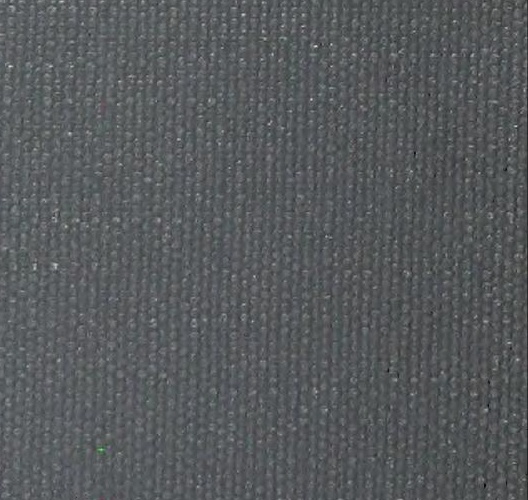

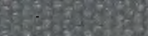

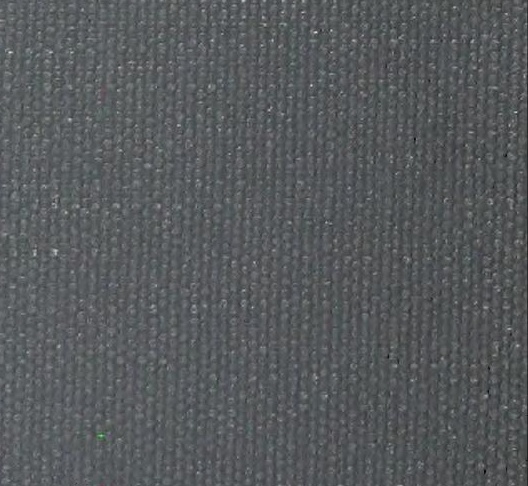

(1. 2.4

(3)

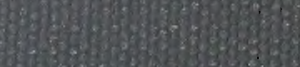

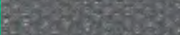

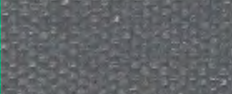

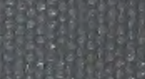

8.t.

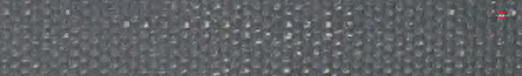

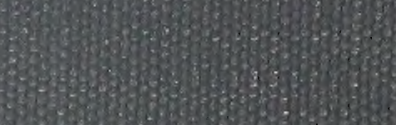
प्र.8.

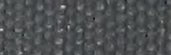

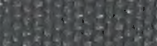

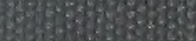

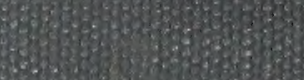

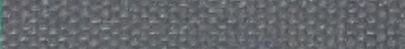

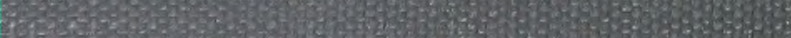
L

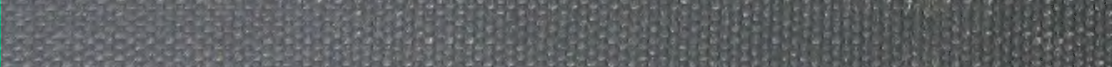
a 20 -

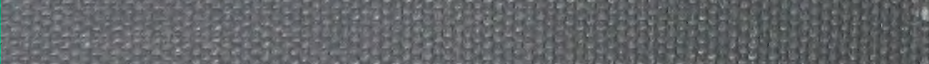

